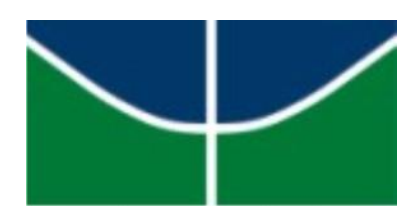

UNIVERSIDADE DE BRASÍLIA

FACULDADE DE TECNOLOGIA

DEPARTAMENTO DE ENGENHARIA CIVIL E AMBIENTAL

\title{
ESTUDO DO CLIMA ACÚSTICO NAS PROXIMIDADES DE RODOVIAS DEVIDO A IMPLANTAÇÃO DE UM MODAL DE TRANSPORTE
}

EDWIN F. F. SILVA

ORIENTADORA: FABIANA SERRA DE ARRUDA CO-ORIENTADOR: SÉRGIO LUIZ GARAVELLI DISSERTAÇÃO DE MESTRADO EM TRANSPORTES

PUBLICAÇÃO:

BRASÍLIA/DF: JULHO/2015 
UNIVERSIDADE DE BRASÍLIA

FACULDADE DE TECNOLOGIA

DEPARTAMENTO DE ENGENHARIA CIVIL

\section{ALTERAÇÕES NO CLIMA ACÚSTICO NAS VIZINHANÇAS DE UMA RODOVIA DEVIDO A IMPLANTAÇÃO DE UM MODAL DE TRANSPORTE}

EDWIN F. F. SILVA

DISSERTAÇÃO SUBMETIDA AO DEPARTAMENTO DE ENGENHARIA CIVIL E AMBIENTAL DA FACULDADE DE TECNOLOGIA DA UNIVERSIDADE DE BRASÍLIA COMO PARTE DOS REQUISÍTOS NECESSÁRIOS PARA A OBTENÇÃO DO GRAU DE MESTRE EM TRANSPORTES.

APROVADA POR:

Prof- Fabiana Serra de Arruda, Doutora (PPGT-UnB)

(Orientadora)

Prof. Sérgio Luiz Garavelli, Doutor (UNIP)

(Co-Orientador)

$\overline{\text { Prof. Augusto Cesar de Mendonça Brasil, Doutor (PPGT-UnB) }}$ (Examinador Interno)

Prof- Ludmila Rodrigues de Moraes, Doutora (UnUCET-UEG) (Examinador Externo)

BRASÍLIA/DF, 15 de julho de 2015 


\section{FICHA CATALOGRÁFICA}

SILVA, EDWIN FRANCISCO FERREIRA.

Alterações no clima acústico nas vizinhanças de uma rodovia devido a implantação de um modal de transporte [Distrito Federal] 2015.

xii, 115p., 210 x 297 mm (ENC/FT/UnB, Mestre, Transportes, 2015).

Dissertação de Mestrado - Universidade de Brasília. Faculdade de Tecnologia.

Departamento de Engenharia Civil e Ambiental.
1. Poluição Sonora
2. Mapa de ruído
3.Transporte Rodoviário
4.Barreira acústica

5. Acústica Ambiental

I. ENC/FT/UnB

II. Título (série)

\section{REFERÊNCIA BIBLIOGRÁFICA}

SILVA, E. F. F. (2015). Alterações no clima acústico nas vizinhanças de uma rodovia devido a implantação de um modal de transporte, Publicação T. DM - 009/2015, Departamento de Engenharia Civil e Ambiental, Universidade de Brasília, Brasília, DF, $115 \mathrm{p}$.

\section{CESSÃO DE DIREITOS}

AUTOR: Edwin F. F. Silva

TÍTULO: Alterações no clima acústico nas vizinhanças de uma rodovia devido a implantação de um modal de transporte

GRAU: Mestre ANO: 2015

É concedida à Universidade de Brasília permissão para reproduzir cópias desta dissertação de mestrado e para emprestar ou vender tais cópias somente para propósitos acadêmicos e científicos. O autor reserva outros direitos de publicação e nenhuma parte dessa dissertação de mestrado pode ser reproduzida sem autorização por escrito do autor.

Edwin F. F. Silva

Programa de Pós-graduação em Transportes. Departamento de Engenharia Civil e Ambiental. Faculdade de Tecnologia, Anexo SG-12, $1^{\circ}$ Andar, Campus Universitário Darcy Ribeiro. Universidade de Brasília, Brasília - DF, Brasil.

CEP: 70.910-900

E-mail: edw3in@gmail.com 


\section{DEDICATÓRIA}

Dedico este trabalho a minha esposa Alinne, por estar ao meu lado nos melhores e piores momentos de minha vida, pela paciência, compreensão durante minha ausência, e por ter me ajudado a não desistir. 


\section{AGRADECIMENTOS}

Inicio meus agradecimentos a DEUS, por ter me abençoado com mais essa conquista e por ter colocado pessoas em minha vida as quais me motivaram a desenvolver esse trabalho.

Agradeço aos meus pais e a minha sogra querida (Maria Célia) pela força e motivação para que esse sonho se tornasse realidade.

A Profa. Dra. Fabiana Serra de Arruda pela amizade, pelas broncas, pela compreensão em momentos difíceis, pela liberdade e confiança no desenvolvimento do meu trabalho.

Ao Prof. Dr. Sérgio Garavelli pela amizade, dedicação e paciência no acompanhamento e desenvolvimento deste trabalho.

Ao meu grande amigo Wesley Cândido pelas discussões, pelos concelhos para o desenvolvimento deste trabalho e também pela companhia, aos sábados domingos e feriados no laboratório de física da Universidade Católica de Brasília.

Agradeço aos colegas do grupo de pesquisa em Acústica Ambiental Benício e Cleber, pelas discursões e orientações a respeito desta pesquisa.

Aos amigos e companheiros do mestrado, especialmente à Michelle Arcúrio, à Ângela Bertazzo, Ana Maria, Luiz Soares e à Profa. Dra. Maria Alice, pelos momentos divididos juntos, que incluem angústias e alegrias. Agradeço a todos pelo enorme aprendizado, apoio e carinho.

Agradeço aos meus sobrinhos (Diogo, João, Lucas e Vinicius) que me ajudaram efetivamente na coleta e tabulação dos dados desse trabalho.

Aos professores e funcionários do Departamento de Engenharia Civil e ambiental que contribuíram efetivamente para a minha formação. Em especial, à secretária Lucinete por suas orientações e paciência com tantos questionamentos.

Aos Professores Ly Freitas e Armando Maroja pelo incentivo no desenvolvimento desse trabalho.

Agradeço ao CNPq processo 474594/2013-0 e à CAPES pelo financiamento e apoio no desenvolvimento deste trabalho.

À Universidade Católica de Brasília, em especial, ao curso de Física pelo espaço e softwares utilizados no desenvolvimento de minha pesquisa.

Por fim, agradeço às demais pessoas que, de uma forma ou de outra, contribuíram na elaboração deste trabalho. 


\section{RESUMO}

O objetivo deste estudo é avaliar o comportamento do clima acústico nas vizinhanças de rodovias com características urbanas devido a alterações na fluidez causadas pela possível implantação de um sistema de transporte de massa. Tem-se como arcabouço teórico estudos sobre o ruído advindo de variações na fluidez causadas pelo elevado número de veículos transitando nas principais rodovias do país, que adentram em áreas habitadas, assim como as consequências negativas disso na saúde da população. Trata-se de um estudo de caso que verifica, por meio de simulações computacionais realizadas com software de predição acústica, os níveis de pressão sonora devido a variações na fluidez da rodovia para uma redução no número de veículos leves e pesados em decorrência da implantação de um novo modal. Esta dissertação trabalhou com a hipótese de que, com a retirada de um quantitativo de veículos leves e pesados, a velocidade média de fluxo do tráfego tenderia a aumentar e, dessa forma, elevaria os níveis de pressão sonora aos quais os moradores dessa região estariam expostos. Após a coleta e análise dos dados, constatou-se que as alterações causadas são pouco significativas e que não ocorreram mudanças perceptíveis no clima acústico da região. Todavia, esta região encontra-se com níveis de pressão sonora acima dos estabelecidos pelas normas vigentes e, desse modo, propõem-se como uma alternativa mitigadora, a implantação de barreiras acústicas ao longo da rodovia - $\mathrm{O}$ que, neste estudo, se mostrou satisfatoriamente viável.

PALAVRAS-CHAVE: Poluição Sonora; Mapa de Ruídos; Transporte Rodoviário; Barreira Acústica; acústica ambiental. 


\begin{abstract}
This work analyses the acoustic climate behaviour due to the implementation of a public transportation system (urban train) on a highway that cross regions of populated areas. The objective of this study is to evaluate the acoustic climate behaviour in the highway neighbourhood, which presents urban characteristics, due to changes in flow caused by the implementation of an urban transportation system. Studies on noise caused by flow variations due to the great number of vehicles in transit on the country's main highways that cross inhabited areas, as well as studies on the negative consequences of this on public health are our theoretical framework. This is a case study that verifies, through computer simulations performed with the acoustic prediction software, sound pressure levels due to variations on the highways fluidity to reduce the number of light and heavy vehicles as a result of the implementation of a new modal. This dissertation worked with the hypothesis that if part of the number of light and heavy vehicles is removed from the highway, the traffic flow average speed will tend to increase, and thus, it will raise the sound pressure levels to which the inhabitants of this region are exposed to. After collecting and analyzing data, we found that the suggested changes are not significant and that noticeable changes have not happened in the acoustic climate of the region. However, this region presents sound pressure levels that are above the one established by current laws, so we propose, as a mitigation alternative, the implementation of noise barriers along the highway - which, in this study, has proved to be satisfactorily viable.
\end{abstract}

KEYWORDS: Noise Pollution; Noise map; Road Traffic; Acoustic barrier; environmental acoustics 


\section{SUMÁRIO}

1. INTRODUÇÃO

1.2 OBJETIVOS

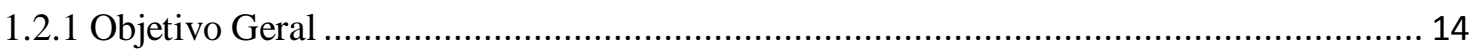

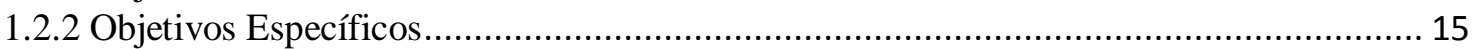

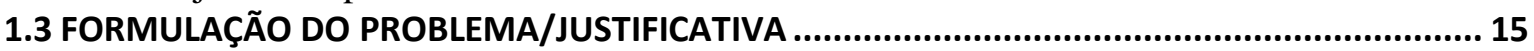

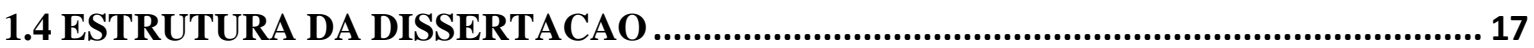

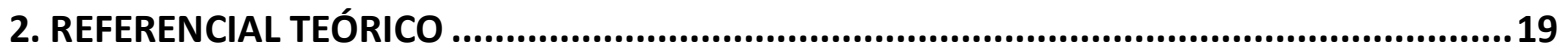

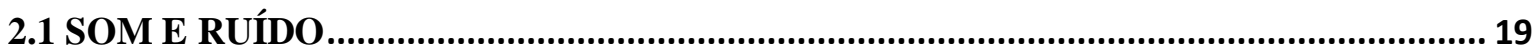

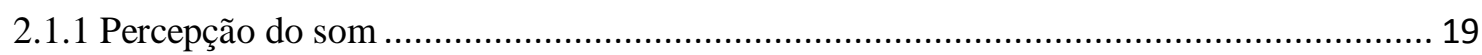

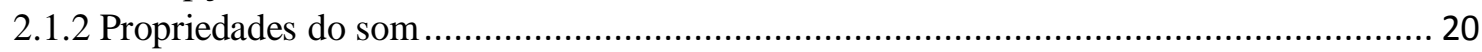

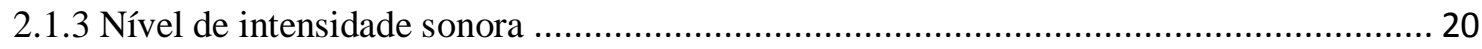

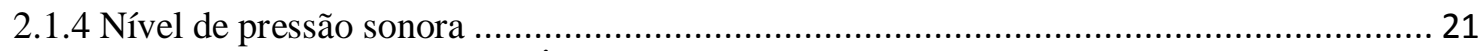

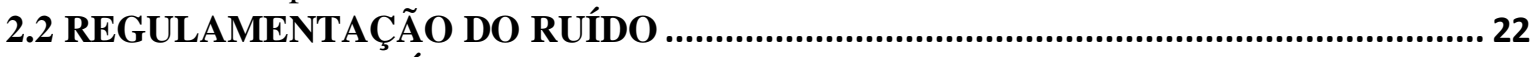

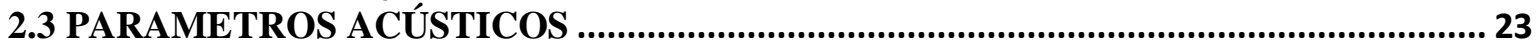

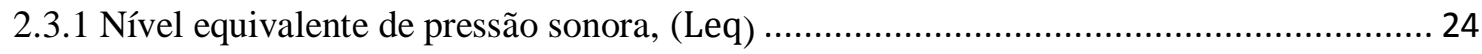

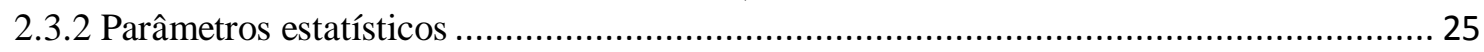

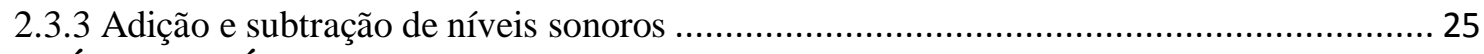

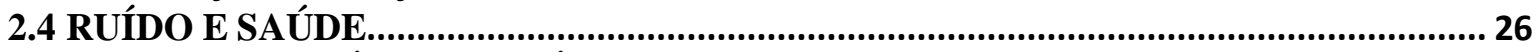

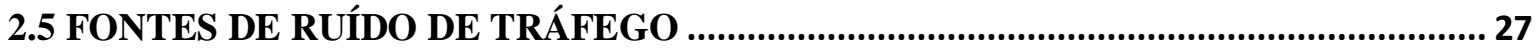

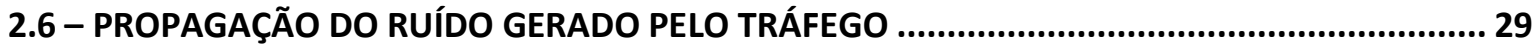

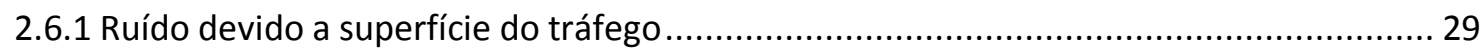

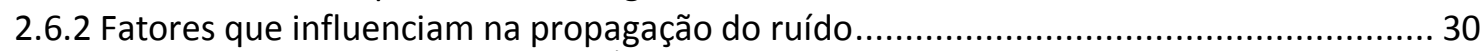

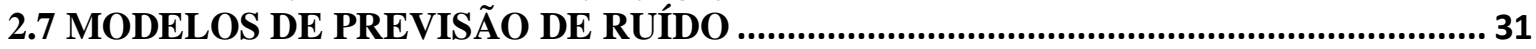

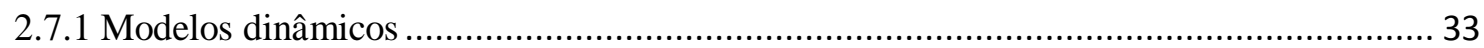

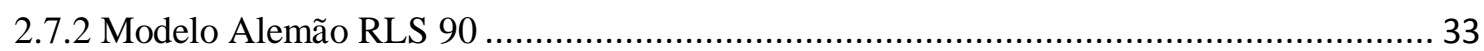

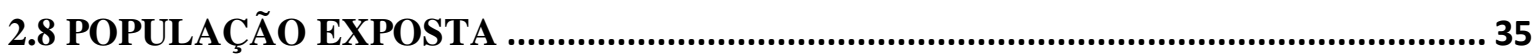

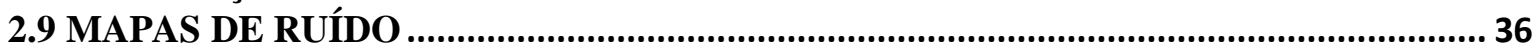

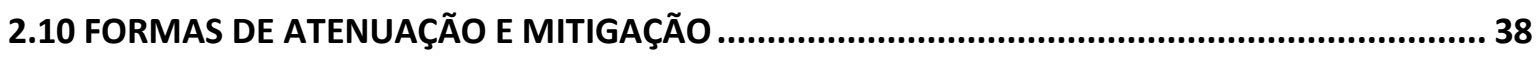

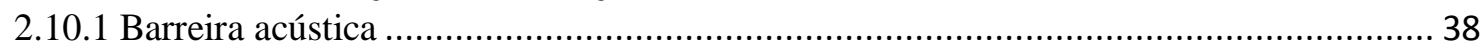

2.10.2 Atenuação do ruído por meio do pavimento ......................................................... 40

3.0 - DESENVOLVIMENTO E APLICAÇÃO DO MÉTODO...................................................40

3.1 DELIMITAÇÃO DA ÁREA DE ESTUDO …………………………………………...... 41

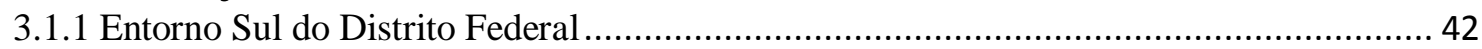

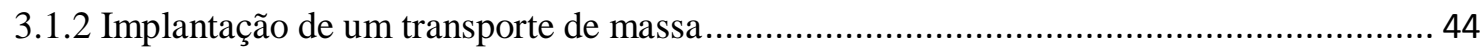

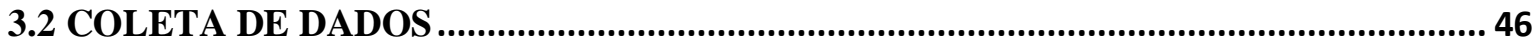

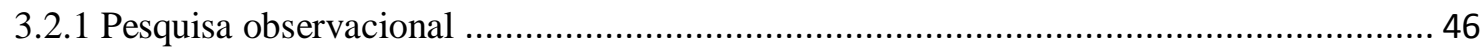

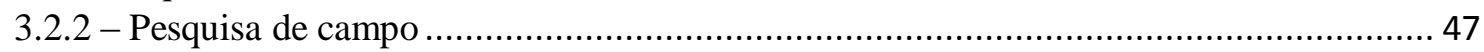

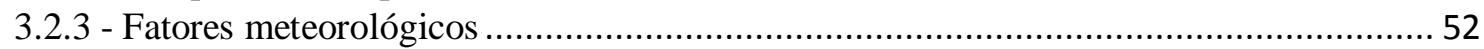

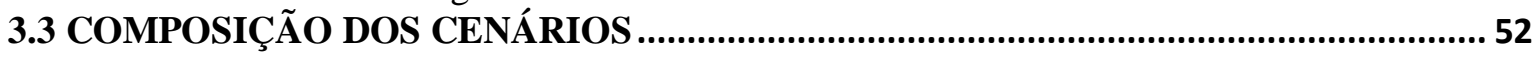

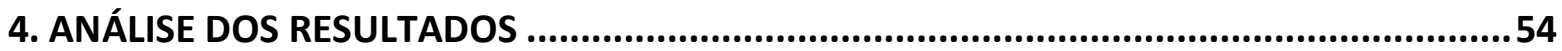

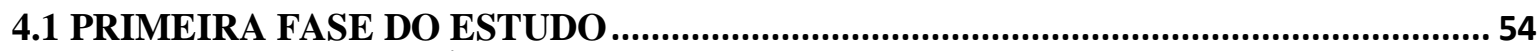

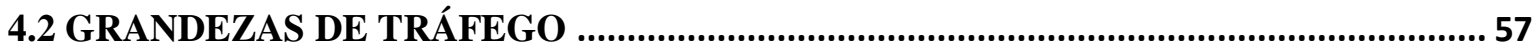

4.2.1 - Ruído e Velocidade média do fluxo de tráfego ........................................................... 59

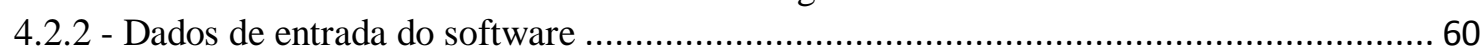

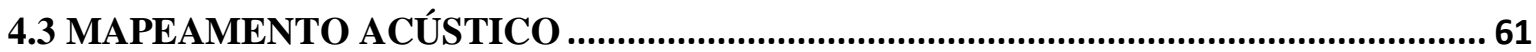




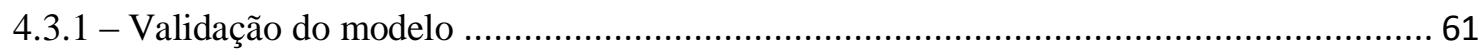

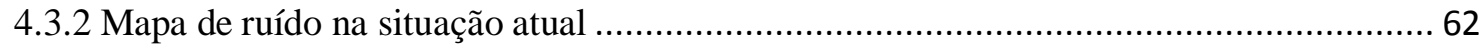

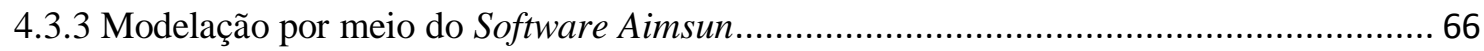

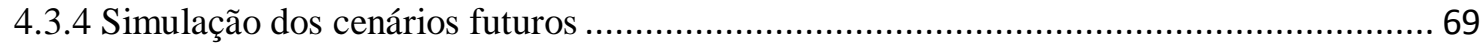

4.4 - DESENVOLVIMENTO DE ALTERNATIVAS PARA REDUÇÃO DE RUÍDO...................................73

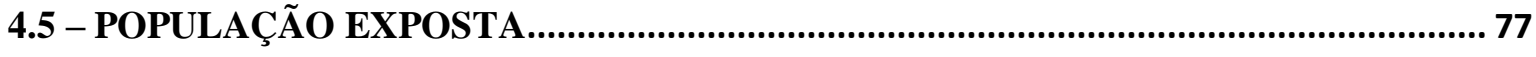

5. CONCLUSÕES E SUGESTÕES PARA TRABALHOS FUTUROS........................................84

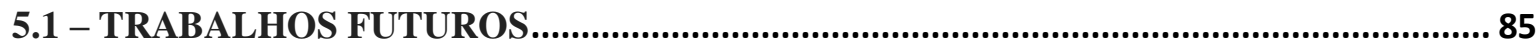

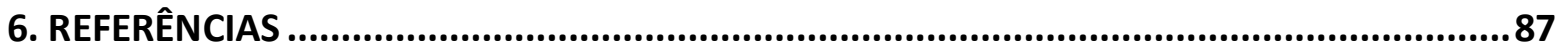

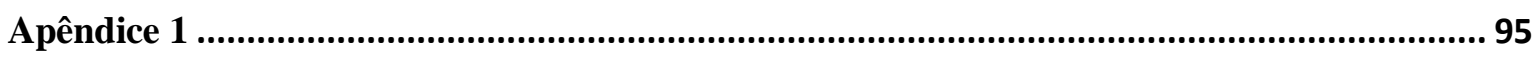

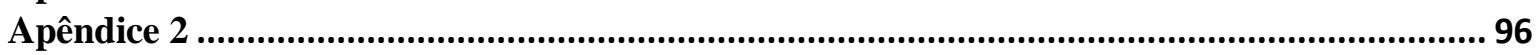

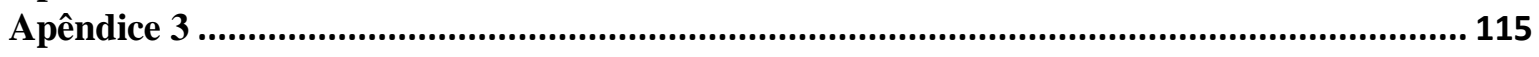




\section{LISTA DE QUADROS}

Quadro 2.1 - Relação entre pressão sonora, intensidade e nível sonoro .............................22

Quadro 2.2- Exemplos de modelos de predição de ruído de tráfego rodoviário ....................32

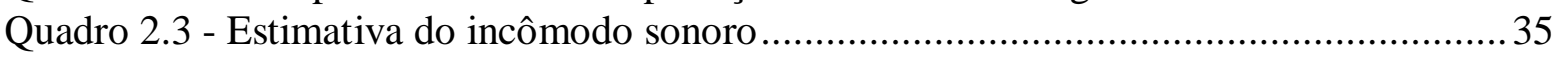

Quadro 2.4 - Polinômios para Distúrbios do Sono - Tráfego Rodoviário........................... 36

Quadro 3.1 - Representação geral das etapas da pesquisa ............................................... 41

Quadro 3.2 - Esquema proposto para na pesquisa observacional..................................... 47

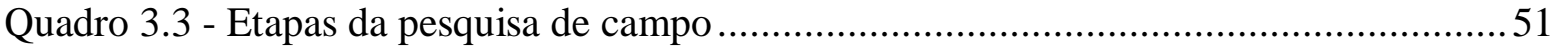

Quadro 4.1 - Dados da pesquisa observacional obtidos para a área de estudo ....................55 Quadro 4.2 - Valores obtidos em diferentes pontos para a velocidade média do fluxo de tráfego e dos diferentes níveis de pressão sonora nos diferentes períodos. .........................55

Quadro 4.3 - Variação dos fatores meteorológicos observados na região de estudo............56

Quadro 4.4 - Valores do Leq(A) medidos vs Leq(A) calculados e respectivas diferenças ...62

Quadro 4.5 - Número médio de veículos por tipo, em horas pico, no trecho em estudo.......67

Quadro 4.6 - Velocidade média em $(\mathrm{km} / \mathrm{h})$ simulada para os diferentes trechos após a redução na frota atual - Sentido Brasília / Luziânia ............................................................6 68

Quadro 4.7 - Velocidade média em $(\mathrm{km} / \mathrm{h})$ simulada para os diferentes trechos após a redução na frota atual - Sentido Luziânia / Brasília ........................................................... 68

Quadro 4.8 - Comparativo entre os NPS para os diferentes cenários .................................72

Quadro 4.9 - Distribuição dos NPS por pontos para três diferentes cenários acústicos ........73

Quadro 4.10 - Principais características da barreira acústica simulada no software CadanaA

Quadro 4.11 - Valores para os NPS referentes aos parâmetros Ldia $e$ Ln para a implantação

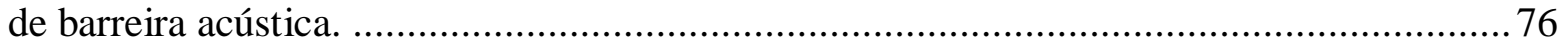

Quadro 4.12 - População exposta por faixa de indicador ................................................ 80

Quadro 4.13 - População incomodada e altamente incomoda para diferentes cenários ........81

Quadro 4.14 - Número de pessoas expostas e número estimado de pessoas com distúrbios no sono. 


\section{LISTA DE FIGURAS}

Figura 2.1 - A influência de diferentes fontes geradoras do ruído ....................................28

Figura 2.2 - Curvas resultantes do modelo de incomodidade para tráfego rodoviário ...........36 Figura 2.3 - Trajetória de uma onda sonora emitida junto a um dispositivo de redução do

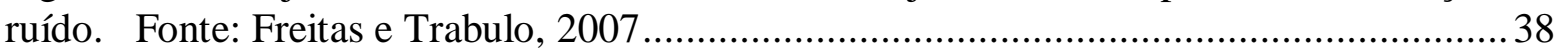

Figura 2.4 - Exemplos de barreiras acústicas, (Bragança et al., 2006)............................... 39

Figura 3.1 - Região de Valpaíso de Goias - GO.

Figura 3.2 - Carregamento da Rede de Transporte Público Coletivo do PDTU/DF na hora-

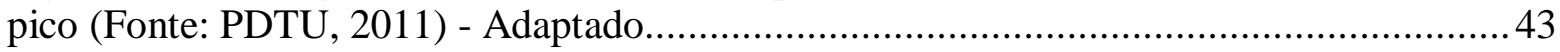

Figura 3.3 - Porcentagem da População do Entorno que Estuda ou Trabalha no DF .......... 43

Figura 3.4 - Representação da linha férrea existente hoje nas proximidades da BR 040.....45

Figura 3.5 - A comparação entre o traçado atual e um traçado alternativo ......................... 45

Figura 3.6 - Localização dos pontos de medição no trecho analisado da travessia urbana da

BR - 040, altura do município de Valparaiso de Goiás - Intervalo (07:00h às 09:00h) .......49

Figura 3.7 - Localização dos pontos de medição no trecho analisado da travessia urbana da

BR - 040, altura do município de Valparaiso de Goiás - Intervalo (14:00h às 16:00h) .......49

Figura 3.8 - Localização dos pontos de medição no trecho analisado da travessia urbana da BR - 040, altura do município de Valparaiso de Goiás - Intervalo (17:00h às 19:00h) .......50

Figura 4.1 - Número de veículos em função do tempo ....................................................58

Figura 4.2 - Número de veículos em função dos horários ...............................................58

Figura 4.3 - Nível de pressão sonora em termos das condições da velocidade média do fluxo

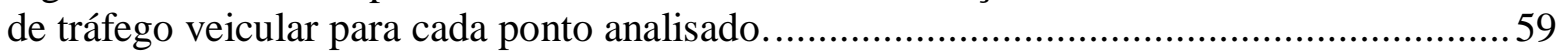

Figura 4.4 - Mapa de ruído da situação atual para o parâmetro Ldia .................................... 64

Figura 4.5 - Mapa de ruído da situação atual para o parâmetro Ln ....................................65

Figura 4.6 - Ilustração de um trecho da simulação para o cenário atual, onde se observa a representação dos veículos na via, o número de faixas, principais interseções, etc. .............68

Figura 4.7 - Mapa de ruído - Cenário futuro - redução de $20 \%$ para o parâmetro Ldia....... 70

Figura 4.8 - Mapa de ruído - Cenário futuro - redução de 50\% para o parâmetro Ldia....... 71

Figura 4.9 - Mapa de ruído - Cenário com Barreira acústica ..............................................75

Figura 4.10 - Representação dos NPS por classes para o cenários atual ............................ 78

Figura 4.11 - Representação dos NPS por classes para o cenários com redução na frota

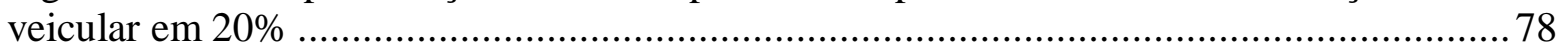

Figura 4.12 - Representação dos NPS por classes para o cenários com redução na frota veicular em $50 \%$

Figura 4.13 - Representação dos NPS por classes para o cenários simulado da implantação

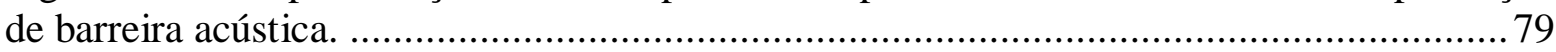

Figura 4. 14 - Representação dos NPS por classes para o cenário (Ln) atual ...................... 82

Figura 4.15 - Representação dos NPS por classes para o cenário (Ln) atual após a implantação de uma barreira acústica nas proximidades da rodovia................................. 82 


\section{LISTA DE ABREVIATURAS}

BRT - Transporte Rápido por Ônibus

VLT - Veículos Leves Sobre Trilhos

OMS - Organização Mundial de Saúde

WHO - Word Health Organization

PDTU - Plano Diretor de Transporte Urbano

CODEPLAN - Companhia de Planejamento do Distrito Federal

DNIT - Departamento Nacional de Infraestrutura de Transporte

AIMSUN - Advanced Interactive Microscopic Simulator for Urban and Non-Urban Networks

CNOSSOS-EU - Commom Noise Assessment Methods in European Union

HARMONOISE - Harmonized Accurate and Reliable Methods for the EU Directive on the Assessment and Management of Environmental Noise

IMAGINE - Improved Methods for the Assessment of the Generic Impact of Noise in the Environment

RLS 90 - Richtlinien für den Lärmschutz an Straßen 


\section{INTRODUÇÃO}

No Brasil, muitas cidades surgem e crescem em torno de perímetros rodoviários, mas raramente isso ocorre de forma planejada, sem que sejam consideradas as demandas locais e a vocação original da rodovia. O que se observa, em muitas situações, é a ocupação do solo de forma desordenada nas proximidades de rodovias, por meio de moradias e comércios não planejados. Isso ocasiona um tráfego transversal e com características locais em vias de grande velocidade, (Voltolini, 2008).

Muitos trechos de rodovias, nos últimos anos, sofreram mudanças quanto às suas funcionalidades transformando-se em importantes avenidas de intenso tráfego, sem que tenham perdido suas funções de rodovias. Desse modo, essas localidades tendem a ter um maior número de veículos transitando nas rodovias. Essa realidade traz consequências negativas, como excesso de congestionamentos, aumento no número de acidentes e aumento das poluições atmosférica e sonora, (Souza, 2003).

Nesse caso, o tráfego veicular tem se destacado como a principal fonte de ruído na maior parte dos países e a maior causa de incômodos à população. (Brüel e Kjaer, 2001; Avsar e Gonullu, 2005, Singal, 2005; Murgel, 2007; Dintrans e Préndez, 2013).

Além disso, há indicações de que o ruído provoca efeitos prejudiciais à saúde como doenças cardiovasculares, pressão arterial elevada e, ainda, o ruído pode levar à diminuição da capacidade de leitura por crianças em idade escolar (Van Kempen et al., 2002; Wismans, e Van Berkum, 2000; Bendtsen, 2009).

O aumento nos níveis de pressão sonora vem reduzindo a qualidade de vida da população. O excesso de ruído pode prejudicar e interferir nas atividades diárias do homem, seja na escola, no trabalho, no lar ou nos momentos de descanso, (WHO, 2011).

Diante dos efeitos negativos à saúde decorrentes dos grandes fluxos de tráfego, pesquisadores na área de transporte, como Hidalgo e Gutiérrez (2012), sugerem a implantação do transporte de massa como uma alternativa para se combater os densos congestionamentos, que afetam tanto o usuário do transporte coletivo como o próprio usuário do transporte motorizado individual, além de atenuar a poluição ambiental. 
Desse modo, destacam-se como alternativas para se minimizar esse problema o investimento em modos de transportes mais sustentáveis. Assim, investimentos no transporte público coletivo, como é o caso do Transporte Rápido por Ônibus (BRT), metrôs, Veículos Leves Sobre Trilhos (VLT), são necessários para o atendimento às necessidades diárias de deslocamentos da massa de usuários (Raia et al., 2010).

Villela (2004) sugere o estímulo ao uso de transporte público de alta capacidade como forma de contribuir para a solução ou atenuação desses problemas atingindo a autossustentabilidade do sistema de transporte sobre o trilho. De forma mais especifica, Kuby et al. (2004) abordam o sistema de veículo leve sobre trilhos como um importante modal para combater os congestionamentos e os impactos ambientais causados por veículos automotivos em cidades norte-americanas.

Entretanto, mesmo em transportes de massa, é necessário o desenvolvimento de estudos que considerem as alterações ambientais causadas por sua implantação. Propõe-se, assim, realizar simulações para diferentes cenários de composição do fluxo a partir da implantação de um sistema de transporte de massa nas proximidades de uma rodovia com características urbanas.

Portanto a hipótese que se assume nesse estudo é de que, após a implantação de sistemas de transporte de massa, os níveis de pressão sonora em áreas lindeiras irão aumentar, deixando parte dessa população exposta a níveis de ruído mais elevados do que antes da implantação desse sistema. Essa hipótese está embasada no fato de que, ao se implantar um transporte de massa, parte dos veículos pesados (ônibus), e uma parcela de veículos leves (carros / motos), serão retirados das rodovias deixando o fluxo de veículos mais livre. Com o fluxo livre, a tendência é que os veículos se desloquem a uma velocidade maior fazendo com que os níveis de intensidade sonora aumentem, visto que a velocidade é um dos parâmetros principais para a produção de ruído.

\subsection{OBJETIVOS}

\subsubsection{Objetivo Geral}

Avaliar o comportamento do clima acústico nas vizinhanças de rodovia com características urbanas, devido a alterações no fluxo de tráfego causadas pela implantação de um sistema de transporte de massa. 


\subsubsection{Objetivos Específicos}

- Investigar os níveis de pressão sonora gerados por variações na fluidez em rodovias;

- Avaliar os parâmetros envolvidos no volume e na composição do fluxo de tráfego quanto à produção de níveis de pressão sonora;

- Calibrar um modelo de previsão de ruído;

- Elaborar simulações e mapas acústicos;

- Determinar níveis de pressão sonora para diferentes cenários em função da migração de pessoas de um modal para outro.

- Avaliar a população exposta por faixa de indicador acústico;

- Determinar a \% da população incomodada e altamente incomodada para os diferentes cenários.

\subsection{FORMULAÇÃO DO PROBLEMA/JUSTIFICATIVA}

As rodovias, em geral, possuem um movimento intenso de veículos, que transitam por áreas densamente habitadas, ou seja, a maioria das grandes cidades brasileiras estão cercadas e atravessadas por uma rede de rodovias de alta velocidade. Moradores próximo à rodovia convivem diariamente com a insegurança, pois geralmente essas rodovias não oferecem condições adequadas de segurança para motoristas, pedestres e ciclistas. Além dos problemas de segurança dos cidadãos, também existe o problema da poluição causada pelo tráfego veicular que circulam próximos aos estabelecimentos residências e comerciais locais.

No que tange à poluição sonora causada pelo tráfego veicular, observa-se que ela é uma das principais formas de poluição ambiental, sendo responsável por impactos negativos que geram prejuízos ao meio ambiente e à qualidade de vida. Pode, ainda, interferir no sono e nas atividades dos indivíduos, incluindo a concentração e a comunicação (Berglund et al., 1999; Ramalingeswara Rao \& Seshagiri Rao, 1992; Robinson, 1971). Um estudo mais recente realizado em Fulton, na Georgia, mostra que muitos moradores dessa comunidade estão expostos a níveis elevados de ruído do tráfego rodoviário local. Isso afeta o bem-estar psicológico dessas pessoas e pode perturbar seu sono, levando-as a graves consequências para a saúde (Kim et al., 2012). 
É comum, cada vez mais, contextos de congestionamentos em rodovias que adentram em cidades, esse fato acaba ocasionando variações na fluidez. Nesses espaços, o ruído do trânsito é influenciado por fatores como: acelerações e desacelerações; composição e velocidade do fluxo de tráfego; forma urbana; distância em relação à fonte de ruído; topografia; condições meteorológicas; além da própria postura do motorista (Guedes, 2005; Kang, 2007). Essas variações, também estão relacionadas a outros fatores como: a presença de dispositivos de controle de velocidade, a sinalização (vertical ou horizontal), as ondulações transversais ("lombadas"), e aos dispositivos de fiscalização eletrônica (Silva, 2009). De forma geral, há uma série de fatores que podem provocar alterações na circulação rodoviária e que têm influência nos níveis de ruído emitidos pelos veículos.

Mudanças na fluidez podem ocorrer por diferentes fatores. Este estudo propõe investigar as alterações na fluidez do tráfego devido à implantação de um transporte de massa nas proximidades de uma rodovia e como estas alterações influenciam no clima acústico da região. Como estudo de caso será estudada a rodovia BR 040, que se caracteriza como uma via de tráfego intenso e de longa distância. Nela transitam constantemente caminhões, veículos leves e motocicletas, além de ligar os estados de Goiás, Minas Gerais, Rio de Janeiro e o Distrito Federal. A escolha desta localidade se justifica por se tratar de um trecho que corta o município de Valparaíso - GO, o qual possui um grande adensamento populacional em suas margens, e por ter uma estrutura ferroviária nas proximidades da rodovia na iminência de ser implantada, de acordo com a Superintendência do Desenvolvimento do Centro-Oeste (Sudeco).

A literatura revisada até o momento demonstra ausência de estudos que tragam uma avalição do comportamento do ruído do tráfego rodoviário devido à implantação de um transporte de massa em suas proximidades. O mais comum é que a avaliação para a implantação de cada modal seja feita de forma individual, sem que haja uma preocupação com as alterações no ruído que um pode causar no outro, como pode ser visto no trabalho de (Simonetti, 2010 e Gonçalves, 2006).

Essas alterações são objeto de estudo desse trabalho, visto que a tendência é parte da frota de ônibus que atende a região deixar de circular pela rodovia. Além disso, poderá haver uma migração de usuários de veículos leves para o transporte de massa. Desse modo, com a diminuição do número de veículos em circulação na rodovia, espera-se que os níveis de pressão sonora aumentem em função do aumento da velocidade de fluidez da via. Em outras 
palavras, nos horários em que a utilização da capacidade da via é menor em virtude de um volume de tráfego menor, o ruído pode ser maior do que em horários de pico. Isso leva a crer que a influência da geração de ruído em função do contato entre pneu e pavimento pode ser preponderante em relação ao número de veículos em horários de pico, de forma que “menos carros podem gerar mais ruído do que mais carros" (Rodrigues, 2010).

A hipótese principal desse estudo é que, com a retirada de veículos leves e pesados da rodovia, a tendência é que haja maior fluidez no deslocamento e, consequentemente, aumento nos níveis de pressão sonora associado à velocidade média de deslocamento dos veículos. Pelas razões apresentadas, faz-se necessário um estudo detalhado a respeito dos níveis de ruído advindos de mudanças nas características do tráfego em decorrência da implantação de um novo modal.

Este trabalho intenta contribuir com estudos na área de transporte e meio ambiente, uma vez que apresentará métodos capazes de mensurar os níveis de pressão sonora referentes a variações na fluidez do tráfego, resultantes da implantação de um transporte de massa nas proximidades da BR-040. Acrescenta-se que este estudo constitui importante ferramenta de planejamento urbano para gestores e especialistas em planejamento, a fim de assegurar qualidade ambiental para a população e, ainda, podendo auxiliar no monitoramento e atenuação de emissões sonoras em áreas habitadas. Assim como servir de ferramenta ao suporte na tomada de decisão.

Por fim, os conhecimentos gerados por esta pesquisa permitirão a caracterização da qualidade do clima acústico nas vizinhanças de rodovias com características urbanas, devido a alterações na fluidez do tráfego. Com isso, a comunidade científica disporá de parâmetros atuais, quantitativos e qualitativos, acerca da poluição sonora ambiental gerada pelo ruído de tráfego.

\subsection{ESTRUTURA DA DISSERTACAO}

Os conteúdos foram segregados em cinco partes. O primeiro refere-se ao objetivo principal da dissertação, como é apresentado na revisão bibliográfica do presente estudo, sendo que muito pouco foi encontrado sobre os possíveis impactos devido a alterações na composição do tráfego em rodovias com características urbanas, e nem das alterações no clima acústico devido a integração de dois sistemas de transportes, (Ferroviário e Rodoviário). O Segundo consiste em uma abordagem conceitual, a fim de auxiliar o leitor quanto ao entendimento de 
alguns temas tratados neste trabalho. O terceiro consiste na coleta de dados (metodologia utilizada). O quarto será a análise dos parâmetros envolvidos na produção dos níveis de ruído, e também a produção de métodos para entender o comportamento do clima acústico de uma região devido a alterações na fluidez para diferentes cenários simulados. Por fim, o quinto será as considerações finais e sugestões para trabalhos futuros. 


\section{REFERENCIAL TEÓRICO}

\subsection{SOM E RUÍDO}

O som pode ser definido como uma sensação produzida no sistema auditivo, ou ainda, uma forma de energia provocada por variação da Pressão Ambiental, (Bistafa, 2007). Ainda, com respeito ao entendimento do conceito de som, Gerges (2000) e Kinsler et al. (1982), definem o som como sendo flutuações de pressão que se propagam em um meio elástico, seja ele sólido, líquido ou gasoso. Tais flutuações de pressão são caracterizadas por movimentos de compressão e expansão de moléculas que se propagam em forma de ondas, a partir do ponto de origem do som.

\subsubsection{Percepção do som}

A percepção do som pode se dar de forma harmoniosa ou de forma desagradável dependendo da subjetividade de cada indivíduo. Neste sentido, o ruído pode ser classificado, de maneira subjetiva, como sendo todo e qualquer som indesejável, ou ainda todo e qualquer distúrbio à tranquilidade, devido a efeitos auditivos. Apesar do ruído ser algo importuno, um mesmo som pode ser ou não um ruído, dependendo do ponto sob o qual é observado (Bistafa, 2007).

Em termos da definição física do ruído, ele é definido como um som indesejável, não periódico, sem componentes harmônicos definidos, que não é possível montar o seu espectro de frequências, mas apenas a densidade espectral, (Fernandes, 2002). Ainda, de forma objetiva o ruído é um sinal acústico aperiódico, originado da superposição de vários movimentos de vibração com diferentes frequências, as quais não apresentam relação entre si (Mello, 1997).

Uma fonte sonora pode emitir ondas sonoras de diversas frequências ao mesmo tempo, e quando essas ondas são do tipo aperiódicas, chama-se basicamente este som de ruído (KINSLER et al., 1982).

O ruído pode ser classificado como "ruído ambiente" quando se dá fora de compasso, associado a um determinado ambiente em um tempo específico, sendo usualmente composto pelo som de muitas fontes em diferentes direções, próximas e distantes, incluindo as fontes sonoras de interesse. Ou ainda, como ruído residual, quando se refere ao ruído total de todas as fontes que não são a fonte de interesse (Harris, 1998). 


\subsubsection{Propriedades do som}

As ondas sonoras dispõem de características especificas como: frequência, comprimento de onda, período, amplitude, intensidade, direção e velocidade. A frequência em uma onda sonora é descrita pelo número de vibrações por unidade de tempo (Hertz, é a unidade derivada do SI para frequência, a qual é expressada em termos de oscilações por segundo $\left(\mathrm{s}^{-1}\right.$ ou $\left.1 / \mathrm{s}\right)$. A faixa de frequência sonora audível pelo ser humano, varia, em média, de $20 \mathrm{~Hz}$ a 20 kHz (Harris, 1998; Gerges, 2000). Sons que ocorrem em frequências inferiores a $20 \mathrm{~Hz}$ são denominados de infrassons, e os que ocorrem em frequências acima de $20 \mathrm{kHz}$ são denominados de ultrassons (Beranek, 1993).

Outra característica das ondas sonoras é a amplitude, que representa o máximo afastamento, durante a oscilação, em relação à posição de equilíbrio. Uma onda de maior amplitude, do que o outra, tem mais energia e, consequentemente o ouvido de uma pessoa recebe sons mais "fortes".

Para caracterizar sons produzido como fraco ou forte utiliza-se a potência sonora, que é definida como a energia acústica total emitida por uma fonte em função do tempo, sendo a unidade de medida o Watt $(1 \mathrm{~W}=1 \mathrm{~J} / \mathrm{s})$.

\subsubsection{Nível de intensidade sonora}

Outro termo bastante usado em acústica é o conceito de intensidade. Esse é definido como a quantidade de energia contida no movimento vibratório, e traduz com uma maior ou menor amplitude de vibração. De forma complementar o conceito de intensidade sonora também pode ser definido como: valor médio do fluxo de energia por unidade de área perpendicular à direção de propagação, sendo utilizado como unidade o Watt por metro quadrado $\left(\mathrm{w} / \mathrm{m}^{2}\right)$.

De forma a classificar um som mais fraco, ou mais forte, em termos da intensidade pode-se utilizar o termo Nível de Intensidade Sonora (NIS), que é definido em termos de uma escala logarítmica. Esse fato é devido a sensibilidade do ser humano variar linearmente, enquanto que o estímulo respectivo varia exponencialmente. Ainda, o nível de Intensidade Sonora é uma grandeza relativa, considerando como referência a intensidade $I_{0}=10^{-12} \mathrm{~W} / \mathrm{m}^{2}$. Assim, o Nível de Intensidade Sonora é representado matematicamente por meio da Equação 1. 


$$
\text { Nível de intensidade Sonora }(\mathrm{NIS})=\log \frac{\mathrm{I}}{\mathrm{I}_{0}}(\mathrm{~dB})
$$

Onde:

I é a intensidade acústica em $\mathrm{W} / \mathrm{m}^{2}$

$\mathrm{I}_{0}$ é a intensidade de referência $=10^{-12} \mathrm{~W} / \mathrm{m}^{2}$

Considerando uma frequência fixa de $1000 \mathrm{~Hz}$, os níveis mínimos e máximos de intensidades sonoras percebidos pela audição humana são de $\mathrm{I}_{0}=10^{-12} \mathrm{~W} / \mathrm{m}^{2}$ para o limiar de audibilidade $\mathrm{I}=1 \mathrm{~W} / \mathrm{m}^{2}$ para o limiar de dor, respectivamente. $\mathrm{O}$ nível de intensidade sonora percebida pelo ouvido humano abrange 12 ordens de grandeza, ou $120 \mathrm{~dB}$ para um tom de referência de $1000 \mathrm{~Hz}$.

\subsubsection{Nível de pressão sonora}

O Nível de Pressão Sonora - NPS (Sound Pressure Level - SPL) em um determinado ponto é expresso em decibéis e tem como valor de referência $\left(\mathrm{P}_{0}\right)$ igual a $20 \mu \mathrm{Pa}\left(2 \times 10^{-5} \mathrm{~N} / \mathrm{m}\right)$. A equação 2 apresenta a relação entre o nível pressão sonora e a intensidade acústica. De acordo com a equação 2 a intensidade acústica é proporcional ao quadrado da pressão acústica.

$$
\frac{\mathrm{I}_{1}}{\mathrm{I}_{2}}=\frac{\mathrm{P}_{1}^{2}}{\mathrm{P}_{2}^{2}}
$$

Portanto, o nível de intensidade acústica em termos do nível de pressão sonora pode ser expresso pela equação 3 .

$$
\mathrm{NIS}=10 \log \frac{\mathrm{I}}{\mathrm{I}_{0}}=10 \log \frac{\mathrm{P}^{2}}{\mathrm{P}_{0}^{2}}=10 \log \left(\frac{\mathrm{P}}{\mathrm{P}_{0}}\right)^{2}=20 \log \frac{\mathrm{P}}{\mathrm{P}_{0}}
$$

Assim, o nível de pressão sonora é dado pela equação 4.

$$
\mathrm{NPS}=20 \log \frac{\mathrm{P}}{\mathrm{P}_{0}}
$$

Onde:

NPS é o Nível de Pressão Sonora (dB);

P é a Pressão Sonora Medida $(\mathrm{Pa})$;

$\mathrm{P}_{0}$ é a Pressão Sonora de Referência, normalmente $20 \mu \mathrm{Pa}$, correspondente ao limiar da 
audição humana a $1000 \mathrm{~Hz}$.

Por meio do Quadro 2.1 pode-se observar a relação entre pressão sonora em $\mu \mathrm{Pa}$, da intensidade em watts $/ \mathrm{m}^{2}$ e o nível sonoro na escala logarítmica em $\mathrm{dB}$, na qual é possível ver claramente que a variação da pressão sonora com o nível sonoro não é linear. Todos os valores são obtidos através da aplicação das equações anteriores.

Quadro 2.1 - Relação entre pressão sonora, intensidade e nível sonoro

\begin{tabular}{|l|l|l|}
\hline $\begin{array}{c}\text { Pressao Sonora } \\
(\mu \mathrm{Pa})\end{array}$ & $\begin{array}{c}\text { Intensidade sonora } \\
\left(10-12 \text { watts } / \mathrm{m}^{2}\right)\end{array}$ & $\begin{array}{c}\text { Nivel sonoro } \\
(\mathrm{dB})\end{array}$ \\
\hline 200000000 & 100.000 .000 .000 .000 & 140 \\
& 10.000 .000 .000 .000 & 130 \\
20000000 & 1.000 .000 .000 .000 & 120 \\
& 100.000 .000 .000 & 110 \\
2000000 & 10.000 .000 .000 & 100 \\
& 1.000 .000 .000 & 90 \\
200000 & 100.000 .000 & 80 \\
& 10.000 .000 & 70 \\
20000 & 1.000 .000 & 60 \\
& 100.000 & 50 \\
2000 & 10.000 & 40 \\
& 1.000 & 30 \\
200 & 100 & 20 \\
20 & 10 & 1 \\
\hline
\end{tabular}

\subsection{REGULAMENTAÇÃO DO RUÍDO}

Os Estados Unidos foram um dos percursores quanto a elaboração de medidas de controle quanto a exposição ao ruído nas populações, o que cominou elaboração de uma legislação específica sobre ruído ambiente. Desde os anos 80 a agência de proteção ambiental americana estabeleceu critérios para a saúde e o bem-estar nas comunidades. Este processo evoluiu lentamente nos anos mais recentes, tendo as políticas americanas sobre ruído ambiente praticamente estagnado, e sendo ultrapassadas, a nível internacional, pelas iniciativas europeias (Bento Coelho, 2007).

A Comunidade Europeia, através da Diretiva 2002/49/EC do Parlamento Europeu, elaborou uma política voltada para o controle do ruído Ambiental. Essa diretiva tem como finalidade controlar o ruído urbano entre os membros da União europeia, e ainda cobrar das autoridades competentes a elaboração de planos de ação que auxiliem na gestão e nos problemas relacionados ao ruído, advindos das rodovias, ferrovias e aglomerações. Esta obrigatoriedade surgiu a partir de estudos ambientais executados no início da criação da 
zona do euro. Constatou-se que "por volta de $20 \%$ da população europeia sofre com níveis de ruído que cientistas e especialistas em saúde consideram inaceitáveis" (Comission of the European Communities, 1996).

A diretiva também estabelece um conjunto de requisitos básicos para a implementação de ações e medidas a serem utilizadas na mitigação do ruído ambiental (Murphy e King, 2011). Sendo seus principais objetivos o mapeamento de ruído, programas de ações e um sistema de informações ao público.

No Brasil, não há uma legislação específica a respeito do ruído devido ao tráfego rodoviário, são ainda escassas ou inexistentes como, por exemplo, no que se refere à emissão de ruído devido a interação pneu/pavimento.

Para a Resolução CONAMA Nº1 de 1990, o ruído excessivo, principalmente o ruído proveniente do tráfego dos veículos rodoviários automotores, causa prejuízo à saúde física e mental, afetando particularmente a audição. Ainda, essa mesma resolução determina que os ruídos com níveis superiores aos considerados suportáveis pela norma NBR - 10.151/2000 Avaliação do Ruído em Áreas Habitadas visando o conforto da comunidade, da Associação Brasileira de Normas Técnicas - ABNT são prejudiciais à saúde e ao sossego público.

\subsection{PARAMETROS ACÚSTICOS}

Há vários índices para avaliação do ruído para comunidades criados em diferentes países. No entanto, o índice mais usado é o nível obtido a partir do valor médio quadrático da pressão sonora (com a ponderação $\mathrm{A})$, referente a todo o intervalo de medição. - $\left(\mathrm{L}_{\text {Aeq }}\right)$ definido pela ISO 1996 (International Organization for Standardization, 2007).

Tendo em vista o que propõe a Diretiva do Parlamento Europeu e do Conselho referente à avaliação e gestão do ruído ambiente, o $\mathrm{L}_{A e q}$, é dividido em três períodos de análise: (1) período Diurno, compreendido entre $7 \mathrm{~h}$ e 19h; (2) período Intermédio: compreendido entre $19 \mathrm{~h}$ e $23 \mathrm{~h}$ e (3) período Noturno, entre $23 \mathrm{~h}$ e $7 \mathrm{~h}$.

Associados a estes períodos são definidos dois indicadores: Nível Dia-Entardecer-Noite $\left(\mathrm{L}_{\text {den }}\right)$ e Nível Noite $\left(\mathrm{L}_{n}\right)$. O nível de pressão sonora por longos períodos e que combina os níveis dia, entardecer e noite, pode ser expresso pela equação 5. 


$$
\mathrm{L}_{\mathrm{den}}=10 \times \log _{10}\left[\frac{1}{24}\left(12 \times 10^{\frac{\mathrm{L}_{\mathrm{Aeq}, \mathrm{dia}}}{10}}+4 \times 10^{\frac{\mathrm{L}_{\mathrm{Aeq}, \text { ent. }}+5}{10}}+8 \times 10^{\frac{\mathrm{L}_{\mathrm{Aeq}, \text { noite }}+10}{10}}\right)\right] \mathrm{dB}(\mathrm{A})
$$

Onde:

$L_{A e q, d i a}$ : É o nível sonoro médio de longa duração, ponderada A, conforme definido na norma ISO 1996/2: 1987, determinado durante todos os períodos diurno de um ano;

$L_{\text {Aeq,ent. }}$ É o nível sonoro médio de longa duração, ponderado A, conforme definido na norma ISO 1996/2: 1987, determinado durante todos os períodos vespertinos de um ano;

$L_{A e q, n o i t e}:$ É o nível sonoro médio de longa duração, ponderado A, conforme definido na norma ISO 1996/2: 1987, determinado durante todos os períodos noturnos de um ano; (Diretiva, 2002).

Constata-se desta forma que, no indicador $L_{d e n}$ os diferentes períodos do dia são ponderados de forma diferenciada, período diurno +0 , período entardecer +5 e período noturno +10 .

\subsubsection{Nível equivalente de pressão sonora, $\left(L_{e q}\right)$}

Para medir o ruído de tráfego pode-se utilizar o nível equivalente $\left(\mathrm{L}_{\mathrm{eq}}\right)$, que é a medida da média energética temporal, independente das características aleatórias do ruído de tráfego, ou seja, não considera se o tráfego flui livremente, ou se ocorrem congestionamentos. $\mathrm{O}$ cálculo é feito integrando-se a variação da pressão no tempo, conforme pode ser visto na Equação 6 (GERGES, 1992):

$$
\mathrm{L}_{\mathrm{eq}}=10 \cdot \log \frac{1}{\mathrm{~T}} \int_{0}^{\mathrm{T}} \frac{\mathrm{P}^{2}(\mathrm{t})}{\mathrm{P}_{0}^{2}} d t
$$

Onde:

T é o tempo de integração;

$\mathrm{P}(\mathrm{t})$ é a pressa acústica instantânea;

$\mathrm{P}_{0}$ é a pressa acústica de referência;

$\mathrm{L}_{\text {eq }}$ representa o nível contínuo equivalente em $\mathrm{dB}(\mathrm{A})$

Pode-se adotar qualquer tempo para o período de determinação do $\mathrm{L}_{\mathrm{eq}}$, sendo assim definido em função dos objetivos da medição que está sendo realizada. O Nível Sonoro Equivalente 
$\left(\mathrm{L}_{\mathrm{eq}}\right)$ é usualmente utilizado para quantificar níveis de ruído ambiental expressos na curva de ponderação "A".

De acordo com Bistafa (2007), para registros sonoros de ruídos não-estacionários, como o ruído de tráfego veicular, deve-se procurar um nível médio durante o período de registro, o que pode ser fornecido através do descritor de nível de pressão sonora equivalente contínuo $\mathrm{L}_{\mathrm{eq}}$.

Segundo a norma NBR 10151, o nível equivalente $\left(\mathrm{L}_{\mathrm{eq}}\right)$ é o "Nível obtido a partir do valor médio quadrático da pressão sonora (com a ponderação A) referente a todo o intervalo de medição" e é o parâmetro utilizado pelas principais normas brasileiras. É considerado ainda, como o nível ponderado de pressão sonora dentro de um determinado período de tempo, (Murgel, 2007). A NBR 10151 (ABNT, 2000) recomenda o $\mathrm{L}_{\mathrm{eq}}$ para análises de ruído referente ao tráfego urbano.

\subsubsection{Parâmetros estatísticos}

O parâmetro " $\mathrm{L}_{\mathrm{x}}$ " é definido como o valor de nível de ruído que é excedido x\% do tempo. $\mathrm{L}_{\text {máx }}$ e $\mathrm{L}_{\text {min }}$ indicam, respectivamente, o nível mínimo e máximo. Desta modo, $\mathrm{L}_{100}=\mathrm{L}_{\min }$ e $\mathrm{L}_{\text {máx }}=\mathrm{L}_{0}$. Em todos os casos, os valores referem-se ao período durante o qual a medição é executada. Os parâmetros usados com mais frequência são: $\mathrm{L}_{10}, \mathrm{~L}_{90}, \mathrm{~L}_{50}, \mathrm{~L}_{0}$ e $\mathrm{L}_{100}$. Ainda, os níveis estatísticos de ruído são níveis de pressões sonoras, que são ultrapassados durante uma determinada fração do tempo total de medição. Os níveis estatísticos de maior interesse para estudos de ruído de tráfego são $\mathrm{L}_{10}$ e L 90 (Schultz, 1978). Os níveis excedidos durante, respectivamente, $10 \%$ e $90 \%$ do tempo de medição (Gerges, 2000). No caso do ruído de tráfego rodoviário, o nível estatístico $\mathrm{L}_{10}$ indica os valores que foram excedidos durante $10 \%$ do tempo total de medição, sendo desta forma, aceito como valores de pico. Já o nível estatístico $\mathrm{L}_{90}$, pode ser considerado como um ruído ambiental, visto que o nível de ruído ultrapassa quase todo o tempo de medição.

\subsubsection{Adição e subtração de níveis sonoros}

Diferentes níveis de ruído produzido por diferentes fontes não devem ser somados de forma algébrica para dar uma resultante do ruído combinado, pois são unidades logarítmicas, (Avsar e Gonullu, 2005). Quando há mais de uma fonte de ruído, a soma dos níveis de ruído no ambiente é calculada em termos da quantidade de energia sonora. O método que é 
geralmente usado é combiná-los em uma base de energia, convertendo número de decibéis para níveis relativos, em seguida, adicionar ou subtrai-los, como a situação pode exigir, e depois converter de volta para os decibéis correspondentes. No caso da adição, são então adicionados os efeitos (pressão sonora) de cada fonte sonora de interesse para se obter um efeito global (Bies e Hansen, 2002).

Para somar níveis de intensidade sonora $\left(\mathrm{L}_{\mathrm{I}}\right)$ em dB tem-se o método numérico que se baseia em operações logarítmicas e pode ser determinado pela Equação 7.

$$
\mathrm{L}_{1+2+\ldots+\mathrm{n}}=\mathrm{L}_{\text {total }}=10 \log \sum_{\mathrm{i}=1}^{\mathrm{n}} 10^{\mathrm{L}_{\mathrm{i}} / 10}
$$

Onde:

$\mathrm{L}_{\mathrm{i}}$ : Representa os níveis de intensidade sonora;

$\mathrm{L}_{1+2+\ldots+\mathrm{n}}$ : Representa os " $\mathrm{n}$ ” níveis sonoros $\mathrm{L}_{1}, \mathrm{~L}_{2} \ldots, \mathrm{L}_{\mathrm{n}}$

\subsection{RUÍDO E SAÚDE}

A World Health Organization - (WHO) classifica a poluição sonora como um dos tipos de poluição que mais atinge a população mundial, sendo considerada como um caso de saúde pública. E ainda, que o ruído ambiental contribui para a carga de doenças quando se analisam os riscos ambientais (WHO, 2011). Uma em cada três pessoas apresenta incômodo durante o dia e uma em cada cinco tem problemas de sono durante a noite em função do ruído do tráfego.

Diversas pesquisas realizadas com objetivo de mensurar os níveis de ruído oriundos do tráfego veicular mostram que, de forma geral, os valores encontrados estão sempre acima do que é indicado ou recomendado pelas legislações e normas técnicas específicas (Garavelli et al., 2013; Ramis et al., 2003; Ali, 2004; Ali e Tamura, 2003; Álvares e Souza, 1992; Bortoli, 2002).

A Organização Mundial de Saúde recomenda que, em áreas residenciais, o nível de ruído não ultrapasse o nível sonoro equivalente a $\mathrm{L}_{\mathrm{eq}}=55 \mathrm{~dB}(\mathrm{~A})$. Associado a isso, estipula-se que o nível sonoro de até $\mathrm{L}_{\mathrm{eq}}=50 \mathrm{~dB}(\mathrm{~A})$ pode perturbar, mas o organismo se adapta a ele, porém, acima deste valor $(55 \mathrm{~dB})$, pode desencadear estresse leve acompanhado de desconforto. Já os valores acima do $\mathrm{L}_{\mathrm{eq}}=70 \mathrm{~dB}(\mathrm{~A})$ são tidos como o nível de desgaste do 
organismo, podendo aumentar os riscos de infarto, derrame cerebral, infecções, hipertensão arterial e outras patologias (WHO, 2003).

Vários estudos demonstram que o ruído produz alterações físico-psicológicas no ser humano, podendo dar origem a distúrbios e doenças diversas (Babisch et al., 2003; Belojevic et al., 1997). Desta forma, a exposição a níveis de intensidade sonora de forma prolongada pode ocasionar danos irreversíveis a saúde. Carmo (1999), aponta em seus estudos que o ruído afeta não somente o funcionamento do sistema auditivo, mas o comprometimento da atividade física, fisiológica e mental do indivíduo a ele exposto. $\mathrm{O}$ ruído excessivo também é um incômodo ao sono, afetando seus principais processos orgânicos e cerebrais (WHO, 2003).

Basner et al. (2014), apresenta um trabalho que traz uma abordagem teórica a respeito dos efeitos auditivos e não-auditivos do ruído na saúde. São mencionados por eles estudos observacionais e experimentais que demonstram que a exposição prolongada ao ruído causa: irritação, perturbação ao sono, sonolência diurna, aumento na ocorrência de hipertensão e doença cardiovascular. Os autores ressaltam a importância da prevenção e da atenuação do ruído como estratégias adequadas para a saúde pública.

\subsection{FONTES DE RUÍDO DE TRÁFEGO}

O ruído gerado pelo tráfego é considerado um som desagradável por não transmitir mensagens harmônicas aos ouvintes, e que na maioria das vezes está acima dos limites de

ruídos permitidos pela legislação. É produzido por vários veículos em diferentes posições, velocidades e acelerações, onde o ruído provocado pelo veículo quando está em circulação é o resultado da sobreposição de vários ruídos provenientes de diferentes partes do veículo (Guedes, 2005).

O ruído rodoviário se dá principalmente da interação do pneu com o pavimento, onde, alterações nos parâmetros pode alterar a intensidade dos níveis sonoros, como por exemplo mudanças na velocidade e no tipo de pavimento. Outros tipos de fontes sonoras presentes na produção do ruído rodoviário são o ruído aerodinâmico e o ruído de propulsão, onde este último pode ser significativo a baixas velocidades. O ruído proveniente do sistema de propulsão, (sistema de motor e sistema de exaustão), pode ser significativo até velocidades na ordem dos $50 \mathrm{~km} / \mathrm{h}$ como no caso de veículos mais antigos, carros a diesel, Vans e veículos com fraco isolamento dos ruídos de escape (Sanderbeg, 2003). Para velocidades 
superiores, onde existe o predomínio do ruído de contato piso/pneu o ruído de propulsão é desprezível (Sanderbeg, 2003).

As fontes de ruído de tráfego em rodovias podem ser divididas em duas categorias principais, ou seja, ruído de motor e escapamento e, atrito entre pneus e pavimento (Tarrio, 1992 e Murgel, 1999). Segundo Avsar e Gonullu (2005), o ruído de tráfego está relacionado com a velocidade do veículo, ou seja, quanto mais alta é a velocidade do veículo, mais intenso o nível de pressão sonora. Esta afirmação é corroborada pelo trabalho desenvolvido por Hanson et al., (2005), conforme pode ser observado na Figura 2.1.

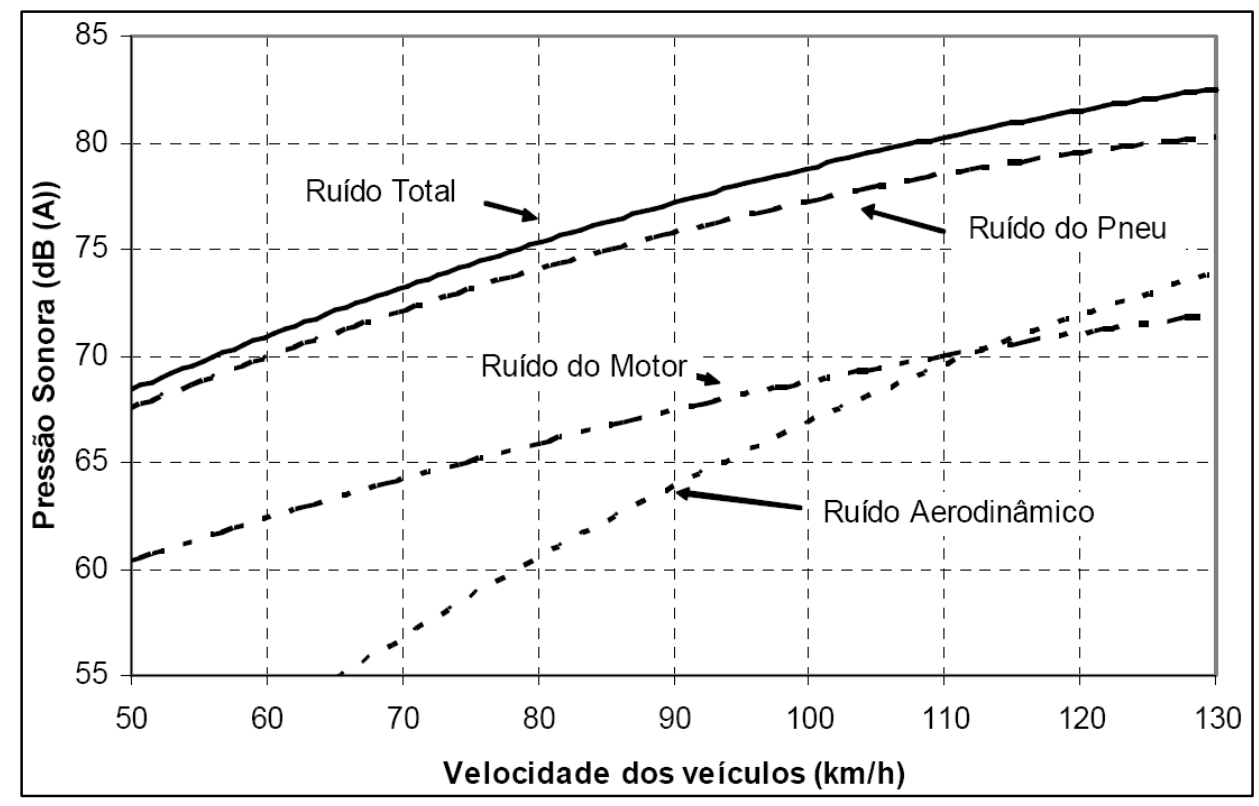

Figura 2.1 - A influência de diferentes fontes geradoras do ruído Fonte: (Hanson et. Al., 2005). Adaptado

O ruído dos veículos é originário no sistema de motor, escapamento e sistema de transmissão, contato pneu/pavimento e efeito aerodinâmico. Na Figura 2.1 está representada a contribuição de cada parcela no ruído total, nota-se claramente a importância do ruído pneu/pavimento no ruído total (Hanson et al., 2005).

O ruído proveniente da interação pneu/estrada está diretamente relacionado com a velocidade, aumentando aproximadamente $12 \mathrm{~dB}$ com o duplicar da mesma, enquanto o ruído proveniente do motor é pouco influenciado. Para baixas velocidades $(<30 \mathrm{Km} / \mathrm{h}$ para ligeiros e $<40 \mathrm{Km} / \mathrm{h}$ para pesados), o ruído total tem origem predominantemente no trabalhar do motor, enquanto que para velocidades mais elevadas ( $>50 \mathrm{Km} / \mathrm{h}$ ligeiros e $>70$ $\mathrm{Km} / \mathrm{h}$ pesados), a fonte dominante é a circulação (IA, 2002). 
Callai (2011) utilizou-se de diferentes ensaios para mostrar as alterações nos níveis de pressão sonora em termos da velocidade média. Os resultados por ele apresentados mostram que a velocidade é muito relevante para os níveis de ruído, visto que a diferença entre o nível de ruído a $60 \mathrm{~km} / \mathrm{h}$ para o de $100 \mathrm{~km} / \mathrm{h}$ é de aproximadamente $10 \mathrm{~dB}(\mathrm{~A})$.

\section{6 - PROPAGAÇÃO DO RUÍDO GERADO PELO TRÁFEGO}

A propagação do ruído rodoviário depende de fatores, tais como: características físicas da superfície e do meio, presença de obstáculos e condições atmosféricas predominantes (Silva, 2008).

O ruído se propaga sobre a forma de ondas mecânicas emitidas por uma ou várias fontes sonoras, como é o caso do tráfego rodoviário que pode ser considerada como um conjunto de inúmeras fontes pontuais (veículos) distribuídas ao longo de um espaço linear (estrada).

O ruído diminui com o aumento da distância do receptor à fonte sonora e propaga-se até atingir um obstáculo. Quando isto acontece parte do ruído é refletido e a restante absorvida sob a forma de calor, podendo parte desta ser transmitida através do obstáculo. Pode ainda ocorrer o fenómeno de difração, em que o ruído chega ao receptor de forma indireta passando pelos bordos superiores e laterais do obstáculo (IA, 2004).

\subsubsection{Ruído devido a superfície do tráfego}

O ruído advindo da interação pneu/pavimento depende de muitos fatores como por exemplo: do modelo e idade do veículo, do peso por eixo, da pressão de inflação dos pneus, do tipo e tamanho dos pneus e das características da superfície (Callai, 2011). A textura superficial é o principal fator responsável pela variabilidade no NPS em um pavimento, seguido do volume de vazios e da rigidez do revestimento. A textura superficial do pavimento deve condicionar características que dizem respeito ao conforto e a segurança dos usuários (Rasmussen et al., 2007).

A geração do som está associado ao efeito do impacto da borracha do pneu com o pavimento. Esse fato é intensificado devido a ondulações na superfície e minimizado pela resiliência da borracha, ao efeito do bombeamento de ar que entra e sai dos sulcos do pneu, ao deslizamento entre as superfícies e pela adesão borracha/pavimento.

Estudos realizados quanto ao mecanismos de geração de ruído de tráfego na interface pneu- 
pavimento, relacionando o índice de vazios, a textura superficial e a irregularidade longitudinal de vários pavimentos asfálticos com os respectivos NPS emitidos por um veículo de passeio trafegando em várias velocidades mostraram que NPS gerado na interface pneu-pavimento é diretamente proporcional ao aumento da velocidade.

Contudo, é possível afirmar que a parcela de NPS derivada da aderência entre pneupavimento deve ser maior para veículos trafegando em baixas velocidades (até de $60 \mathrm{~km} / \mathrm{h}$ ), sob ampla ação dos efeitos da microtextura. A irregularidade também é influenciada pelos defeitos de maiores dimensões no pavimento (Albuquerque e Núñez, 2011). Em baixas velocidades, os impactos absorvidos pelo pneu devido a irregularidade do pavimento também são responsáveis por grandes parcelas do NPS produzido.

\subsubsection{Fatores que influenciam na propagação do ruído}

Há vários fatores que influenciam na propagação do ruído. Os mais importantes, que agem na propagação do ruído, podem ser divididos em influências meteorológicas (absorção atmosférica, vento, temperatura, umidade e precipitações) e influências urbanas (obstáculos, barreiras, efeitos do piso e de fachadas).

A atenuação do ruído, à medida que esse se propaga no ar, depende principalmente da temperatura, umidade relativa e pressão atmosférica (Brüel e Kjaer, 2001). A atenuação devido aos efeitos atmosféricos se dão devido à perda de energia sonora devido a dois mecanismos principais: viscosidade do ar e pelos processos de relaxamento (Rossing, 2007). O primeiro é devido a fricção das moléculas do ar e resulta na geração de calor, também conhecida como absorção clássica; e a segunda, ocorre quando a energia sonora é momentaneamente absorvida pelas moléculas de ar e causa as moléculas de ar a vibrar e rotar. Essas moléculas podem então reemitir som um instante posterior, o que pode interferir no som que chega.

Já a atenuação dos efeitos devido ao solo são interferências que podem ocorrer no transcurso do som, propagando diretamente da fonte sonora ao receptor com o som refletido próximo à fonte, assim como o som refletido próximo ao receptor. Nesse fenômeno, pode ocorrer interferência do tipo construtiva, em que há aumento na amplitude de onda, ou do tipo destrutiva. Essa situação depende do tipo de solo e da frequência da onda sonora.

A atenuação devido à topografia e às dimensões dos edifícios podem ser naturais, devido à topografia da região, ou artificiais, criadas por alguma construção projetada ou não para esse 
fim. As ondas sonoras ao se chocar contra uma superfície, parte da energia acústica é refletida, parte é absorvida e parte é transmitida através desta. Se a absorção e a transmissão são pequenas, caso geral de fachadas de edifícios, a superfície pode ser classificada como acusticamente refletora. A quantidade de energia absorvida, assim como a direcionalidade das ondas refletidas, são maiores para as altas frequências e dependem diretamente das propriedades físicas e geométricas da superfície

\subsection{MODELOS DE PREVISÃO DE RUÍDO}

Uma das formas de prever os níveis de intensidade sonora devido ao tráfego rodoviário é por meio de modelos matemáticos que são usados para simular descritores médios de ruído. Esses modelos geralmente consideram o fluxo de tráfego como uma fonte de ruído constante, cujo nível depende principalmente da taxa de fluxo e da velocidade média.

Entretanto, essa representação estática não leva em consideração a dinâmica de tráfego das rodovias com características urbanas. Para superar essa deficiência, trabalhos recentes têm incrementado modelos dinâmicos para o tráfego rodoviário levando em consideração as leis de emissão de ruído (Leclercq, L. e Lelong, J., 2001; De Coensel, et al., 2005).

Um modelo de cálculo de propagação do som é desenvolvido para representar o nível de ruído em um ponto de recepção em um determinado instante (Harmonoise, 2004). Assim, os descritores acústicos podem ser calculados levando em conta as respectivas variações devido ao tráfego de veículos em rodovias com características urbanas. Isto oferece um avanço substancial na predição dos níveis de intensidade sonora considerando o tráfego dinâmico. Modelos de ruído atualmente disponíveis para o mapeamento do ruído são principalmente semiempíricos, combinando a física da propagação do som ao ar livre com dados empíricos de repetidos experimentos (Watts, 2005).

Existe uma série de modelos, Quadro 2.2, utilizados na predição dos níveis de ruído ambiental para descrever os níveis de intensidade sonora advindos do tráfego rodoviário e ferroviário, que trazem algumas lacunas, tais como: as condições de propagação, as limitações na separação entre a fonte de ruído e a propagação do mesmo. 
Quadro 2.2- Exemplos de modelos de predição de ruído de tráfego rodoviário Fonte: Adaptado a partir de Guedes (2005) e Ferreira (2008)

\begin{tabular}{|c|c|c|c|}
\hline MODELO & FÓRMULA & ELEMENTOS COMPONENTES & $\begin{array}{c}\text { QUANTIDADE } \\
\text { TOTAL DE DADOS } \\
\text { DE ENTRADA }\end{array}$ \\
\hline $\begin{array}{c}\text { RLS-90 } \\
\text { (Modelo Alemão) }\end{array}$ & $\mathrm{L}_{25}=37,3+10 \log [\mathrm{I} \times(1+0,082 \times \mathrm{P})]+\mathrm{C}_{\mathrm{vel}}+\mathrm{C}_{\text {sup }}+\mathrm{C}_{\mathrm{ref}}+\mathrm{C}_{\text {grad }}$ & $\begin{array}{l}\text { I = Tráfego médio dos veículos; } \\
\text { P = Percentagem de veículos pesados (que excedem 2,8 ton.); } \\
\text { C }_{\text {vel }}=\text { Correção adicionada devido às variações das velocidades medias dos veículos; } \\
\text { C }_{\text {sup }} \text { = Correção adicionada devido ao tipo de superfície de pavimentação da via; } \\
\text { C }_{\text {ref }} \text { = Correção devido às múltiplas reflexões ocorridas na via; } \\
\text { Cgrad }_{\text {graceção adicionada devido ao gradiente da rua. }}\end{array}$ & 6 \\
\hline $\begin{array}{c}\text { FHWA } \\
\text { (Modelo } \\
\text { Americano) }\end{array}$ & Leq $=\mathrm{L}_{\mathrm{o}}+10 \log \left[\mathrm{N}_{\mathrm{i}} /\left(\mathrm{V}_{\mathrm{i}} \times \mathrm{T}\right)\right]+(15 / \mathrm{d}) 1+\alpha+\mathrm{A}_{\text {combinado }}-13$ & $\begin{array}{l}\mathrm{L}_{\mathrm{o}}=\text { Nível sonoro de referência emitido por um determinado tipo de veículo; } \\
\mathrm{N}_{\mathrm{i}}=\text { Volume de trafego de um determinado tipo de veículo; } \\
\mathrm{V}_{\mathrm{i}}=\text { Velocidade média da via; } \\
\mathrm{T}=\text { Tempo de duração para o qual se deseja o Leq; } \\
\text { d = Distancia perpendicular da via até o receptor; } \alpha \text { = Fator de absorção sonora da cobertura do solo } \\
\text { entre a via e o receptor; } \\
\mathrm{A}_{\text {combinado }} \text { = Fatores de absorção dos atenuadores acústicos combinados. }\end{array}$ & 6 \\
\hline $\begin{array}{l}\text { HARMONOISE } \\
\text { (União Europeia) }\end{array}$ & $\mathrm{L}_{\mathrm{weq}}=\mathrm{L}_{\mathrm{wP}}+\mathrm{L}_{\mathrm{wR}}+10 \log (\mathrm{Q} / \mathrm{v})$ & $\begin{array}{l}\mathrm{L}_{\mathrm{wP}}=\text { Ruído instantâneo de propulsão de referência, de acordo com o tipo de veículo; } \\
\mathrm{L}_{\mathrm{wR}}=\text { Ruído instantâneo de rolamento de referência, de acordo com o tipo de veículo; } \\
\mathrm{Q}=\text { Intensidade do trafego; } \\
\mathrm{v}=\text { Velocidade do trafego. }\end{array}$ & 4 \\
\hline \multirow{3}{*}{$\begin{array}{l}\text { NMPB-Routes96 } \\
\text { (Francês) }\end{array}$} & $\mathrm{L}_{\mathrm{Ai}, \mathrm{LT}}=10 \log \left[\mathrm{pi} 10(0,1 \mathrm{LAi}, \mathrm{F})+\left(1 \mathrm{p}_{\mathrm{i}}\right) 10(0,1 \mathrm{LAi}, \mathrm{H})\right]$ & $\begin{array}{l}\mathrm{L}_{\mathrm{Ai}, \mathrm{LT}}=\text { nível sonoro de longo prazo (Long term sound level); } \\
\mathrm{p}_{\mathrm{i}}=\text { ocorrência a longo prazo de condições meteorológicas favoráveis à propagação sonora; } \\
\mathrm{L}_{\mathrm{Ai}, \mathrm{F}}=\text { nível sonoro calculado em condições meteorológicas favoráveis de propagação sonora; } \\
\mathrm{L}_{\mathrm{Ai}, \mathrm{H}}=\text { nível sonoro calculado em condições meteorológicas homogêneas de propação sonora. }\end{array}$ & 3 \\
\hline & $\mathrm{L}_{\mathrm{Ai}, \mathrm{F}}=\mathrm{L}_{\mathrm{A}, \mathrm{w}}-\mathrm{A}_{\mathrm{div}}-\mathrm{A}_{\mathrm{atm}}-\mathrm{A}_{\mathrm{grd}, \mathrm{F}}-\mathrm{A}_{\mathrm{diff}, \mathrm{F}}$ & $\begin{array}{l}\mathrm{L}_{\mathrm{A}, \mathrm{w}}=\text { Nível de potência sonora da fonte; } \\
\mathrm{A}_{\mathrm{div}}=\text { Atenuação geométrica (pela distância - cálculo de propagação esférica); } \\
\mathrm{A}_{\mathrm{atm}}=\text { Atenuação (absorção) atmosférica (Segundo ISO 9613); } \\
\mathrm{A}_{\mathrm{grd}, \mathrm{F}}=\text { Atenução do solo em condições meteorológicas favoráveis de propagação sonora; } \\
\mathrm{A}_{\text {diff,F }}=\text { Atenuação por difração em condições meteorológicas favoráveis de propagação sonora. }\end{array}$ & 5 \\
\hline & $\mathrm{L}_{\mathrm{Awi}}=\left[\left(\mathrm{E}_{\mathrm{L}}+10 \log \mathrm{Q}_{\mathrm{L}}\right)+\left(\mathrm{E}_{\mathrm{P}}+10 \log \mathrm{Q}_{\mathrm{P}}\right)\right]+20+10 \log (\mathrm{Ii})+\mathrm{R}(\mathrm{j})$ & $\begin{array}{l}\mathrm{L}_{\mathrm{Awi}}=\mathrm{L}_{\mathrm{A}, \mathrm{w}} \\
\mathrm{E}_{\mathrm{L}}=\text { Níveis de emissão sonora de veículos leves; } \\
\mathrm{Q}_{\mathrm{L}}=\text { Fluxo de veículos leves por hora; } \mathrm{EP}=\text { Níveis de emissão sonora de veículos pesados; } \\
\mathrm{E}_{\mathrm{P}}=\text { Níveis de emissão sonora de veículos pesados; } \\
\mathrm{Q}_{\mathrm{P}}=\text { Fluxo de veí́culos pesados por hora; } \\
\mathrm{Ii}=\text { Comprimento da via em metros; } \\
\mathrm{R}(\mathrm{j}) \text { = Valor do espectro de ruído normalizado da CEN 1793-3 (1995). }\end{array}$ & 7 \\
\hline
\end{tabular}


O Quadro 2.2 apresenta uma série de métodos de previsão do ruído ambiental devido ao tráfego rodoviário e ferroviário. Projetos como o Harmonoise, (2005) e Silvia (2006) foram desenvolvidos para métodos de cálculo mais rigorosos, com o objetivo de permitir estimar os níveis de ruído ambiental através de métodos harmonizados em nível europeu.

\subsubsection{Modelos dinâmicos}

Nos últimos anos têm se verificado o desenvolvimento de importantes projetos na área de modelação. O projeto Cnossos-EU (Commom Noise Assessment Methods in European Union), visa dar assessoria técnica na preparação do método de avaliação comum a ser utilizado pelos Estados Membros da União Europeia em mapas de ruído estratégicos. Este projeto refere ainda a dois outros projetos elaborados pela União Europeia que contêm métodos de avaliação do ruído de tráfego rodoviário que são o Harmonoise (Harmonized Accurate and Reliable Methods for the EU Directive on the Assessment and Management of Environmental Noise), e o IMAGINE (Improved Methods for the Assessment of the Generic Impact of Noise in the Environment).

$\mathrm{O}$ projeto Harmonoise foi desenvolvido antes do Imagine e contém métodos computacionais de previsão de níveis de ruído ambiental provocados pelo tráfego rodoviário e ferroviário. Esse estabelece relações entre alguns parâmetros, como o nível de ruído provocado pelos fatores: contato pneu/pavimento; ruído de propulsão; temperatura; humidade, idade do pavimento, entre outros. É importante referir que este corresponde a um modelo geral, sendo necessário aplicar regionalmente alguns fatores corretivos. O projeto IMAGINE, por sua vez, contém informações complementares ao Harmonoise, tais como orientações, bases de dados e exemplos, acrescentando ainda métodos para o tráfego aéreo e o ruído industrial.

\subsubsection{Modelo Alemão RLS 90}

O modelo Alemão RLS 90 (Richtlinien für den Lärmschutz an Straßen) é um algoritmo utilizado para determinar o nível de ruído rodoviário. O modelo tem como entrada de dados: o fluxo de tráfego, veículos leves e pesados, a velocidade média para cada tipo de veículo, geometria da rodovia e tipo de estrada. Ainda, considera as principais características que interferem na propagação do ruído, como obstáculos, a vegetação, a absorção de ar, reflexões e difração. 
O modelo RLS-90 estima que o nível de pressão sonora gerado pelo tráfego em uma rodovia longa, plana, retilínea e com tráfego contínuo, em cada pista é dada pela equação 8, como é apresentada no trabalho de Calixto, (2002).

$$
L_{m}=L_{m, E}+D_{s \perp}+D B M+D B
$$

Onde:

$L_{m, E}$ é o nível equivalente médio de emissão, em dB(A), a $25 \mathrm{~m}$ do centro da pista;

$D_{S \perp}$ é a atenuação devido à distância e a absorção do ar;

$D B M$ é a atenuação devido aos efeitos atmosféricos e do solo;

$D B$ é a atenuação devido à topografia e às dimensões dos edifícios.

O nível equivalente médio de emissão é dado pela equação 9:

$$
L_{m, E}=L_{m(25)}+D_{V}+D_{S t r o}+D_{S t g}+D_{E}
$$

onde:

$L_{m(25)}$ é o nível equivalente a $25 \mathrm{~m}$ do centro da pista, em $\mathrm{dB}(\mathrm{A})$,

$D_{V}$ é a correção devido à velocidade,

$D_{S t r o}$ é a correção devido à superfície da rodovia,

$D_{S t g}$ é a correção devido ao gradiente (aclive ou declive),

$D_{E}$ é a correção devido à absorção das superfícies dos edifícios.

Por meio da equação 10 é possível estimar os valores dos níveis equivalentes médios, à distância horizontal de $25 \mathrm{~m}$ do centro da pista mais próxima do receptor.

$$
L_{m(25)}=37,3+10 \log [M \cdot(1+0,082 p)]
$$

Onde:

M é o tráfego de veículos por hora, sob as seguintes condições:

- Asfalto liso,

- Velocidade média do tráfego igual a $100 \mathrm{~km} / \mathrm{h}$,

- Gradiente (aclive ou declive) $\leq 5 \%$;

p é a porcentagem de veículos pesados (maior que 2,8 t). 


\subsection{POPULAÇÃO EXPOSTA}

A World Health Organization publicou um relatório, em 2011, sobre os efeitos causados pela excessiva exposição ao ruído. Dentre eles estão os problemas cardíacos, perturbação no sono, danos cognitivos e aborrecimentos frequentes (WHO, 2011).

Quando se avalia o impacto sonoro, determina-se a quantidade de pessoas expostas e afetadas pelo nível de pressão sonora. Desse modo uma das formas de se avaliar o incomodo percebido pelas populações, relacionado com o nível sonoro, é por meio de modelos "dose-resposta". Essas relações são estabelecidas mediante as análises dos dados recolhidos por meio de estudos sobre as atitudes das populações, sob a forma de questionários.

Miedema e Oudshomm (2001), tendo por base os estudos feitos por Miedema e Vos (1998), exibiram novos modelos para os indicadores acústicos DNL e $L_{\text {den }}$ com aproximações polinomiais e com estimativas e intervalos de confiança melhoradas. Com isso, eles estabeleceram a relação de causa e efeito entre o ruído de uma fonte de transporte e o incômodo sonoro causado por ele. (Miedema e Oudshoorn, 2001).

Essas equações foram aprovadas pela Comunidade Europeia e pela Organização Mundial de Saúde (WHO, 2011) e recomendadas por essas duas organizações, pois determinam o percentual de pessoas incomodadas (\%A) e altamente incomodadas (\%HA). O resultado da equação demonstra a estimativa de incômodo sonoro produzida pelo ruído. Miedema e Vos (2003) descrevem a equação por meio do Quadro 2.3.

Quadro 2.3 - Estimativa do incômodo sonoro

Fonte: Miedema e Vos, (2003). Adaptado.

\begin{tabular}{|c|c|}
\hline $\begin{array}{c}\text { Fonte } \\
\text { sonora }\end{array}$ & $\begin{array}{c}\text { Aproximação polinomial }(\% \text { A e \% HA) } \\
\text { Indicador acústico } \boldsymbol{L}_{\text {den }}\end{array}$ \\
\hline \multirow{2}{*}{ Rodoviário } & $\% A=1,795 \times 10^{-4}\left(L_{d e n}-37\right)^{3}+2,110 \times 10^{-2}\left(L_{d e n}-37\right)^{2}+0,5353\left(L_{d e n}-37\right)$ \\
\cline { 2 - 3 } & $\% H A=9,868 \times 10^{-4}\left(L_{d e n}-42\right)^{3}-1,436 \times 10^{-2}\left(L_{d e n}-42\right)^{2}+0,5118\left(L_{d e n}-42\right)$ \\
\hline
\end{tabular}

A Figura 2.2 apresenta os gráficos destas funções e também, a indicação dos valores limite estipulados na legislação Europeia para o indicador $L_{d e n}$ e em função do zoneamento acústico (misto ou sensível). 


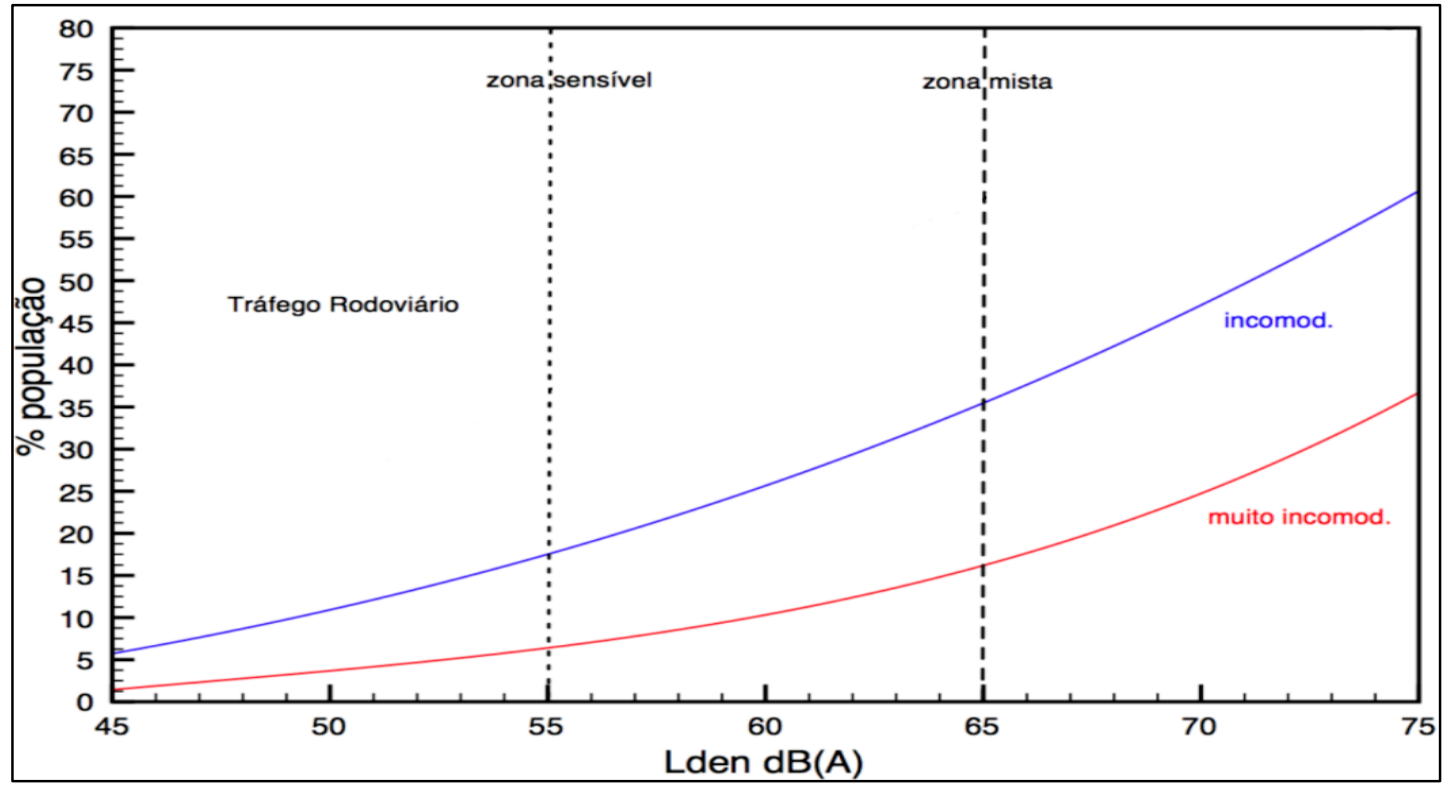

Figura 2.2 - Curvas resultantes do modelo de incomodidade para tráfego rodoviário Fonte: (Miedema, 2001). Adaptado.

Os autores também propõem equações com aproximações polinomiais para estabelecer o nível de pessoas com o sono altamente perturbado (\% SAP). Utiliza-se o indicador $L_{n}$, que possui a função de prever antecipadamente os efeitos crônicos de exposição ao ruído noturno (Quadro 2.4).

Quadro 2.4 - Polinômios para Distúrbios do Sono - Tráfego Rodoviário Fonte: (Miedema et. al., 2003) Adaptado.

\begin{tabular}{|c|}
\hline Ruído do Tráfego Rodoviário \\
\hline$\% P D S=13,8-0,85\left(L_{n}\right)+0,01670\left(L_{n}\right)^{2}$ \\
\hline$\% P S L P=-8,4+0,16\left(L_{n}\right)+0,01081\left(L_{n}\right)^{2}$ \\
\hline
\end{tabular}

Os polinômios apresentados no Quadro 2.4 descrevem a relação entre o \%PDS (percentual de pessoas com distúrbios no sono) e \%PSLP (percentual de pessoas com o sono levemente perturbado).

\subsection{MAPAS DE RUÍDO}

A partir da Diretiva 2002/49/CE a elaboração de mapas estratégicos de ruído tornou-se obrigatória na Europa para as aglomerações urbanas com mais de 250 mil habitantes. E tem como proposta central definir uma abordagem comum para evitar, prevenir ou reduzir os efeitos prejudiciais da exposição ao ruído ambiental nos Estados - Membros Europeus (Parlamento Europeu e do Conselho, 2002). 
De acordo com as diretrizes para elaboração de mapas de ruído de dezembro 2011 um mapa de ruído é uma representação geográfica do ruído ambiente exterior, onde se visualizam as áreas às quais correspondem determinadas classes de valores expressos em dB(A), reportando-se a uma situação existente ou prevista (Parlamento Europeu, 2002).

O Mapa de ruído pode, ainda ser caracterizado como uma apresentação de dados sobre uma situação de ruído existente ou prevista em termos de um indicador de ruído, onde se representam as áreas e os contornos das zonas de ruído às quais corresponde uma determinada classe de valores expressos em $\mathrm{dB}(\mathrm{A})$, valores esses calculados numa malha quadrada de pontos e a uma dada altura relativa ao solo.

Eles são usados como ferramentas para determinar os níveis de intensidade sonora em termos da propagação, que vão desde a fonte até uma determinada distância de referência. Esses mapas representam os níveis de intensidade sonora por uma escala de cores, e podem ser usados para predizer níveis de intensidade sonora, e ainda, realizar simulações para diferentes cenários através das variáveis de entrada.

Na elaboração de um mapa de ruído são necessárias informações que vão desde a base cartográfica da área de estudo até o levantamento das fontes de ruído e da ocupação do solo (Jesus et. al., 2013). Os resultados dos dados de entrada são normalmente apresentados sob a forma de linhas isofônicas e/ou manchas coloridas, representando as áreas cujo nível de ruído se situa numa dada gama de valores (Barretto e Freitas, 2008; Bento Coelho e Alarcão, 2004; Garavelli et. al., 2010).

Um mapa de ruído constitui, essencialmente, uma ferramenta de apoio à decisão sobre planejamento e ordenamento do território que permite visualizar condicionantes dos espaços por requisitos de qualidade do ambiente acústico devendo, portanto, ser adaptado na preparação dos instrumentos de ordenamento do território e na sua aplicação. A vantagem da modelação está na precisão e no planejamento ambiental em longo prazo. $\mathrm{O}$ efeito da mudança do tráfego em uma avenida, a construção de um shopping ou de uma indústria pode ser simulado com facilidade uma vez que o mapa esteja pronto (Garavelli, 2010)

O mapeamento acústico é realizado com a produção de Mapas de Ruído executados com o auxílio de software que possibilita não apenas a leitura de um panorama existente, mas principalmente a geração de alternativas baseadas em cenário e em investigações futuras, 
servindo de base na realização de políticas públicas, firmando se cada vez mais como uma ferramenta a serviço do desenvolvimento sustentável e da qualidade de vida, (Ansay, 2013).

\subsection{FORMAS DE ATENUAÇÃO E MITIGAÇÃO}

Medidas mitigadoras quanto a poluição sonora são necessárias quando os NPS ultrapassam os limites aceitáveis e ocasionem danos ao ser humano. Dentre as alternativas mais utilizadas na mitigação dos níveis de pressão sonora em rodovias com adensamento populacional em suas proximidades são: A implantação de barreiras acústicas; redução da velocidade na via e substituição do pavimento por outro que torne a interação pneupavimento mais silencioso.

\subsubsection{Barreira acústica}

Uma das formas adotadas para minimizar os efeitos do ruído rodoviário e trazer um maior conforto às pessoas, é a implantação de barreiras acústicas. As barreiras acústicas funcionam como obstáculos entre as fontes geradoras de ruídos e os receptores. Nesses dispositivos a trajetória do som é interrompida com a colocação de um obstáculo reduzindo os níveis de pressão sonora entre a fonte e o receptor, ou seja, uma parte da energia sonora é refletida ou dispersada em direção à fonte, enquanto que outra parte é absorvida pelo material ou transmitida através da barreira, podendo ainda ser difratada pelo topo da barreira (Harris, 1979). A Figura 2.3 traz uma representação da trajetória de uma onda sonora emitida junto a uma barreira acústica.

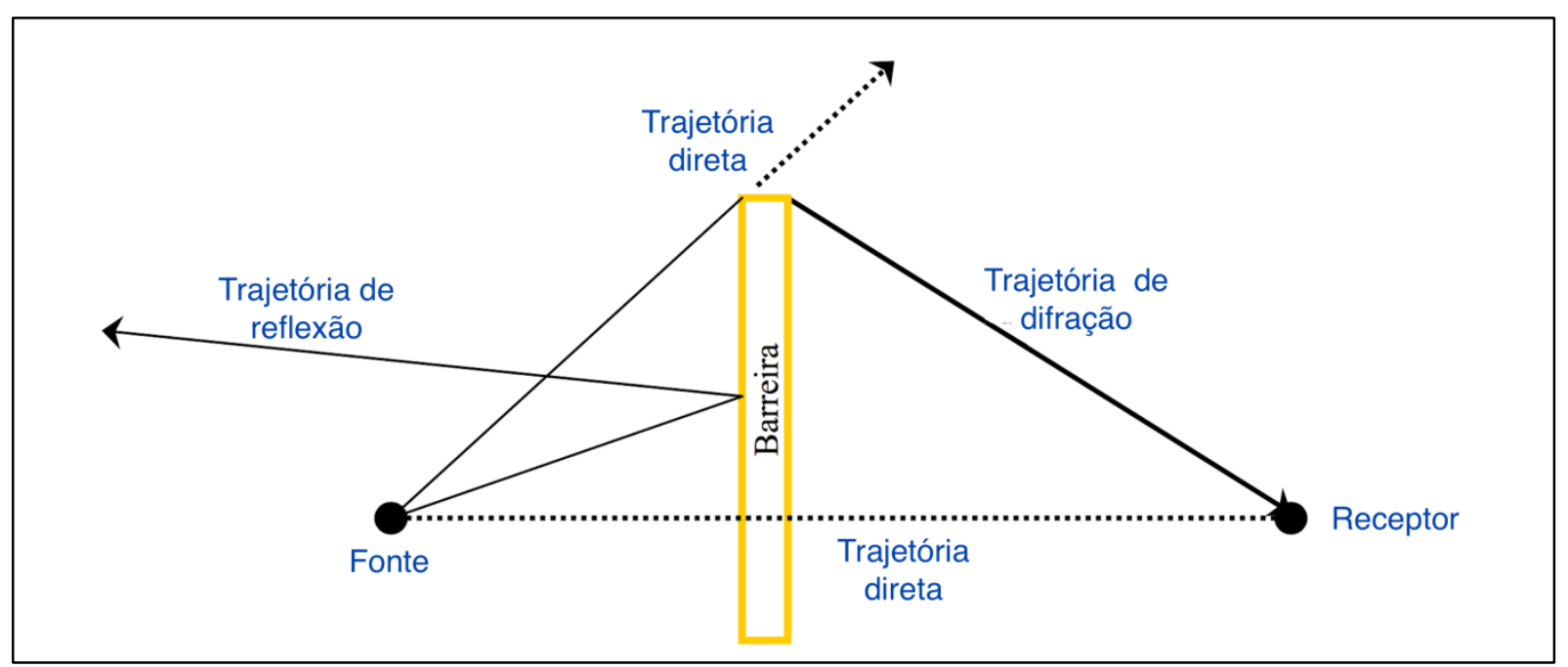

Figura 2.3 - Trajetória de uma onda sonora emitida junto a um dispositivo de redução do ruído. Fonte: Freitas e Trabulo, 2007 
A eficácia das barreiras acústicas depende de fatores como a sua geometria, as características acústicas dos materiais, a qualidade da instalação, a sua deterioração ao longo do tempo, a geometria do local onde são instaladas as barreiras, as características acústicas do local, e as condições meteorológicas (Freitas, 2008; Házyová, 2010 e Fonseca et al., 2008). A Figura 2.4 traz alguns exemplos de diferentes tipos de barreiras construídas com diferentes dimensões. Morais (2008) sugere que para que uma barreira acústica seja eficiente ela deve proteger a região de recepção da maior parte possível da energia sonora irradiada pela fonte, considerando o seu aspecto visual, econômico, estrutural e de segurança.

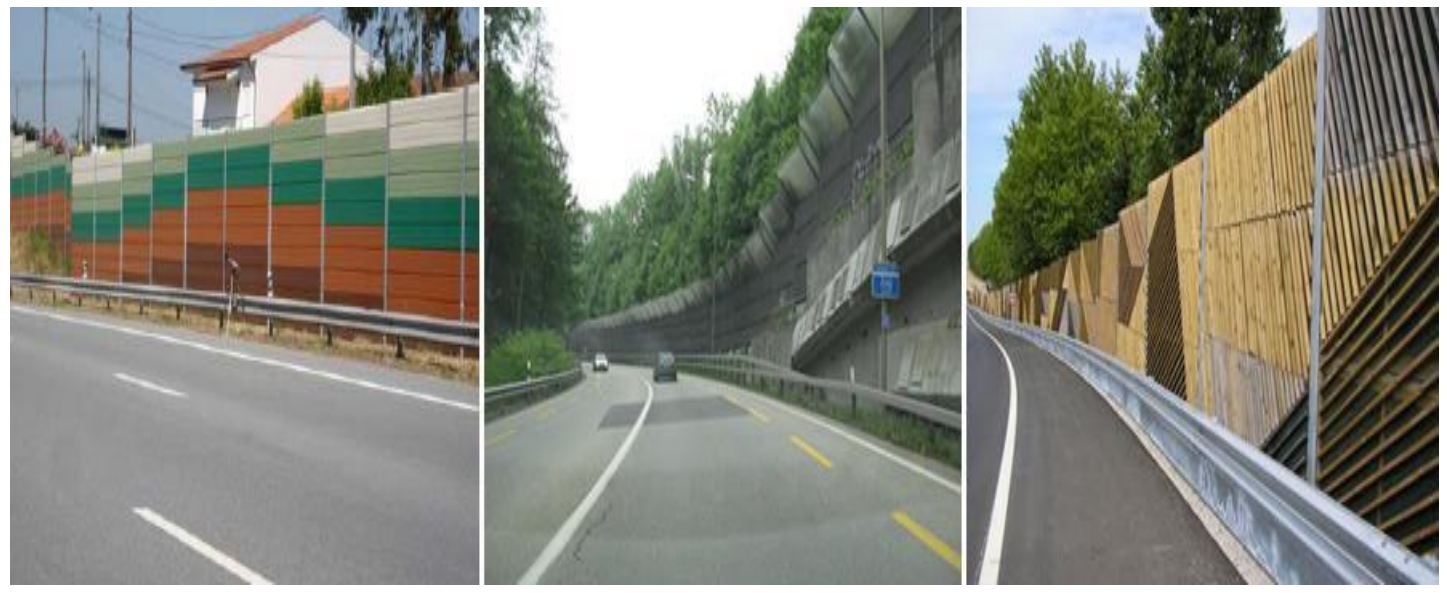

Figura 2.4 - Exemplos de barreiras acústicas, (Bragança et al., 2006).

Quanto às características das barreiras, os materiais para sua confecção são diversos, as de blocos de concreto, além serem mais baratas, tem a vantagem de requererem menor manutenção. Contudo, o impacto visual pode ser desagradável, prejudicando a integração do sistema com o entorno. Os painéis metálicos apresentam baixo custo e facilidade de montagem. Segundo Neto (2002), o método mais utilizado para o cálculo de atenuação provocada por uma barreira acústica é o de Maekawa.

De acordo com Souza (2010), a eficiência da barreira acústica depende de 6 fatores principais, a citar: a) Frequência dos sons: Os sons de alta frequência tem a tendência de serem refletidos para o alto, ao passo que, os sons de baixa frequência sofrerão o fenômeno acústico da difração do som, ou seja, quando o som faz uma curva diante de algum obstáculo. b) Proximidade da fonte e barreira: Quando mais próximo da barreira for da fonte sonora, maior será a eficiência da barreira. c) Altura da barreira: Quanto mais alta a barreira, maior será sua eficiência. d) Massa da estrutura: Os elementos mais sólidos são 
mais eficazes. e) Estanqueidade: A barreira deverá ser estanque para evitar que os sons de baixa frequência se propaguem. f) Movimentação do ar: $O$ vento pode influenciar na eficiência da barreira.

\subsubsection{Atenuação do ruído por meio do pavimento}

Além das barreiras acústicas há outras medidas de atenuação do ruído do tráfego rodoviário, como é o caso de mudar os materiais de recobrimento do pavimento. De acordo com Rasmussen et. al. (2007), a textura superficial é o principal fator responsável pela variabilidade no NPS em um pavimento, seguido do volume de vazios e da rigidez do revestimento.

Recentemente surgiu como alternativa o uso de camadas de desgaste para revestimentos com características específicas (relacionadas às magnitudes de textura do revestimento, ao índice de vazios e a rigidez), que proporcionam um melhor desempenho do pavimento em relação aos níveis sonoros (Sandberg e Ejsmont, 2002).

Para Sandberg e Ejsmont (2002), um pavimento é considerado silencioso quando é capaz de, na interação pneu-pavimento, reduzir o ruído do veículo em pelo menos $3 \mathrm{~dB}(\mathrm{~A})$ em relação ao gerado em um pavimento comum ou convencional.

\section{0 - DESENVOLVIMENTO E APLICAÇÃO DO MÉTODO}

Para o desenvolvimento do objetivo geral desse trabalho foram realizadas as seguintes etapas: (1) Caracterização da área de estudo; (2) pesquisa observacional e de campo; (3) tabulação dos dados coletados; (4) mapeamento acústico da situação atual; (5) análise comparativa dos resultados medidos e calculados; (6) predição acústica para cenários futuros; (7) Proposta de atenuação do ruído rodoviário (8) avaliação conclusiva.

Neste capitulo são apresentados os materiais e métodos utilizados na realização do estudo de caso na BR 040 - altura da cidade de Valparaiso de Goiás - GO, bem como as metodologias adotadas para aferir os níveis de pressão sonora em campo. Com os dados obtidos foram realizada a calibração de um modelo que represente o clima acústico da situação atual. Em seguida, foram realizadas simulações para diferentes cenários de forma a avaliar o ambiente acústico da região, em termo das variações na fluidez do tráfego. 
Por fim, dentro dos cenários simulados foram utilizados os parâmetros $L_{d e n} \mathrm{e} L_{n}$ para verificar o número de pessoas incomodadas e altamente incomodadas por faixa da curva de ruído. De forma resumida, o esquema do Quadro 3.1 apresenta as diferentes fases utilizadas neste estudo de caso.

Quadro 3.1 - Representação geral das etapas da pesquisa

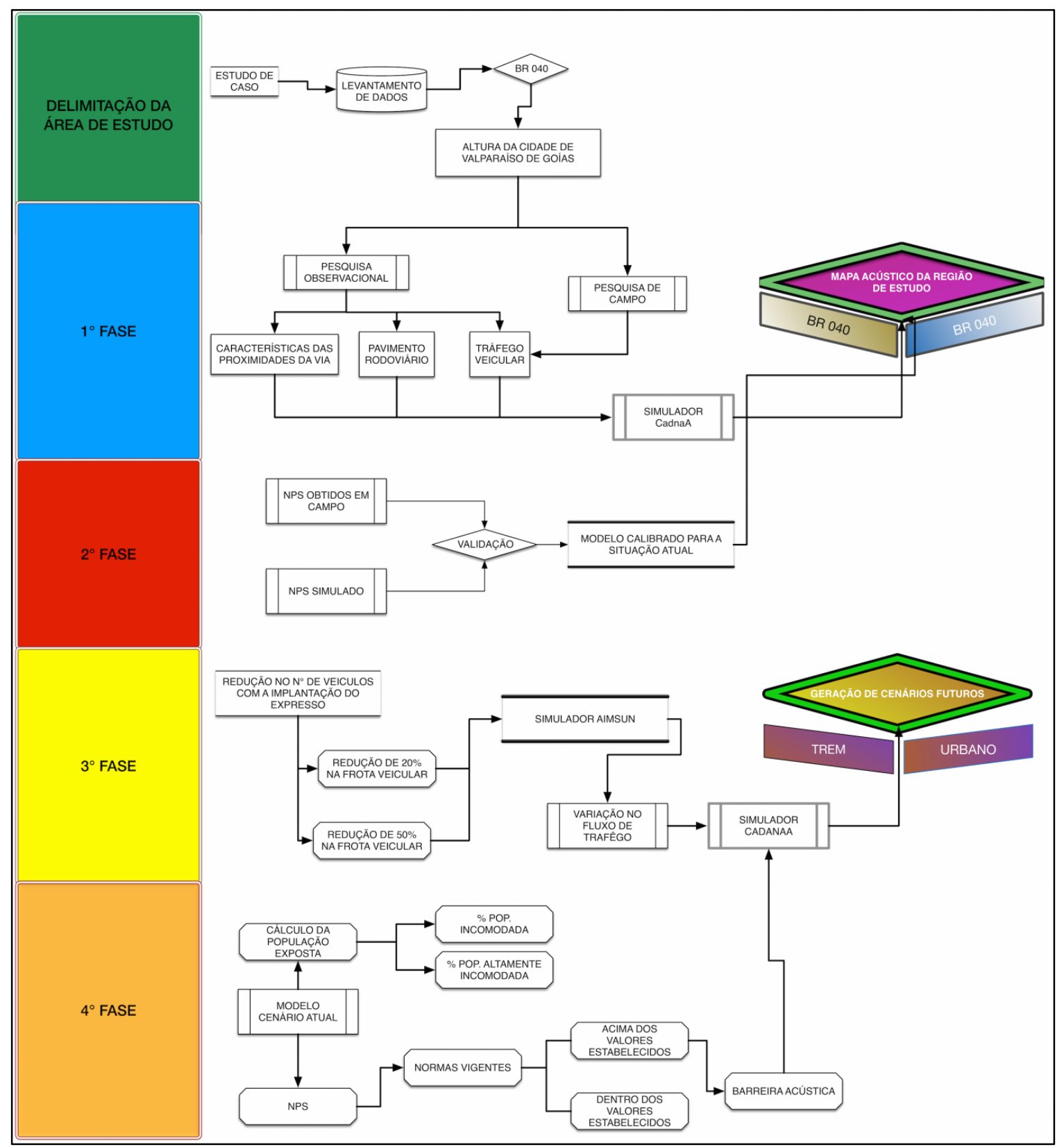

\subsection{DELIMITAÇÃO DA ÁREA DE ESTUDO}

A BR 040 é uma Rodovia Federal radial do Brasil e se destaca como uma das mais importantes do país. Ela é caracterizada por ser uma via de tráfego intenso e de longa distância, composta de caminhões, veículos leves e motocicletas que transitam em suas 
imediações. São mais de mil quilômetros, passando por cidades do Rio de Janeiro, de Minas Gerais, do Goiás e do Distrito Federal. Apesar de a BR 040 ser uma via de alta velocidade, possui, em alguns dos seus trechos, um tráfego com características urbanas, como é o caso do trecho que corta o município de Valparaíso de Goiás (Figura 3.1).

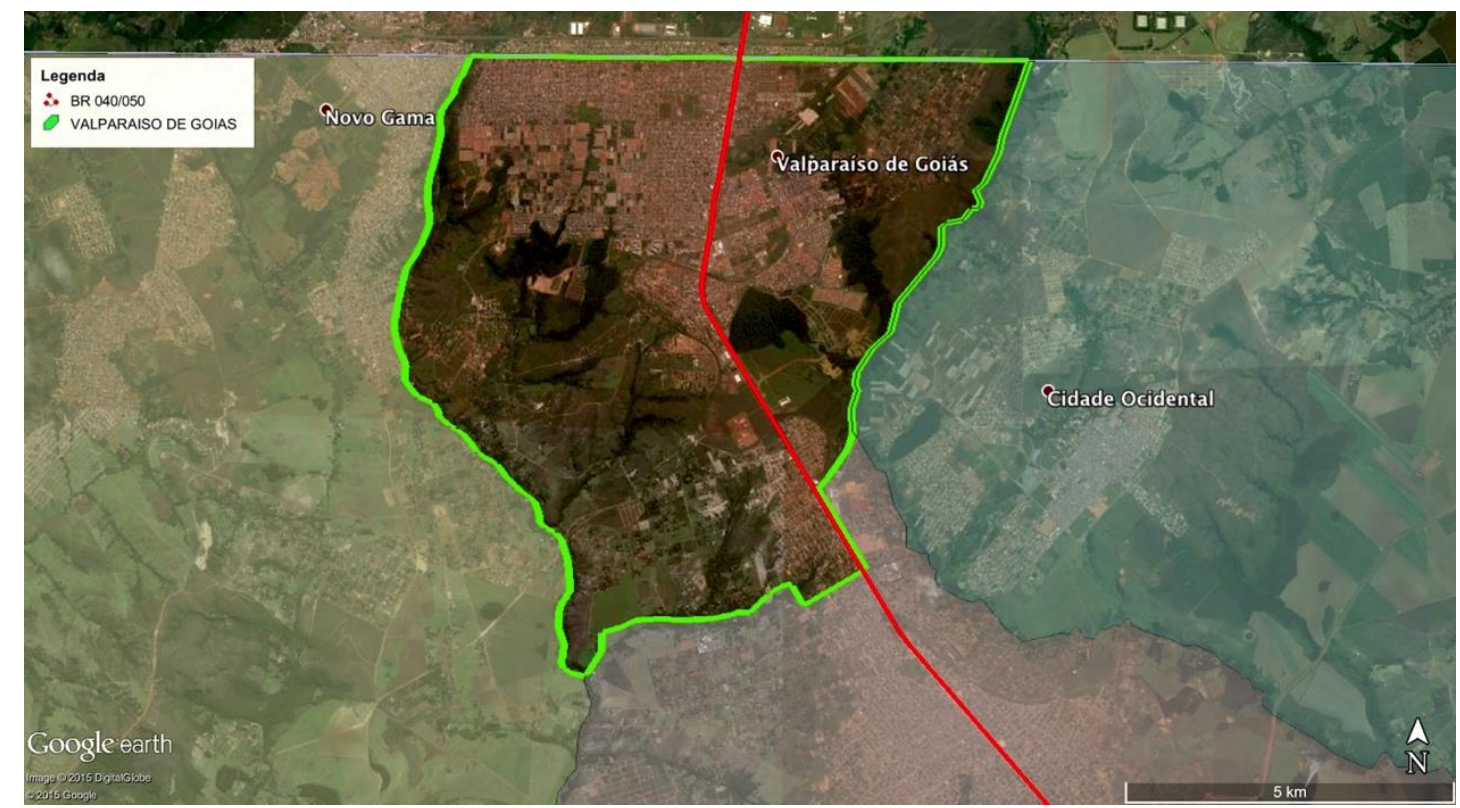

Figura 3.1 - Região de Valpaíso de Goias - GO.

Fonte: Google Earth - Adaptado

Dada a distribuição espacial dos núcleos urbanos do Distrito Federal e das regiões do seu Entorno, há situações em que se manifesta um conflito entre o tráfego de passagem e o tráfego local, sobretudo, nos trechos que margeiam áreas habitacionais ou de atividade econômica, gerando repercussões na fluidez e na segurança de trânsito.

\subsubsection{Entorno Sul do Distrito Federal}

O Distrito Federal recebe diariamente uma grande quantidade de veículos e boa parte provém das regiões do Entorno. Com base nos dados da matriz origem/destino do Plano de Diretrizes de transporte Urbano do Distrito Federal (PDTU/DF), a rede de transporte público coletivo do serviço semiurbano apresentava, no ano de 2009, a realização diária de cerca de 220 mil viagens do entorno para o Distrito Federal, apresentando aproximadamente esse mesmo número no fluxo de regresso (PDTU/DF, 2011).

A Figura 3.2 apresenta os carregamentos da Rede de Transporte Público Coletivo (PDTU/DF) na hora-pico da manhã, em 2009. Nota-se que a região sul, (em destaque 
amarelo), apresenta grande demanda por serviços de transportes coletivos, principalmente, a partir da cidade de Valparaíso - GO.

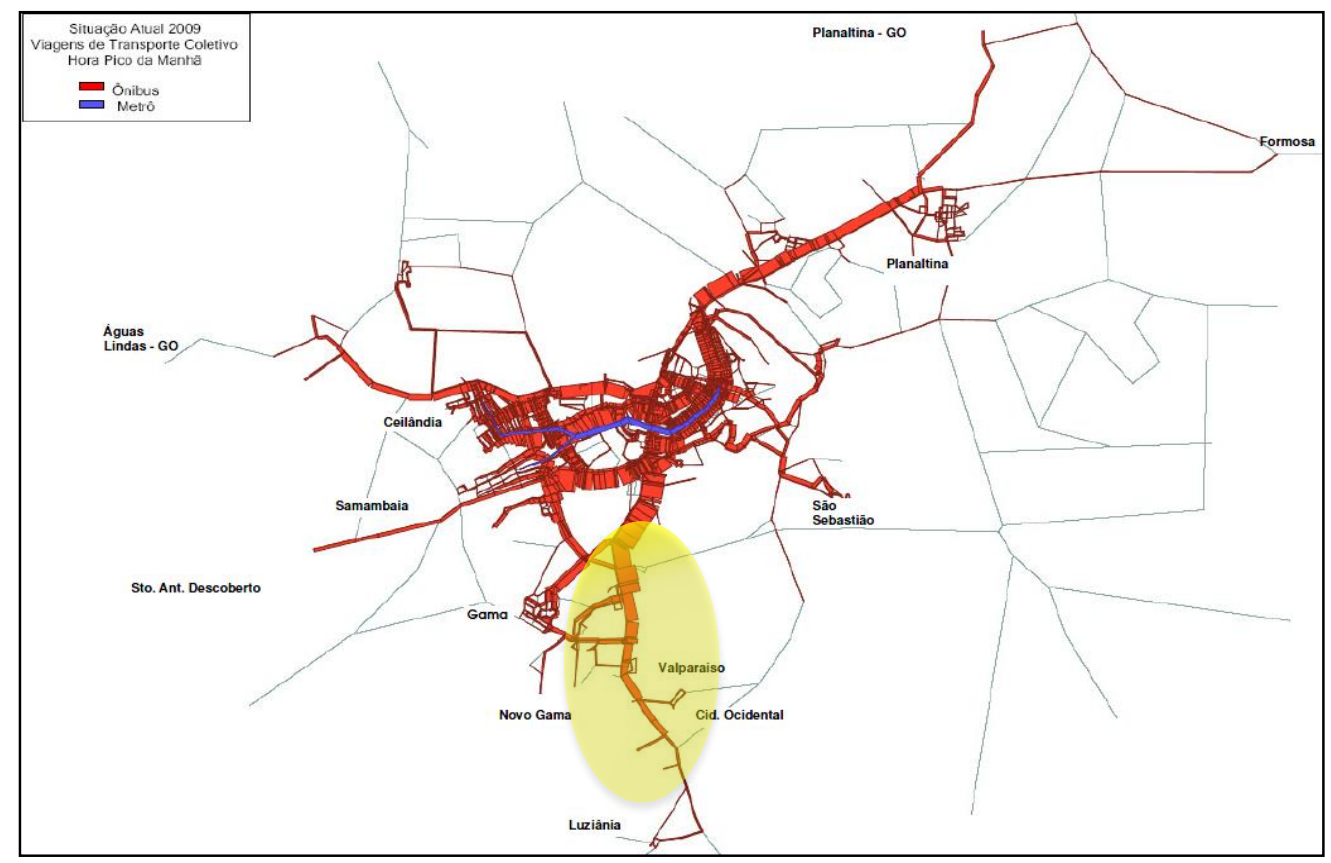

Figura 3.2 - Carregamento da Rede de Transporte Público Coletivo do PDTU/DF na hora-pico (Fonte: PDTU, 2011) - Adaptado.

Estudos relativos à interação dos municípios do Entorno com o Distrito Federal realizados pela Companhia de Planejamento do Distrito Federal (CODEPLAN, 2003) mostram que a região do Entorno Sul é classificada como de alta polaridade. Esse fato pode ser observado na Figura 3.3 onde mostra que 54\% da população residente no Eixo Sul do Entorno desloca-se para o Distrito Federal diariamente para fins de estudo ou de trabalho.

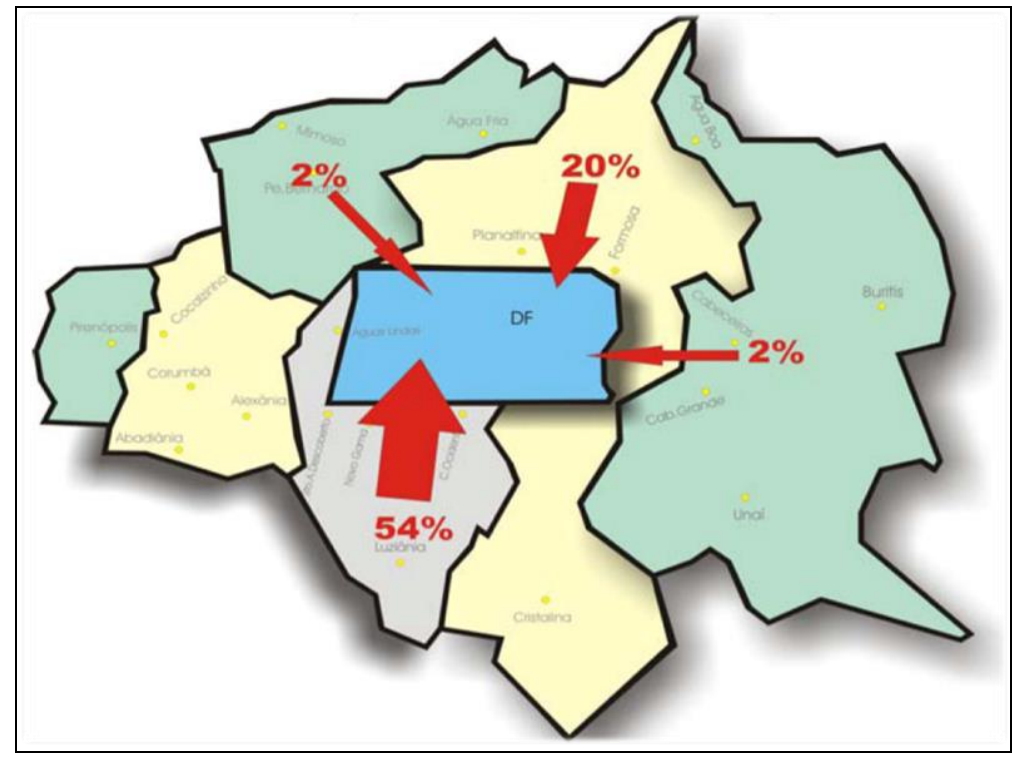

Figura 3.3 - Porcentagem da População do Entorno que Estuda ou Trabalha no DF (Fonte: CODEPLAN, 2003) 
Como apresentado o Entorno Sul contribui de forma significativa para o aumento no fluxo de tráfego nas vias de acesso à Capital Federal com cerca de 600 mil pessoas trafegando diariamente entre Luziânia e demais cidades do entorno até Brasília, (SUDECO, 2012).

\subsubsection{Implantação de um transporte de massa}

Os moradores do Entorno Sul do Distrito Federal (Luziânia, Cidade Ocidental, Valparaíso e Novo Gama), sofrem com a precariedade do transporte público e com os altos índices de acidentes. Ainda, nos arredores do Distrito Federal, todas as manhãs, milhares de pessoas permanecem em longas filas de um trânsito lento. Os moradores, que há dez anos levavam de 15 a 20 minutos para chegar ao local de trabalho ou de estudo, atualmente, levam cerca de duas horas, segundo estudos da SUDECO (2012).

Dentre os dados fornecidos pelo PDTU/DF (2011), há previsão da compra de 1,9 mil ônibus, da criação de faixas exclusivas em vias de todo o Distrito Federal, da implantação do Veículo Leve Sobre Trilhos na via W3 do Plano Piloto e da criação de quatro estações de metrô. Inclui-se nesses dados a proposta de construção do Veículo Leve Sobre Trilhos entre a cidade de Luziânia - GO e Brasília - DF. A implantação de um trem urbano no Entorno Sul tende a contribuir para diminuição do número de veículos que transitam na rodovia BR-040, principalmente nos horários de pico. Isso leva ao aumento da qualidade de vida da população destas regiões.

Países como França, Espanha, Holanda e Inglaterra têm priorizado o investimento em transporte de massa e o fornecimento de subsídios nas tarifas, com soluções que qualificam o transporte público coletivo e restringem a circulação de veículos particulares, como forma de produzir cidades ambientalmente sustentáveis (Affonso et al.2009). Esses investimentos precisam ser também executados na realidade analisada como modo de reduzir os longos congestionamentos vividos pela população que transita a BR-040.

Dentro do percurso estipulado para a implantação do Veículo Leve Sobre Trilhos entre Luziânia e Brasília há a possibilidade de utilização da linha férrea existente hoje (Figura $3.4)$. 


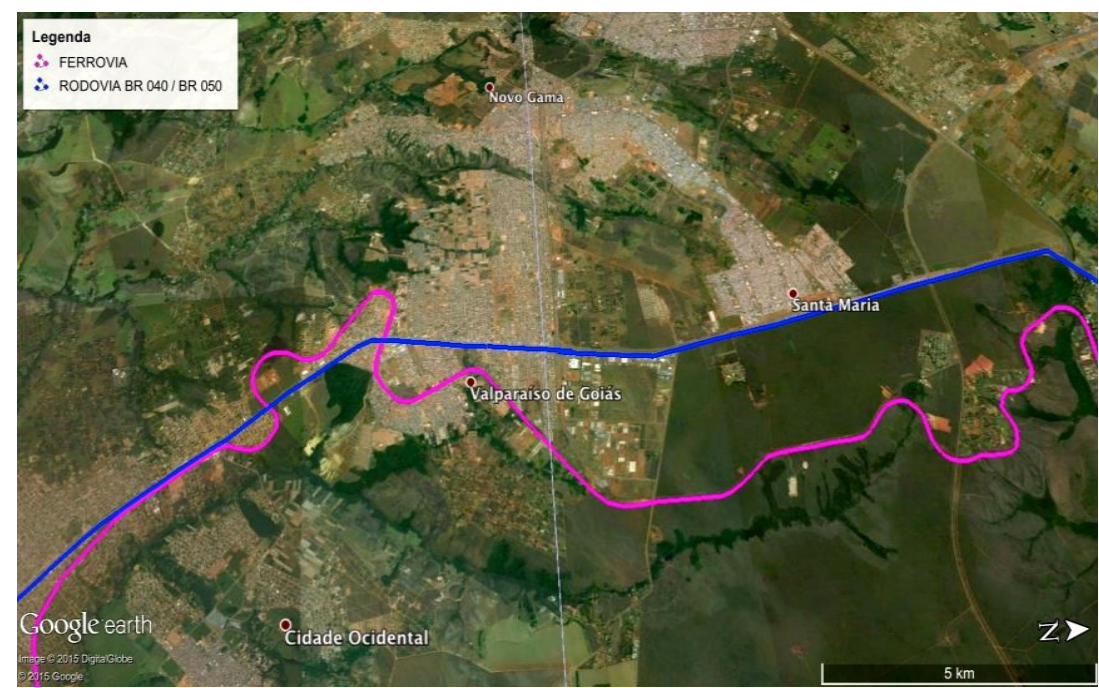

Figura 3.4 - Representação da linha férrea existente hoje nas proximidades da BR 040. Fonte: Google Earth com adaptações.

Com respeito à linha férrea entre Brasília e Luziânia, Mota et al. (2014) propõem alterações no traçado existente hoje, com intuito de otimizar e contemplar um maior número de usuários. A comparação entre o traçado atual e o traçado proposto podem ser visto na Figura 3.5.

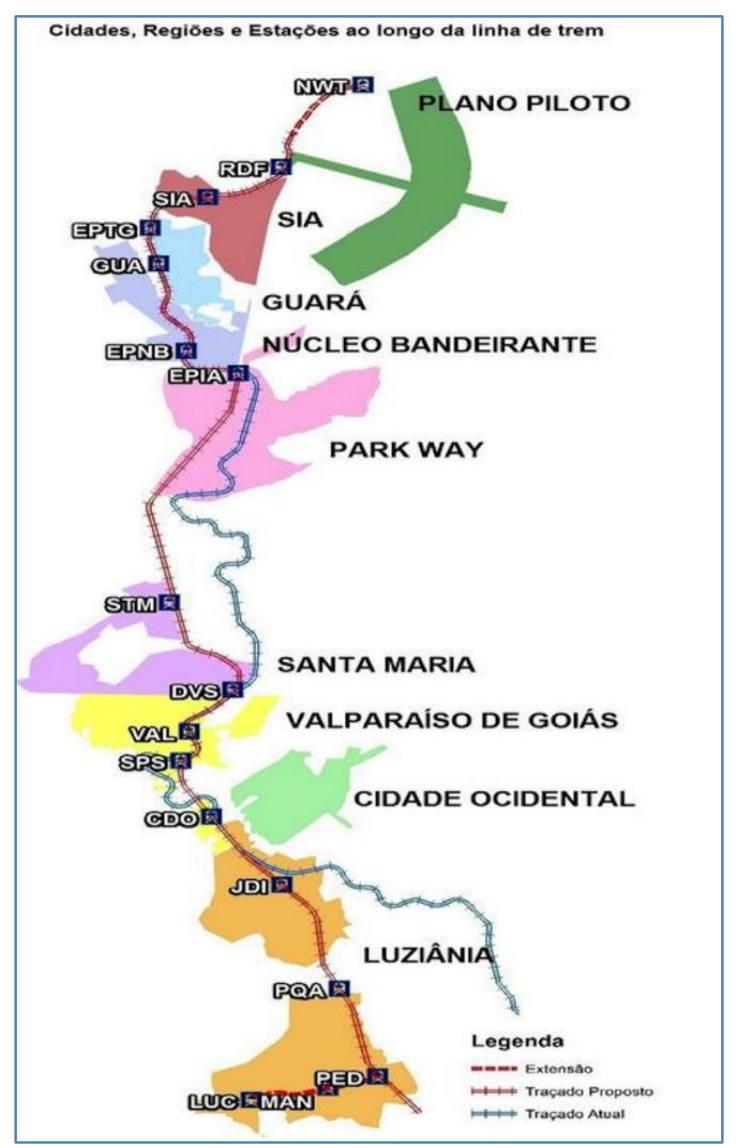

Figura 3.5 - A comparação entre o traçado atual e um traçado alternativo Fonte: Adaptado de Mota et al 2014. 
A figura anterior apresenta, ainda, a disposição das estações ao longo da linha. O traçado tem cerca de $75 \mathrm{~km}$ e a expectativa é de que a viagem entre a estação Luziânia Central (LUC) e a estação Noroeste (NWT) tenha duração de aproximadamente 62 minutos, (Mota et al. , 2014).

\subsection{COLETA DE DADOS}

Para a obtenção dos dados e dos atributos da região de estudo, dois tipos de avaliação foram realizados: uma de caráter exploratório, que apresenta dados referentes às características da região de estudo, e outra de modo prático, com a coleta de dados em campo para investigar os níveis de intensidade sonora em função das variações na fluidez do tráfego.

\subsubsection{Pesquisa observacional}

A primeira etapa da pesquisa foi de caráter exploratório, denominada estudo piloto, que teve como finalidade caracterizar a região de estudo. Dentro dessa região foi feito levantamento de três fatores gerais, são eles: características das proximidades da via, características do pavimento e características do tráfego veicular. Os elementos coletados para cada fator têm como finalidade descrever, de forma geral, a região de estudo, ou seja, delimitar fatores que possam influenciar nos fenômenos acústicos como a absorção, a difração e a reflexão que se devem a obstáculos (edifícios, barreiras acústicas, vegetação, topografia), condições atmosféricas (temperatura, humidade e vento). Espera-se, com esse procedimento, evitar diferenças significativas nos valores calculados em relação aos valores medidos. O Quadro 3.2 representa, de forma sintetizada, os elementos avaliados na pesquisa observacional. 
Quadro 3.2 - Esquema proposto para na pesquisa observacional.

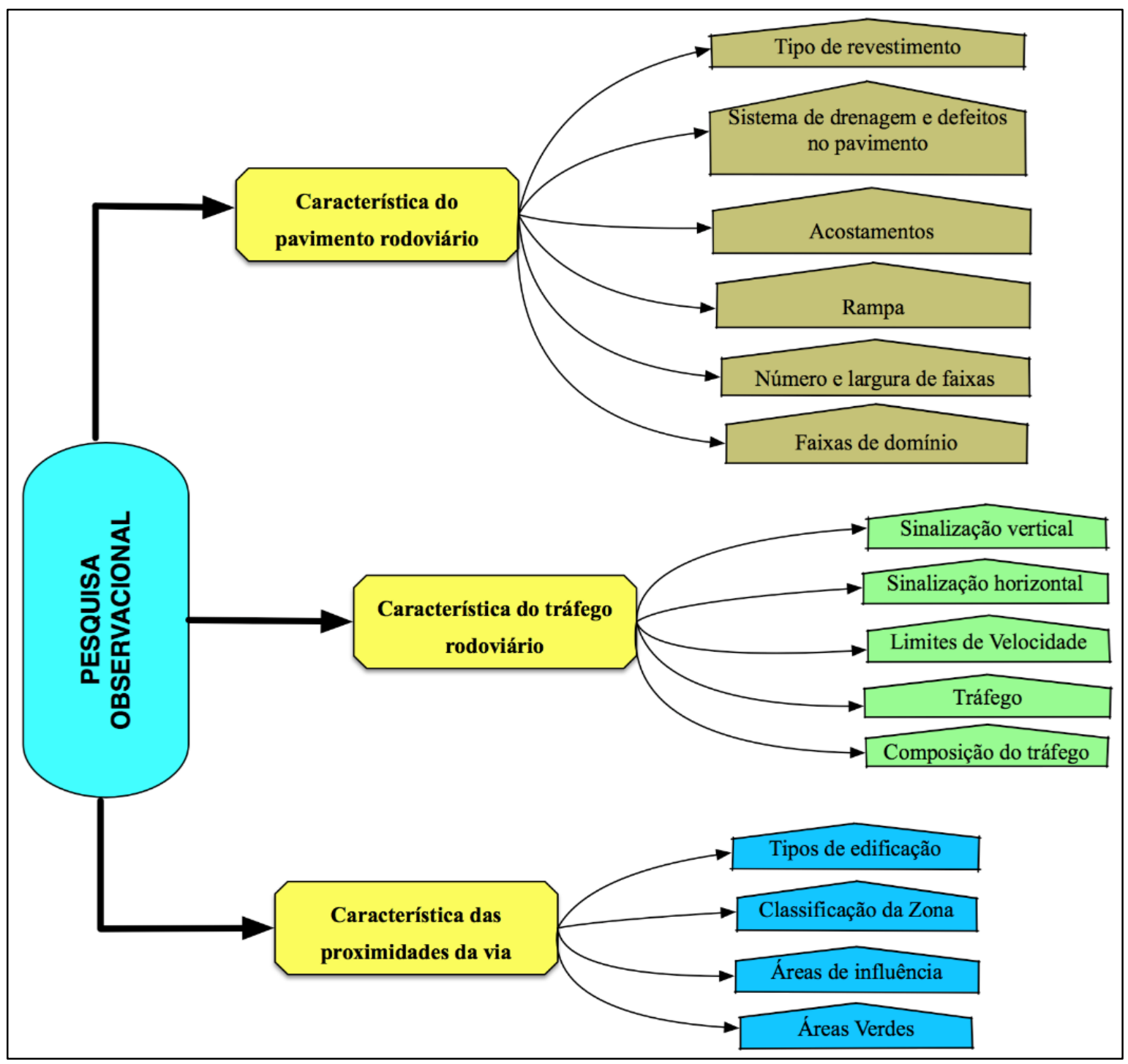

\subsection{2 - Pesquisa de campo}

No Brasil, não há um procedimento normativo de medição de ruído de tráfego em nível nacional. Assim, as medidas em campo foram realizadas, com as recomendações da norma alemã RLS-90, uma vez que autores, como Diniz e Zannin (2002), Zannin et al. (2007) e Calixto (2002) chegaram a resultados satisfatórios da utilização dessa norma para as vias brasileiras.

As medições foram realizadas considerando o tráfego circulante no sentido Luziânia GO/Brasília - DF, nos intervalos das 07:00h às 9:00h e das 14:00h às 16:00h; e de Brasília/Luziânia, no intervalo de 17:00h às 19:00h.

Como o objetivo desta pesquisa foi analisar o conforto acústico dos habitantes ao longo da 
rodovia, foram feitas medições nos dias úteis, pois estas configuram as situações de maior fluxo de veículos. As medições foram realizadas entre os meses de novembro e dezembro de 2014, nas terças, quartas e quintas.

A escolha dos intervalos de tempo para a realização da coleta de dados partiu do objetivo de englobar tanto o horário de pico da manhã e do entardecer, como situações no período das 14:00h às 16:00h com baixos volumes de tráfego. Essa estratégia teve o intuito de caracterizar diversas situações possíveis de composição do fluxo de tráfego. Esta maneira de obter os dados por faixa de tempo, contemplando os horários de tráfego mais intenso (horário de pico), se deu de forma eficiente, conforme apresentado na pesquisa realizada por Rodrigues (2006).

Para a obtenção dos dados em campo, foram selecionados pontos ao longo da BR 040, altura da cidade de Valparaíso de Goiás. A escolha pelo quantitativo de pontos teve como intuito contemplar toda a área de estudo, que tem aproximadamente $4 \mathrm{~km}$ de extensão e, assim, observar as várias composições do fluxo de tráfego ao longo da via, nos diferentes turnos. Durante o período de coleta de dados, foram monitorados e registrados os eventos acústicos que não se referissem ao ruído do tráfego veicular, como buzinas, sirenes, alarmes, entre outros, para que pudessem ser retirados posteriormente de modo a manter somente os NPS advindos do tráfego rodoviário.

Com respeito ao posicionamento dos pontos utilizados para coletar os níveis de pressão sonora, foram seguidos os procedimentos determinados pela norma ISO 1996/2 (1987), os quais asseveram que, mesmo os pontos estando a distâncias aproximadamente iguais entre si, recomenda-se que o nível de pressão sonora não seja maior que $5 \mathrm{~dB}$ entre dois pontos adjacentes. Desse modo, pontos intermediários devem ser criados se as diferenças forem maiores. As Figuras 3.5, 3.6 e 3.7, trazem a representação da distribuição dos pontos ao longo da área de estudo para diferentes períodos do dia. 


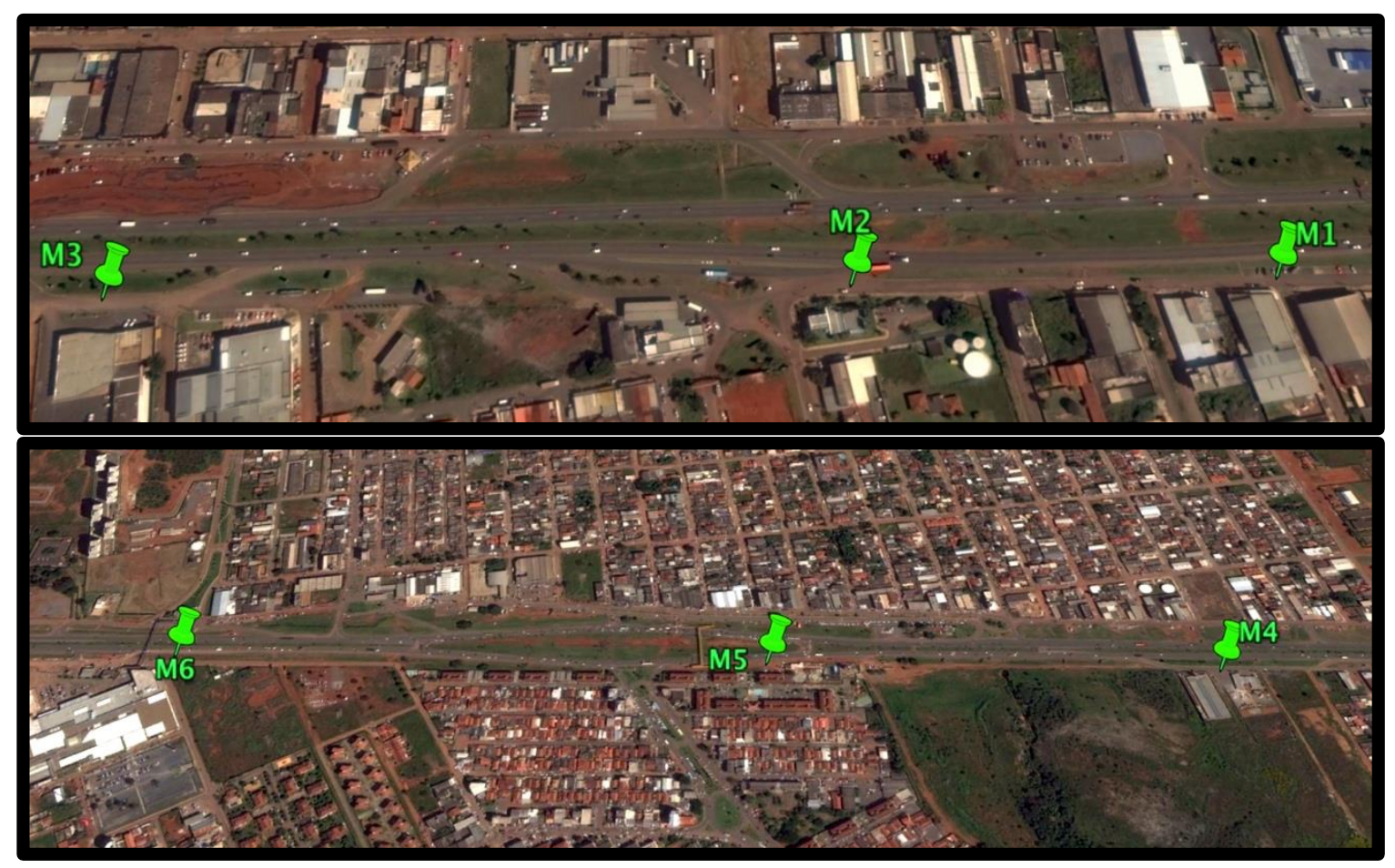

Figura 3.6 - Localização dos pontos de medição no trecho analisado da travessia urbana da BR 040, altura do município de Valparaiso de Goiás - Intervalo (07:00h às 09:00h) Fonte: Google Earth. Adaptado.

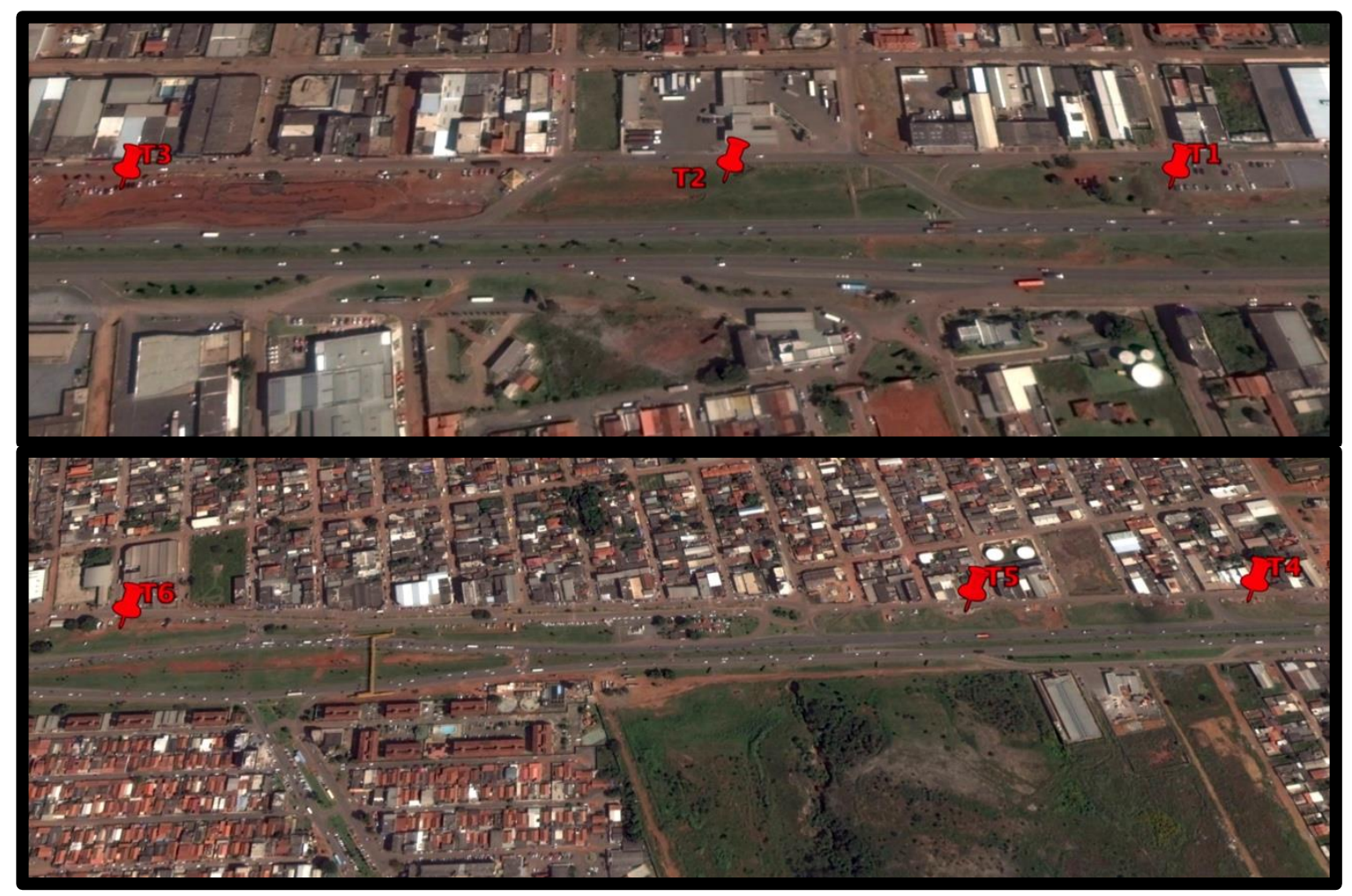

Figura 3.7 - Localização dos pontos de medição no trecho analisado da travessia urbana da BR 040, altura do município de Valparaiso de Goiás - Intervalo (14:00h às 16:00h) Fonte: Google Earth. Adaptado. 


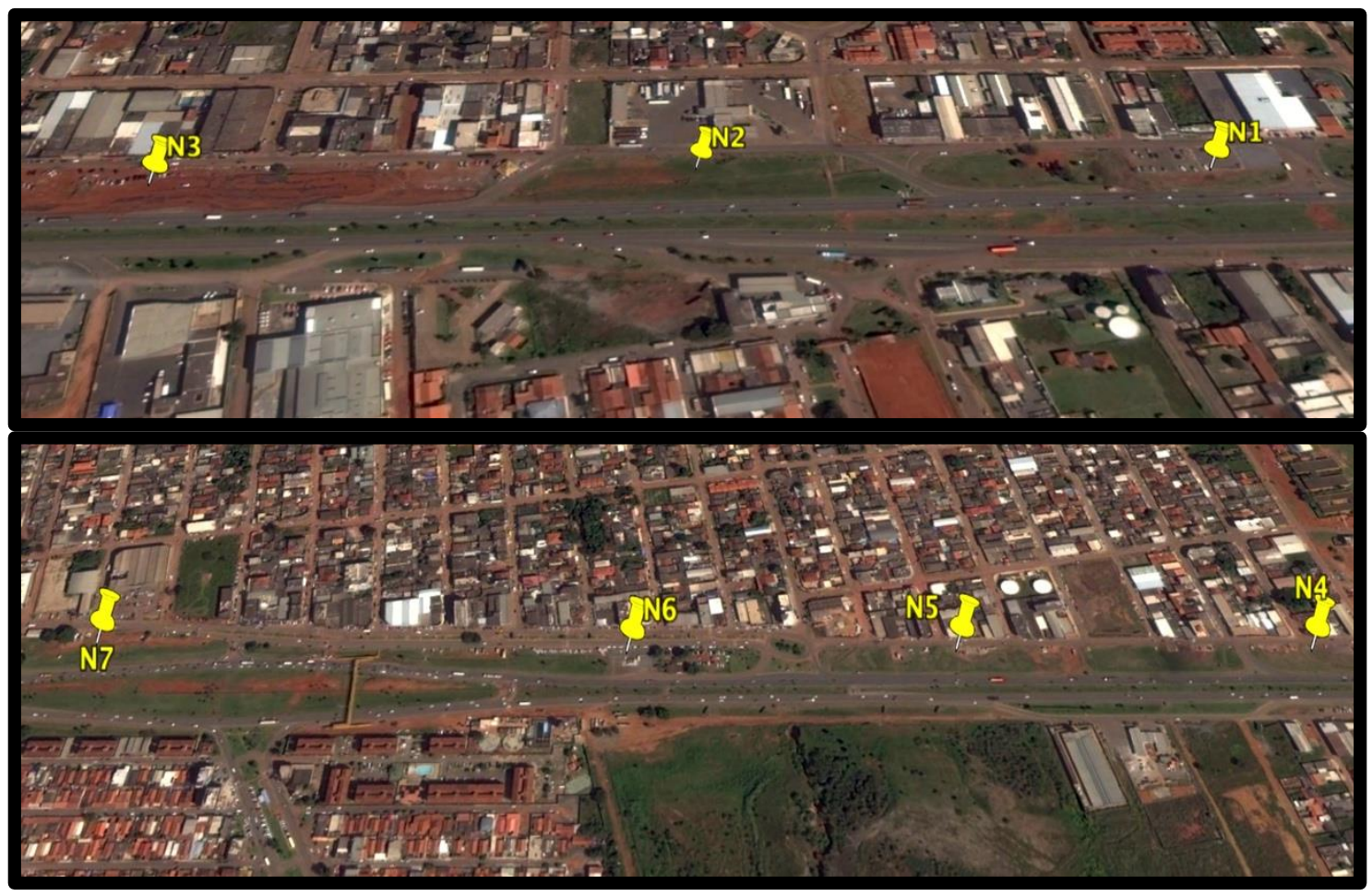

Figura 3.8 - Localização dos pontos de medição no trecho analisado da travessia urbana da BR 040, altura do município de Valparaiso de Goiás - Intervalo (17:00h às 19:00h) Fonte: Google Earth. Adaptado.

Para cada ponto de medida foram coletados dados de velocidade média do fluxo de tráfego, além de serem realizadas filmagens da passagem dos veículos nas duas vias, e, por fim, houve aferição dos níveis de pressão sonora. Esse procedimento ocorreu seguindo as normas estabelecidas na NBR 10.151/2000 - Acústica - Avaliação do ruído em áreas habitadas visando ao conforto da comunidade. Esse procedimento encontra-se especificado na Resolução CONAMA 01/1990, artigo VI.

Foi utilizado, neste estudo, um sonômetro portable de modelo Solo Black da 01 dB tipo 1, que ficou posicionado respeitando a distâncias de 25 metros em relação ao eixo central da via de fluxo mais intenso e, ainda, a uma altura de 1,5 metros em relação ao chão. As variáveis obtidas, simultaneamente, no período de medição observado, com o sonômetro foram: nível sonoro equivalente $\left(L_{A e q}\right)$, valores de limite $\left(L_{\max }\right)$ e $\left(L_{\min }\right)$.

No momento da aferição dos níveis de pressão sonora, em cada ponto, foi instalado um sistema de vídeo para registro do fluxo de tráfego durante o processo de coleta de dados para se determinar posteriormente o número de veículos leves (automóveis, caminhonetes de pequeno porte até $6 \mathrm{t}$, por eixo, e motocicletas) e veículos pesados (caminhões, ônibus e caminhonetes de grande porte acima de 6t, por eixo), nos dois sentidos de tráfego, com 
tempo de contagem de 15 minutos, conforme recomendação da (NBR 10151, 2000).

Ainda, durante a aferição dos dados em cada ponto foi utilizado o equipamento radarpistola, modelo ultra lyte, disponibilizado pelo Programa de Pós-Graduação em Transporte da Universidade de Brasília, para determinar a velocidade média do fluxo veicular nos pontos de medida, e sobretudo, analisar possíveis influências da composição do tráfego veicular sobre o clima acústico da região.

Para a medição do ruído devido a passagem dos veículos, utilizou-se um sonômetro no modo analisador $1 / 3$ de oitava, configurado para o tempo de integração de 1 segundo, com ponderação temporal rápida (Fast) e microfone de campo livre de 1/2 Tipo 4188. Ao microfone foi acoplado um protetor de vento para minimizar as possíveis interferências causadas pelo vento com velocidade superior a 2,0 m/s (GERGES, 2000). Desse modo, o equipamento regista o $L_{e q}$ em cada segundo de medição e o nível de pressão sonora equivalente em cada banda de 1/3 de oitava (Silva, 2009). As etapas da pesquisa de campo estão, de forma resumida, especificadas no esquema do Quadro 3.3.

Quadro 3.3 - Etapas da pesquisa de campo

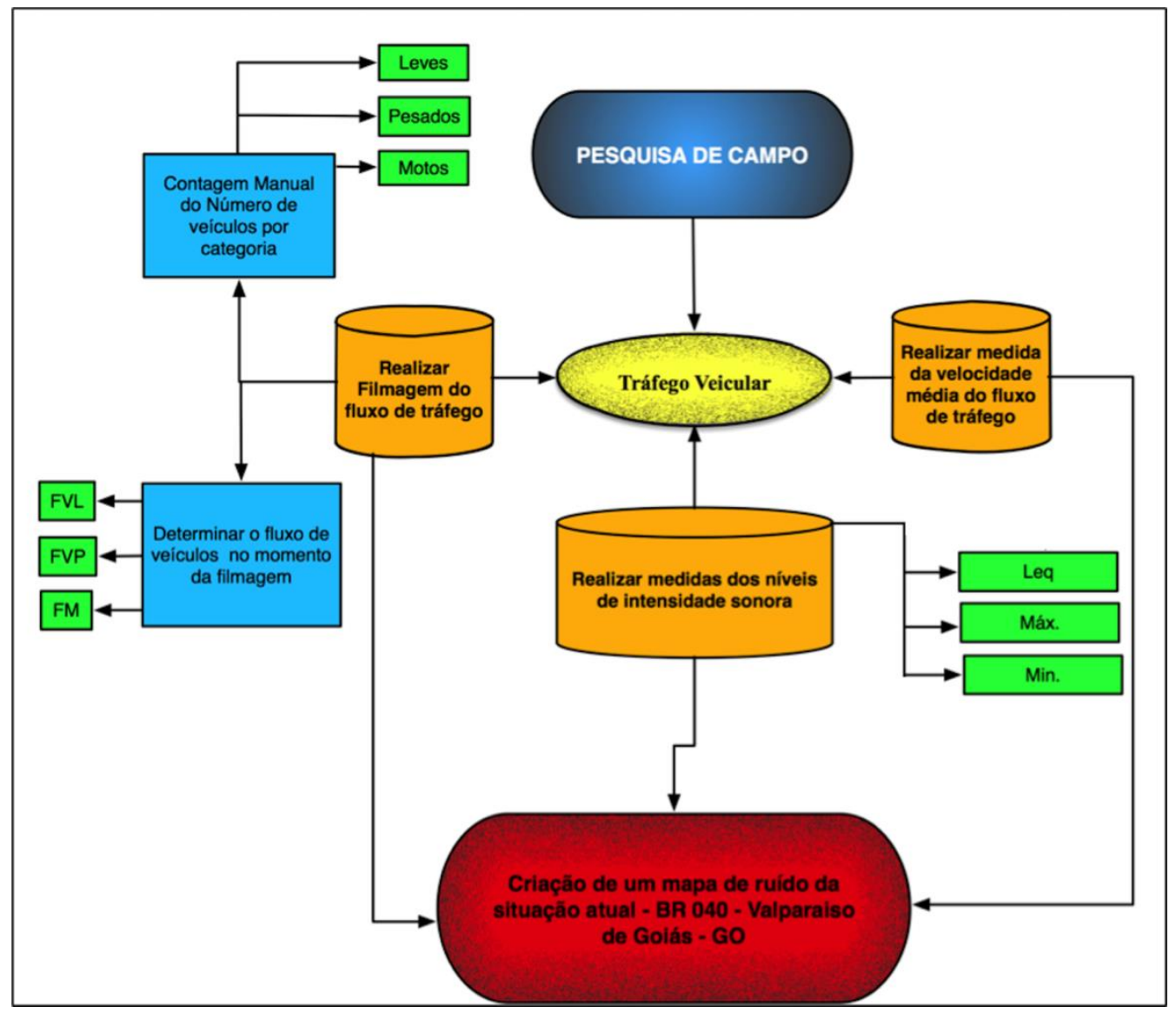




\subsection{3 - Fatores meteorológicos}

De acordo com a norma ISO 1996/1 (2003), os níveis sonoros são afetados pelas condições meteorológicas e, segundo ISO 1996/3 (1987), as alterações nas mesmas podem afetar o nível de pressão sonora recebido caso a distância entre a fonte sonora e o receptor seja superior a $30 \mathrm{~m}$.

Segundo Barretto (2005), as atenuações devido a gradientes de temperatura, ventos e absorção atmosférica são ignorados na maioria dos métodos de previsão de ruído devido a grande instabilidade dos mesmos.

Carey (1996) determinou, para medições de nível de pressão sonora, que as condições de temperatura do ar e umidade relativa do ar devem estar entre os limites de $-10{ }^{\circ} \mathrm{C}$ e $50{ }^{\circ} \mathrm{C}$ e $30 \%$ e $90 \%$, respectivamente. Palhares et al. (1996) afirmam que, para os mesmos fins, tais condições devem se enquadrar nas faixas de $10{ }^{\circ} \mathrm{C}$ a $35{ }^{\circ} \mathrm{C}$ e $40 \%$ a $90 \%$.

Para esse estudo foram descritas e monitoradas, durante os períodos de coleta dos dados acústicos, a temperatura do ar $\left({ }^{\mathrm{O}} \mathrm{C}\right)$ e a umidade relativa do ar $(\%)$ considerando as recomendações das normas ISO. Nenhuma medição foi realizada em dia de chuva ou com a pista de rolamento úmida. A temperatura aferida e a umidade relativa do ar foram monitoradas e registradas por meio de um Termo-Higrômetro Digital da Incoterm com cabo Temperatura e Umidade, localizado sempre à sombra, o mais próximo possível do medidor de nível de pressão sonora. Quanto ao registro da velocidade do vento utilizou-se um anemômetro digital. Os registros dos elementos meteorológicos foram feitos acompanhando os períodos de registro das medidas dos níveis de pressão sonora em campo.

\subsection{COMPOSIÇÃO DOS CENÁRIOS}

De posse dos dados obtidos nas pesquisas observacionais, de campo e dos dados dos contadores eletrônicos (radares), foi possível gerar o mapa de ruído da situação atual. Para o dia $\left(L_{\text {dia }}\right)$ e a noite $\left(L_{n}\right)$, foram desenvolvidos mapas acústicos para área de estudo que englobassem todos os pontos medidos. Por fim, foi realizado o comparativo entre os níveis de pressão sonora coletados e os simulados no software CadnaA de modo a realizar a calibração do modelo atual. 
Em um segundo momento da pesquisa, utilizou-se o software AIMSUN, (Advanced Interactive Microscopic Simulator for Urban and Non-Urban Networks), V.8.1, disponibilizado pelo Programa de Pós-Graduação em Transporte da Universidade de Brasília, para determinar as velocidades médias do fluxo de tráfego na região de estudo, levando em consideração a redução no número de veículos leves e pesados decorrente de uma possível implantação de transporte de massa (trem urbano). O percentual de redução da frota veicular utilizado nas simulações foi de $20 \%$ e $50 \%$ da frota atual. Esses percentuais foram utilizados em consonância com estudos tratados na literatura pesquisada, como pode ser visto em Mamede (2009).

Por meio do software de simulação Aimsun, foram desenvolvidos cenários de simulação microscópica de forma a analisar os efeitos da diminuição do número de veículos na velocidade média do fluxo de tráfego. A procura baseia-se em matrizes origem-destino, com a duração da hora de pico. Segundo Rodrigues e Araújo (2012), o software que adota a abordagem microscópica e é capaz de representar os cenários em três dimensões, além de operar com volumes de tráfego ou com matrizes (origem/destino), permite a modelagem do comportamento individualizado do motorista, que reage à ocorrência de incidentes capazes de bloquear uma via ou à indicações de painéis de mensagens.

Por fim, a proposta de usar o Software Aimsun para determinar as variações no fluxo de tráfego médio, devido à redução do número de veículos, foi de determinar a velocidade média em zonas da região de estudo. Após a modelagem no Software Aimsun e, com os resultados das velocidades médias em cada um dos setores da região de estudo para a redução de 20 e 50\% da frota atual, foi possível simular, utilizando o software CadnaA, as alterações no clima acústico da região decorrente das novas velocidades adotadas para as zonas variações.

Essa redução de 20 e 50\% na frota atual está pautada na redução do número de usuários que migrariam para um modal alternativo, no caso deste trabalho, para o Veículo Leve Sobre Trilhos dentro do trecho Brasília - DF / Luziânia - GO. 


\section{ANÁLISE DOS RESULTADOS}

Nesta seção, serão apresentadas as análises, as discursões e os resultados obtidos com a coleta de dados. Foram relacionadas informações relativas ao comportamento do tráfego, às grandezas geométricas e às grandezas acústicas. Posteriormente, realizaram-se medições do ruído emitido por veículos rodoviários na passagem em cinco locais para diferentes períodos e condições de circulação. Diante destas análises foi possível identificar os níveis de ruído mínimo, médio e máximo nos locais de medição. Dessa forma, foi possível realizar simulações computacionais e assim calibrar o modelo que retrata o clima acústico para o cenário atual. Após realizar calibração do modelo para o cenário atual, foi possível simular diferentes cenários futuros que demonstrem o comportamento do clima acústico devido à implantação de um novo modal.

A seguir, serão apresentados e discutidos os dados levantados na área de estudo conforme delimitado no capítulo metodológico.

\subsection{PRIMEIRA FASE DO ESTUDO}

Com respeito à primeira fase do estudo de caso, delimitado no capítulo anterior, as pesquisas observacional e de campo foram realizadas simultaneamente. O Quadro 4.1 traz, de maneira sintetizada, os dados obtidos durante a realização da coleta dos dados observacionais. Por meio dos resultados obtidos pela pesquisa observacional, consta-se que a região de estudo é composta por residências e comércios às margens da rodovia BR-040. Às margens da rodovia, foram detectadas edificações comerciais com uma média de dois pavimentos, que funcionam como barreiras à propagação das ondas sonoras, atenuando o ruído nas áreas residenciais, todavia, para este estudo, não foram consideradas as alturas das edificações.

Os dados coletados demonstraram não haver outras fontes sonoras que pudessem influenciar naquela advinda do tráfego veicular. Além disso, observou-se que as vias se encontram em boas condições de circulação e, ainda, atendem as respectivas sinalizações verticais e horizontais, tendo apenas alguns trechos que necessitam de reforço na pintura. 
Quadro 4.1 - Dados da pesquisa observacional obtidos para a área de estudo

\begin{tabular}{|c|c|c|}
\hline Fatores Gerais & Dados de Entrada & Dados Obtidos \\
\hline \multirow{6}{*}{$\begin{array}{c}\text { Característica do pavimento } \\
\text { rodoviário }\end{array}$} & Tipo de pavimento & $\begin{array}{c}\text { Liso - Revestimento flexíveis - } \\
\text { concreto betuminoso }\end{array}$ \\
\hline & Defeitos no pavimento & Não \\
\hline & Acostamento & Sim \\
\hline & Rampa & Não \\
\hline & Número de Faixas & 2 \\
\hline & Largura de cada faixa & 3,4 metros \\
\hline \multirow{4}{*}{$\begin{array}{c}\text { Características do tráfego } \\
\text { rodoviário }\end{array}$} & Sinalização vertical & Sim \\
\hline & Sinalização horizontal & Parcial \\
\hline & Limite de velocidade & $40 / 60(\mathrm{~km} / \mathrm{h})$ \\
\hline & Composição do tráfego & Veículos leves / veículos pesados \\
\hline \multirow{4}{*}{$\begin{array}{l}\text { Características das } \\
\text { proximidades da via }\end{array}$} & Tipo de edificação & Comércio e residências \\
\hline & Classificação das zonas & Comercial e Residencial \\
\hline & Áreas de influência & Não observado \\
\hline & Áreas verdes & Não \\
\hline
\end{tabular}

Ainda com respeito à primeira fase deste estudo de caso, foram realizadas medidas em diferentes pontos (Figuras 3.6, 3.7 e 3.8) para os níveis de pressão sonora devido ao tráfego veicular, em três períodos distintos. De forma a sintetizar os dados obtidos, o Quadro 4.2 traz uma representação dos valores obtidos para a velocidade média do fluxo de tráfego, e ainda, os valores mínimos, máximos e médios referentes aos níveis de pressão sonora equivalente, por período, obtidos na área de estudo.

Quadro 4.2 - Valores obtidos em diferentes pontos para a velocidade média do fluxo de tráfego e dos diferentes níveis de pressão sonora nos diferentes períodos.

\begin{tabular}{|c|c|c|c|c|c|c|}
\hline \multirow{2}{*}{ Período } & \multirow{2}{*}{$\begin{array}{c}\mathbf{N}^{\mathbf{o}} \\
\text { Med. }\end{array}$} & Vel. Média do Fluxo & $L_{m i n}$ & $L_{e q}$ & $L_{\text {máx }}$ & \multirow{2}{*}{ Sentido } \\
\hline & & $(\mathbf{K m} / \mathbf{h})$ & $\mathrm{dB}(\mathrm{A})$ & $\mathrm{dB}(\mathrm{A})$ & $\mathrm{dB}(\mathrm{A})$ & \\
\hline \multirow{6}{*}{$\begin{array}{c}\text { 07:00h } \\
\text { às } \\
\text { 09:00h }\end{array}$} & M1 & 67 & 62,7 & 70,4 & 87,5 & \multirow{6}{*}{ Luziânia / Brasília } \\
\hline & M2 & 60 & 64,2 & 72,1 & 88,7 & \\
\hline & M3 & 57 & 61,5 & 67,2 & 77,3 & \\
\hline & M4 & 58 & 59,6 & 69,4 & 82,8 & \\
\hline & M5 & 36 & 60,7 & 70,2 & 90,3 & \\
\hline & M6 & 61 & 64,5 & 70,3 & 87,5 & \\
\hline \multirow{7}{*}{$\begin{array}{l}\text { 14:00h } \\
\text { às } \\
\text { 16:00h }\end{array}$} & T1 & 40 & 59,6 & 65,8 & 76,5 & \multirow{7}{*}{ Brasília / Luziânia } \\
\hline & $\mathrm{T} 2$ & 40 & 63,6 & 68,5 & 73,9 & \\
\hline & T3 & 50 & 63,7 & 68,9 & 75,3 & \\
\hline & $\mathrm{T} 4$ & 54 & 64,3 & 68,2 & 80,1 & \\
\hline & T5 & 53 & 62,7 & 69,3 & 88,9 & \\
\hline & T6 & 42 & 62,1 & 68,3 & 81,9 & \\
\hline & T7 & 40 & 63,2 & 68,3 & 80,6 & \\
\hline \multirow{6}{*}{$\begin{array}{c}\text { 17:00h } \\
\text { às } \\
\text { 19:00h }\end{array}$} & N1 & 40 & 59,4 & 66,5 & 76,4 & \multirow{6}{*}{ Brasília / Luziânia } \\
\hline & $\mathrm{N} 2$ & 51 & 57,8 & 66,8 & 76,0 & \\
\hline & N3 & 42 & 58,2 & 64,8 & 77,0 & \\
\hline & N4 & 40 & 57,9 & 63,7 & 70,5 & \\
\hline & N5 & 55 & 57,9 & 70,4 & 73,7 & \\
\hline & N6 & 40 & 57,8 & 67,1 & 76,2 & \\
\hline
\end{tabular}


Por meio do Quadro 4.2, é possível observar que o nível de pressão sonora médio para os pontos coletados, na região de estudo, no período das 07:00 às 09:00, chegaram a valores superiores aos $70 \mathrm{~dB}(\mathrm{~A})$. Isso se relaciona, principalmente, ao elevado número de veículos transitando na via e aos processos de aceleração e de frenagem verificados no momento da coleta dos dados. Outro fator que contribuiu para o aumento dos níveis de pressão sonoras médios nesse período é o fato de as velocidades médias de propagação do fluxo terem sido as maiores observadas.

Por outro lado, no período das 14:00 às 16:00h a via encontrava-se com um tráfego menos intenso. Os valores obtidos para o nível de pressão sonora médio, na maior parte, mantiveram-se constantes e com valores mais baixos dos que os que foram obtidos nos outros dois períodos.

Por fim, no período das 17:00 às 19:00h, o fluxo de tráfego, em boa parte dos pontos, deuse de forma pulsante e com valores médios de pressão sonora em torno de $68 \mathrm{~dB}$. Em grande parte destes pontos predomina o ruído devido às acelerações e às frenagens por causa das condições de fluidez da via.

As variáveis atmosféricas obtidas no momento da coleta de dados em campo mostram que a temperatura, a umidade relativa do ar e velocidade do vento sofreram variações dentro dos aceitáveis pelas normas. Os intervalos de variações podem ser visto no Quadro 4.3

Quadro 4.3 - Variação dos fatores meteorológicos observados na região de estudo

\begin{tabular}{|c|c|c|}
\hline $\begin{array}{c}\text { Temperatura } \\
\text { em }{ }^{\mathbf{O}} \mathbf{C}\end{array}$ & $\begin{array}{c}\text { Umidade relativa do ar } \\
\text { em } \%\end{array}$ & $\begin{array}{c}\text { Velocidade do vento } \\
\mathbf{e m} \mathbf{~ K m} / \mathbf{h}\end{array}$ \\
\hline 23 à 27 & 51 à 80 & 8,73 à 15,48 \\
\hline
\end{tabular}




\subsection{GRANDEZAS DE TRÁFEGO ${ }^{1}$}

De acordo com o procedimento metodológico proposto, pode-se, por meio da filmagem, determinar o número dos veículos, por categoria, que transitavam nas vias durante a coleta de dados. Desse modo, foi possível comparar com os dados oficiais referentes aos contadores (radares) presentes na via de estudo. Os dados dos contadores para o número de veículos foram disponibilizados pelo Departamento Nacional de Infraestrutura de Transporte (DNIT) e dizem respeito aos meses de outubro e novembro de 2014. Dentro desses dois meses, os valores utilizados foram obtidos por meio da função máximo do Excel, que diz respeito à escolha do maior valor encontrado referente ao número de veículos por hora detectados pelos contadores eletrônicos (radares) nos horários de fluxo mais intenso. O intuito de trabalhar com o número máximo de veículos dentro dos dois meses se deu pensando em um pior cenário possível a fim de delinear uma previsão que leve em consideração o aumento do tráfego veicular para situações futuras.

Em relação aos valores máximos para o volume de tráfego obtidos por contadores eletrônicos, no período de um dia, para os dois sentidos da via dentro da área de estudo. As Figuras 4.1 e 4.2 trazem uma representação do comportamento da variação do número de carros ao longo das 24 horas, conforme os dados fornecidos pelo órgão oficial de gerenciamento de rodovias e rodagens (DNIT). Os detalhes e a localização geográfica dos radares, presentes na área de estudo, encontram-se no Apêndice 3.

\footnotetext{
${ }^{1}$ Os dados de tráfego obtidos em campo foram caracterizados para os dois sentidos da via.
} 


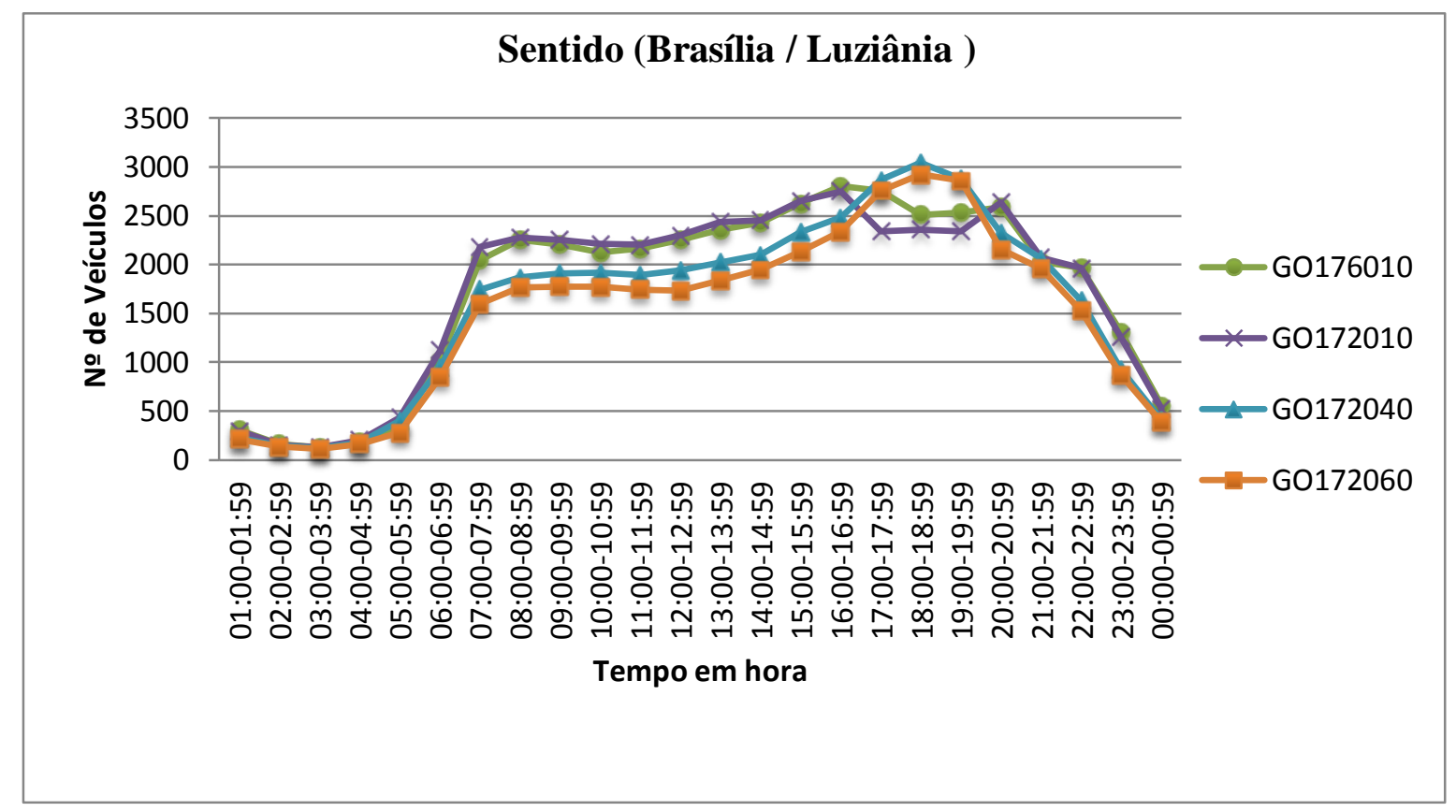

Figura 4.1 - Número de veículos em função do tempo

A queda no fluxo de tráfego no período das 17:00 às 20:00 para os radares de código GO176010 e GO172010 se deve ao local onde se observou o fluxo mais intenso e engarrafado, ou seja, com pouca fluidez neste período. Já nos equipamentos de códigos GO172040 e GO172060, observou-se uma maior fluidez, visto que uma parcela dos carros deixava de transitar na via principal da rodovia passando a transitar na via marginal.

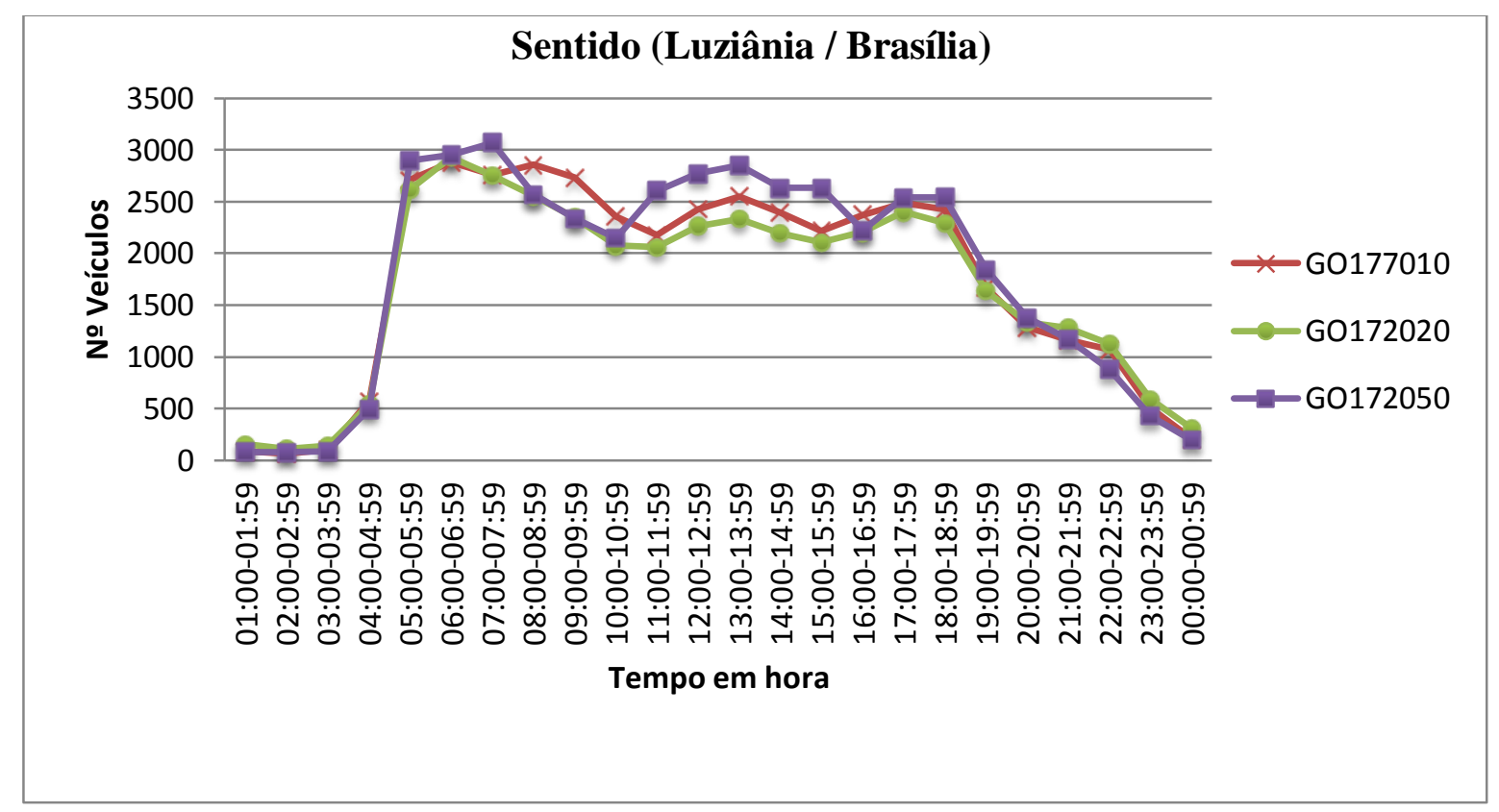

Figura 4.2 - Número de veículos em função dos horários 
A Figura 4.2 apresenta que, no geral, houve conservação no número de veículos, principalmente nos horários de pico, que são registrados pelos equipamentos de código GO177010, GO172020 e GO172050, ou seja, grande parte dos veículos que se deslocam das cidades de Luziânia, Jardim Ingá, Ocidental e Valparaíso tendem a se deslocar para o Distrito Federal. Por meio dos Quadros 4.1 e 4.2 é possível observar, ainda, que os horários que apresentaram maior número de veículos no sentido Luziânia/Brasília se deu aproximadamente no período das 7 h. Já no sentido contrário (Brasília/Luziânia), o maior número de veículos por hora se deu aproximadamente às $19 \mathrm{~h}$, chegando a ter mais 3000 veículos.

\subsection{1 - Ruído e Velocidade média do fluxo de tráfego}

De forma analisar a influência da velocidade média do fluxo de tráfego na produção de ruído, os dados de velocidade média do fluxo, obtidos em campo, foram sintetizados em uma ordem crescente em função dos níveis de pressão sonora observados (Figura 4.3). Assim, é possível observar, uma tendência linear de aumento nos níveis de pressão sonora em termos do aumento da velocidade média do fluxo de tráfego. Os valores obtidos para a velocidade média ficaram aproximadamente dentro do intervalo de 40 e $70 \mathrm{~km} / \mathrm{h}$, e os NPS ficaram entre 64 a $74 \mathrm{~dB}$.

Figura 4.3 - Nível de pressão sonora em termos das condições da velocidade média do fluxo de tráfego veicular para cada ponto analisado.

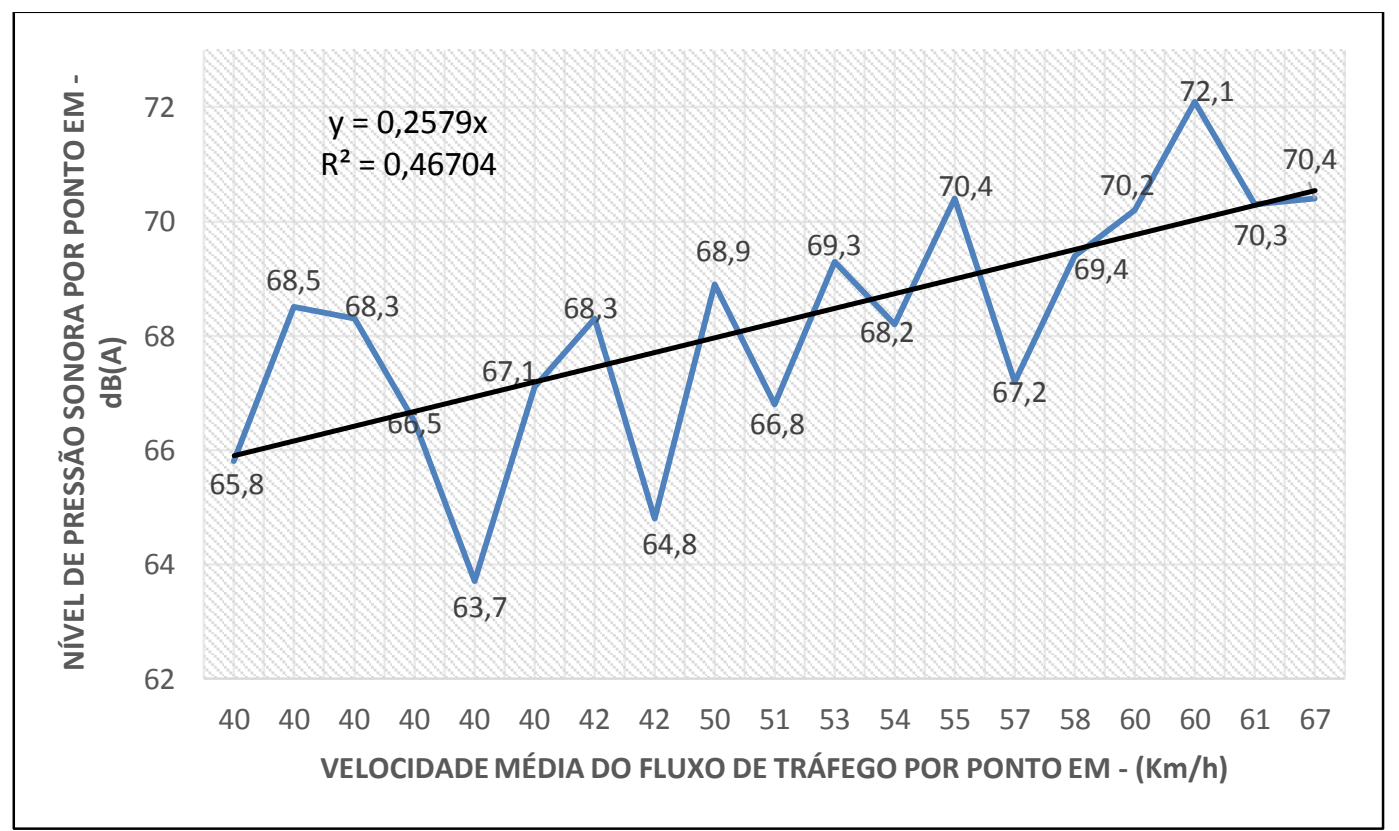


Como pode-se observar no Quadro anterior, há uma tendência de aumento nos NPS devido ao aumento na velocidade média referente ao fluxo de tráfego. A diferença para os NPS observados para a variação da velocidade de $40 \mathrm{Km} / \mathrm{h}$ a $60 \mathrm{~km} / \mathrm{h}$ foi de aproximadamente 3 dB. Esse comportamento já era esperado, visto que, com o aumento da velocidade há consequentemente um aumento nos movimentos de adesão/deslizamento entre pneu e o pavimento, elevando as vibrações e, consequentemente, o ruído. Vale ressaltar que os resultados encontrados condizem com os encontrados nos trabalhos de (Rodrigues, 2010; Iannone, 2011).

É verificada uma relação de proporcionalidade direta entre a velocidade e pressão sonora, com variação chegando a $3 \mathrm{~dB}(\mathrm{~A})$ nos extremos o que é bastante expressivo. Tal aumento está relacionado com o efeito aerodinâmico e à dinâmica do contato pneu/pavimento. $\mathrm{O}$ ajuste linear apresentado com $\mathrm{R}^{2}$ de 0,467 não tem objetivo de servir como modelo de previsão, mas de indicar a complexidade de fatores que não são controlados e afetam o ruído; isso também é denotado pela dispersão dos dados.

\subsection{2 - Dados de entrada do software}

Os dados de entrada no software CadnaA, referente ao fluxo de tráfego, foram caracterizados em global e pela porcentagem de veículos pesados. O global corresponde ao fluxo/hora da quantidade total de veículos (leves e pesados) de um determinado trecho da via, referente ao período correspondente ao Indicador de Ruído a ser mapeado (diurno, entardecer e noite). Já a porcentagem de veículos pesados refere-se a uma parcela do fluxo total dos veículos pesados em termos do número total de veículos.

O termo global representa a média do número total de veículos leves e pesados, que nesse estudo são caracterizados por: períodos diurno, das 07:00 às 20:00h; entardecer, das 20:00 às 23:00h e noturno, das 23:00 às 07:00h.

A organização e a forma de tratamento dos dados de fluxo de veículos, distribuídos em global e pesados para os diferentes períodos e para diferentes pontos está descrita no Apêndice 1. ${ }^{2}$ Para este estudo, os veículos leves foram categorizados como soma da classe 1 e 2 , enquanto que os pesados foram categorizados pelas classes 3 e 4 .

\footnotetext{
${ }^{2}$ Os dados oficiais do DNIT são classificados em quatro classes: classe 1 , menores que $5 \mathrm{~m}$; classe 2 , entre 5 e $10 \mathrm{~m}$; classe 3 , entre 10 e 15 metros e maiores que 15 metros.
} 
A distribuição dos contadores eletrônicos se refere ao trecho da BR-040 que engloba os municípios de Valparaíso, Ocidental e Luziânia, maiores informações estão no Apêndice 1. A quantidade de veículos para os dois sentidos é praticamente igual ao longo do período analisado. Para o sentido Brasília/Luziânia, observa-se uma maior concentração de veículos para o global diurno, e isso se deve ao fato de englobar os principais horários de pico.

Quanto ao percentual de veículos pesados, cabe destacar que há um aumento desses valores no global noturno devido à redução do número de veículos leves por conta do horário e à maior presença de veículos pesados transitando nesses horários.

\subsection{MAPEAMENTO ACÚSTICO}

Nesta seção serão apresentados os mapas de ruído com a disposição espacial dos níveis de pressão sonora equivalente contínuos, medidos e simulados nos pontos da área de estudo.

Para a representação dos mapas de ruído, referente ao $L_{\text {dia }}$, foram considerados intervalos entre $55 \mathrm{~dB}(\mathrm{~A})$ e $85 \mathrm{~dB}(\mathrm{~A})$. Os índices de ruído ambiente são apresentados por meio de uma variação de $5 \mathrm{~dB}$, sendo a cada intervalo atribuída uma cor diferente. As cores adotadas nesse trabalho são as mesmas apresentada no documento "Diretrizes para Elaboração de Mapas Diretrizes para Elaboração de Mapas de Ruído" (Agência Portuguesa do Ambiente, 2011).

\subsection{1 - Validação do modelo}

De modo a validar o mapa para o cenário atual, os resultados dos níveis de pressão sonora obtidos nas medições in loco foram comparados aos calculados no software de mapeamento acústico (CadnaA). Os resultados desta análise encontram-se no ${ }^{3}$ Quadro 4.4, no qual é possível verificar que os parâmetros descritos nos itens anteriores propiciam um grau de precisão de $\pm 3 \mathrm{~dB}$, entre o $L_{e q}(A)$ medido e o simulado. Para Silva (2010), com base nos valores apontados pelo EU-WG3 (2001), esse limite pode ser ainda menos restritivo para áreas urbanas, sendo aceitos até $\pm 4 \mathrm{~dB}(\mathrm{~A})$.

\footnotetext{
${ }^{3}$ Maiores informações a respeito do Quadro 4.5 estão disponíveis no Apêndice 2
} 
Quadro 4.4 - Valores do $\boldsymbol{L}_{\boldsymbol{e q}}(\boldsymbol{A})$ medidos vs $\boldsymbol{L}_{\boldsymbol{e q}}(\boldsymbol{A})$ calculados e respectivas diferenças

\begin{tabular}{|c|c|c|c|c|c|}
\hline \multirow{3}{*}{$\begin{array}{c}{ }^{4} \text { Pontos } \\
\text { de } \\
\text { Monitori } \\
\text { zação }\end{array}$} & \multicolumn{2}{|c|}{ Local } & \multirow{2}{*}{$\begin{array}{c}L_{e q}(A) \\
\text { Calculado }\end{array}$} & \multirow{2}{*}{$\begin{array}{l}L_{e q}(A) \\
\text { Medido }\end{array}$} & \multirow{2}{*}{$L_{e q}(A) \operatorname{Med}-L_{e q}(A)$ Cal } \\
\hline & \multirow{2}{*}{$\begin{array}{c}\text { Longitude } \\
\text { (UTM) }\end{array}$} & \multirow{2}{*}{$\begin{array}{c}\text { Latitude } \\
\text { (UTM) }\end{array}$} & & & \\
\hline & & & $\mathrm{dB}(\mathrm{A})$ & $\mathrm{dB}(\mathrm{A})$ & $\mathrm{dB}(\mathrm{A})$ \\
\hline M1 & 180568.73 & 8220177.66 & 72,9 & 70,4 & 2,5 \\
\hline M2 & 180707.32 & 8221068.02 & 69,7 & 72,1 & $-2,4$ \\
\hline M3 & 180800.91 & 8221737.30 & 67,7 & 67,2 & 0,5 \\
\hline M4 & 180887.11 & 8222407.13 & 68,2 & 69,4 & $-1,2$ \\
\hline M5 & 180950.72 & 8222809.57 & 67,8 & 70,2 & $-2,4$ \\
\hline M6 & 180991.18 & 8223034.68 & 67,7 & 70,3 & $-2,6$ \\
\hline T1 & 180878.17 & 8222897.66 & 66,6 & 65,8 & 0,8 \\
\hline $\mathrm{T} 2$ & 180740.98 & 8221948.89 & 65,8 & 68,5 & $-2,7$ \\
\hline T3 & 180803.95 & 8222375.38 & 66,1 & 68,9 & $-2,8$ \\
\hline $\mathrm{T} 4$ & 180740.98 & 8221948.89 & 65,8 & 68,2 & $-2,4$ \\
\hline T5 & 180695.24 & 8221630.55 & 67,5 & 69,3 & $-1,8$ \\
\hline T6 & 180545.37 & 8220698.17 & 66,2 & 68,3 & $-2,1$ \\
\hline $\mathrm{T} 7$ & 180488.02 & 8220137.86 & 67,4 & 68,3 & $-0,9$ \\
\hline N1 & 180875.61 & 8222908.28 & 66,0 & 66,5 & $-0,5$ \\
\hline $\mathrm{N} 2$ & 180846.30 & 8222682.24 & 66,1 & 66,8 & $-0,7$ \\
\hline N3 & 180802.48 & 8222388.63 & 65,6 & 64,8 & 0,8 \\
\hline $\mathrm{N} 4$ & 180742.90 & 8221963.18 & 65,7 & 63,7 & 2,0 \\
\hline N5 & 180691.51 & 8221606.46 & 67,4 & 70,4 & $-3,0$ \\
\hline N6 & 180550.71 & 8220698.80 & 66,9 & 67,1 & $-0,2$ \\
\hline
\end{tabular}

Pode-se constatar que os valores dos indicadores $L_{e q}(A)$ medidos e modelados são bastante próximos, sendo que sua diferença não ultrapassa os $3 \mathrm{~dB}(\mathrm{~A})$. Portanto, afirma-se que o modelo está calibrado.

A partir da calibração do modelo (Quadro 4.5), foi possível estabelecer uma análise das características e das tendências acústicas da área de estudo. A forma de apresentação visual e a distribuição gradual dos níveis de pressão sonora por toda a área de estudos mostram com mais clareza o impacto do ruído ambiental nas proximidades da rodovia BR 040 altura da cidade de Valparaíso de Goiás.

\subsubsection{Mapa de ruído na situação atual}

Com os dados tabulados referentes à região de estudo, foram realizadas simulações no software CadnaA para gerar os mapas de ruído referentes à "situação atual" dentro dos parâmetros $L_{d i a}$ e $L_{n}$. Esses mapas (Figuras 4.4 e 4.5) demonstram os níveis de pressão

\footnotetext{
${ }^{4}$ Os receptores utilizados nas simulações têm a mesma localização geográfica dos medidos in loco
} 
sonora equivalente para a situação atual nos períodos diurno e noturno.

Nas simulações realizadas os pontos de cálculo de NPS, coincidentes com os pontos de medição de ruído ambiental que foram inseridos nas mesmas coordenadas UTM (objetos georreferenciados). Estes objetos são reconhecidos no CadnaA como entidade denominada Receiver. 


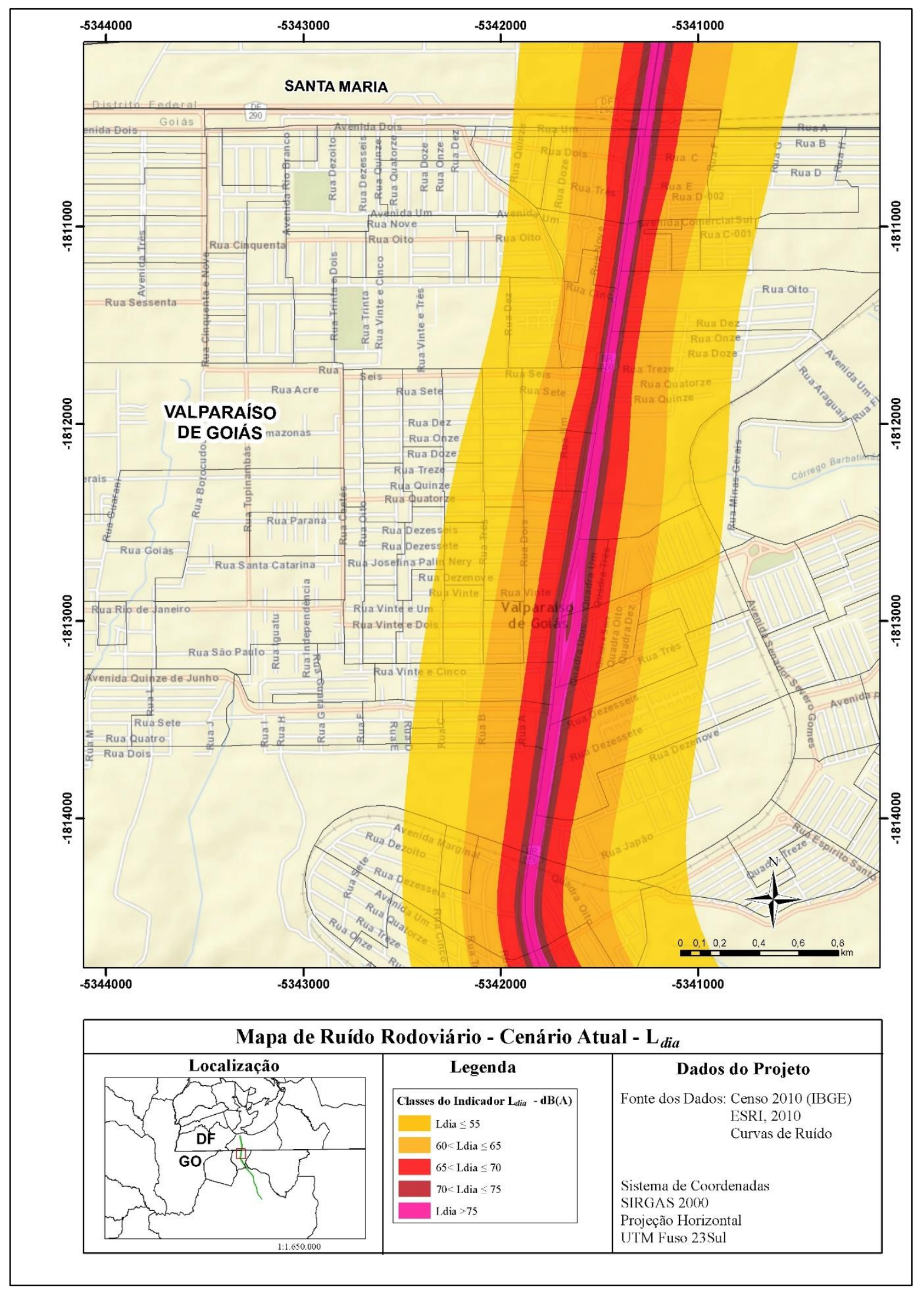

Figura 4.4 - Mapa de ruído da situação atual para o parâmetro $\boldsymbol{L}_{\text {dia }}$ 


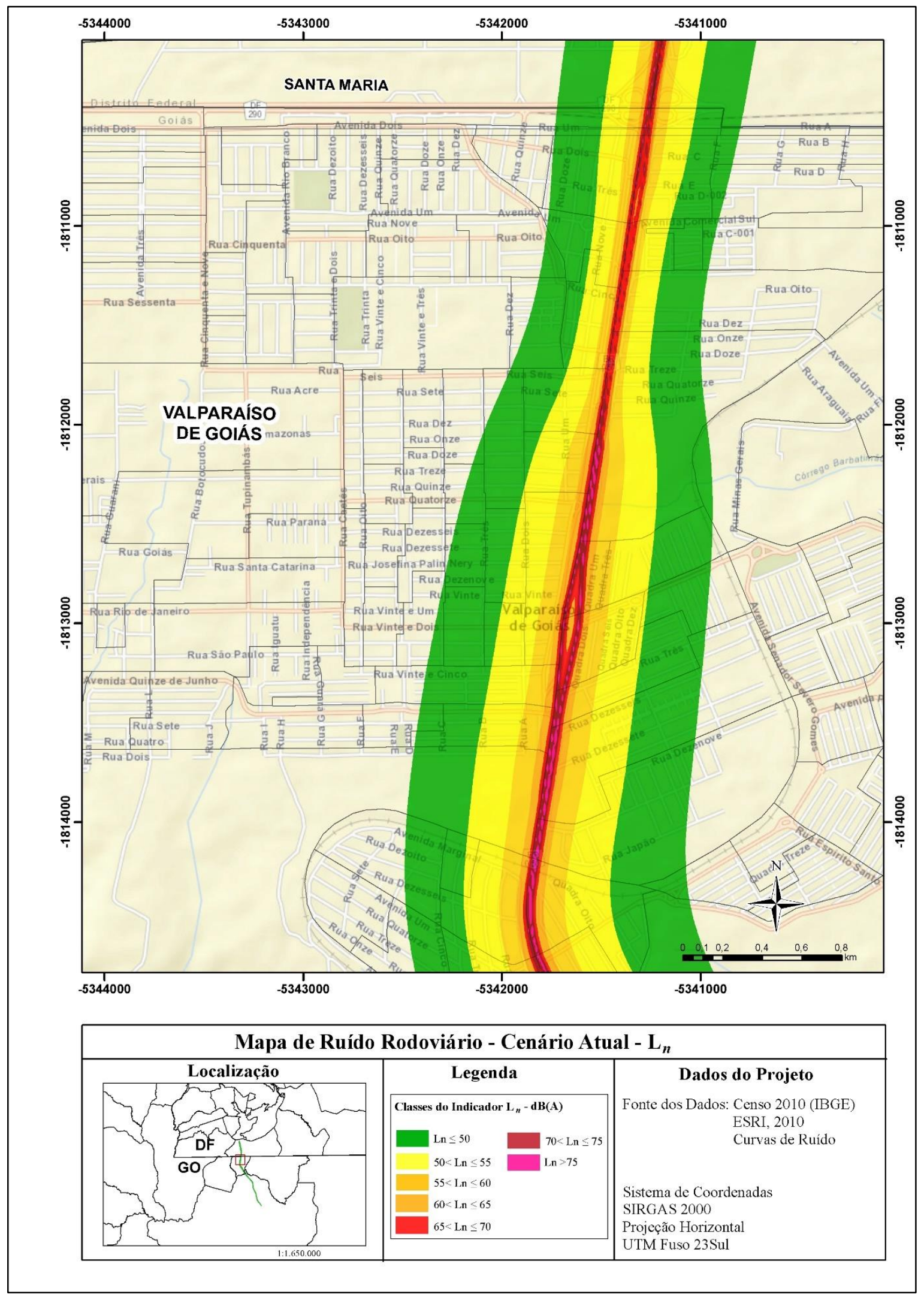

Figura 4.5 - Mapa de ruído da situação atual para o parâmetro $\boldsymbol{L}_{\boldsymbol{n}}$ 
Por meio do mapa de ruído exposto na Figura 4.4, é possível inferir que lojas e residências com fachadas diretamente voltadas para a rodovia sofrem uma maior incidência do ruído emitido pelas vias de trânsito. No tocante à avaliação do impacto do ruído ambiental na rodovia BR-040 - altura da cidade de Valparaiso de Goiás, mostra que os níveis de ruído,

tanto para $L_{\text {dia }}$ como para o $L_{n}$, na maior parte dos pontos, ultrapassam os valores máximos estabelecidos pelas normas vigentes. A norma brasileira NBR 10151, especifica para áreas mistas um limite máximo de $55 \mathrm{~dB}(\mathrm{~A})$ no período diurno e $50 \mathrm{~dB}(\mathrm{~A})$ para o período noturno. No caso do $L_{n}$, no contexto de rodovias, em certos momentos, esse parâmetro é intensificado, pois sofre influência direta da quantidade de veículos pesados que transitam no período noturno.

De acordo com os dados obtidos com o mapa de ruído da Figura 4.4 e 4.5 para ambos os parâmetros $\left(L_{d i a}\right.$ e $\left.L_{n}\right)$ da situação atual, pode-se afirmar a existência de uma situação de impacto ambiental negativo classificado como "ruidosos" em relação às emissões sonoras locais. Neste sentido, o trecho urbano desta rodovia atualmente pode ser classificado como um local de alta poluição acústica, o que coloca pessoas que tem seus comércios e residências próximas a rodovias a uma situação de impacto ocorrente.

O mapeamento realizado na área de estudo não permite uma abordagem tridimensional, mas pode ser usado como um método quanto ao entendimento da distribuição espacial dos níveis encontrados na área e das tendências de propagação de ruído.

\subsubsection{Modelação por meio do Software Aimsun}

Os dados de entrada no software CadnaA para a geração dos cenários futuros se deram devido a simulações feita pelo software Aimsun com o propósito de simular o comportamento da velocidade média do fluxo de tráfego na região de estudo, devido à redução na frota veicular da região decorrente da implantação de um transporte de massa. Para a calibração do cenário atual, foram utilizados os dados de volume veicular do Entorno Sul do DF em horários de pico para os dois sentidos da via, conforme Quadro 4.5. 
Quadro 4.5 - Número médio de veículos por tipo, em horas pico, no trecho em estudo.

\begin{tabular}{|c|c|c|c|c|c|c|c|c|}
\hline & \multicolumn{2}{|c|}{ Brasília / Luziânia } & \multicolumn{2}{|c|}{ Luziânia / Brasília } & \multicolumn{2}{|c|}{ Brasília / Luziânia } & \multicolumn{2}{|c|}{ Luziânia / Brasília } \\
\hline & \multicolumn{4}{|c|}{$07: 00-09: 00$} & \multicolumn{4}{|c|}{$17: 00-19: 00$} \\
\hline & Leves & Pesados & Leves & Pesados & Leves & Pesados & Leves & Pesados \\
\hline Ponto 1 & 2752 & 272 & 2612 & 332 & 2876 & 296 & 2684 & 248 \\
\hline Ponto 2 & 3092 & 172 & 2924 & 160 & 2620 & 212 & 2412 & 176 \\
\hline Ponto 3 & 2764 & 236 & 2564 & 272 & 2724 & 320 & 2724 & 264 \\
\hline Ponto 4 & 2116 & 220 & 1956 & 248 & 2740 & 244 & 2632 & 212 \\
\hline
\end{tabular}

Fazendo-se uma média entre os volumes de tráfego em ambos os sentidos viários, com os dados oficiais do DNIT, identificou-se que o pico volumétrico na área de estudo aconteceu nos períodos das 07:00 às 09:00h e das 17:00 às 19:00h. Estes resultados também podem ser confirmados por meio das Figuras 4.1 e 4.2.

Para possibilitar a simulação no Software Aimsun, foi necessário integrar os volumes dos diversos modos. Assim, foram utilizados os dados de ônibus mais os de caminhão, como "pesados", e os de automóveis mais os de motocicletas 5 denominados como "leves".

A modelagem, utilizando o Software Aimsun, se deu para três cenários: o atual - que corresponde à calibração do software, outro com uma redução de $20 \%$ na frota veicular e, por fim, o último, com uma redução de $50 \%$ na frota veicular total.

A Figura 4.6 ilustra um trecho da simulação para o cenário atual, na qual se observa a representação dos veículos na via, o número de faixas, principais interseções, entre outros fatores. Maiores informações a respeito do posicionamento dos e identificação dos radares estão disponíveis no Apêndice 3.

\footnotetext{
${ }^{5}$ Foi adotado o valor de 0,2 por ser o fator multiplicador para comparação de espaço físico ocupado pelas motocicletas com os automóveis, conforme recomendado pelo manual de Semáforos do DENATRAN.
} 


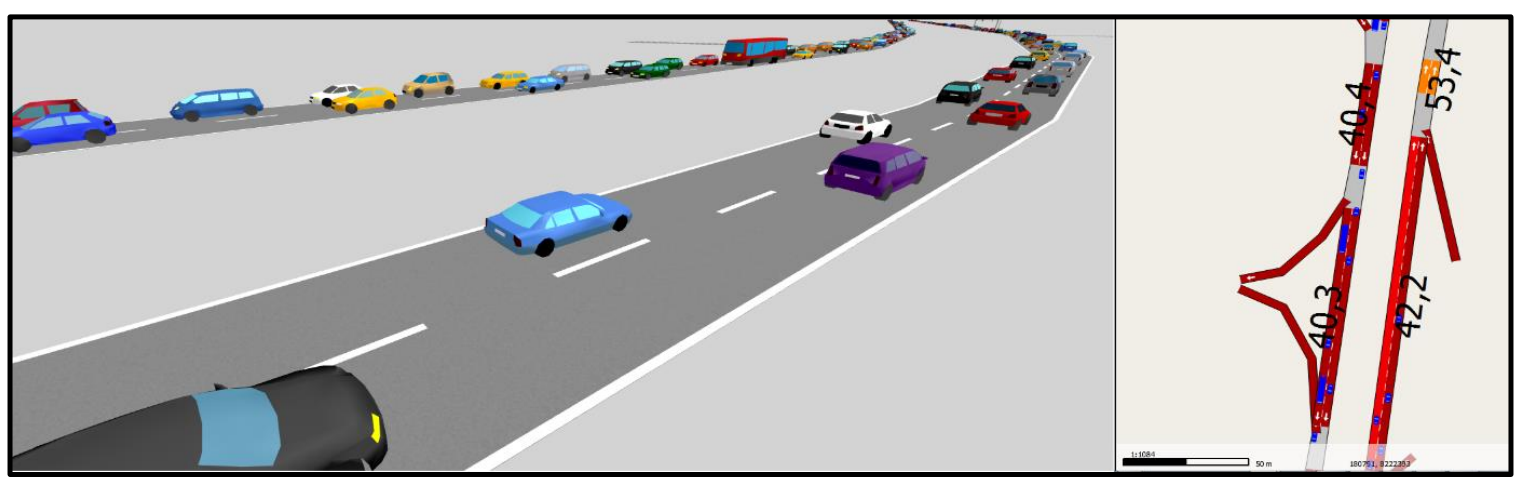

Figura 4.6 - Ilustração de um trecho da simulação para o cenário atual, onde se observa a representação dos veículos na via, o número de faixas, principais interseções, etc.

A partir das simulações feitas, foram obtidos os resultados para o indicador de desempenho escolhido, que se refere à velocidade média do fluxo de tráfego por seção e, em seguida, realizou-se a comparação dos cenários atual e futuro. Os resultados para a velocidade do fluxo de tráfego por trechos para os diferentes cenários estão descritos nos Quadro 4.6 e 4.7.

Quadro 4.6 - Velocidade média em $(\mathrm{km} / \mathrm{h})$ simulada para os diferentes trechos após a redução na frota atual - Sentido Brasília / Luziânia

\begin{tabular}{|c|c|c|c|c|c|}
\hline $\begin{array}{c}\text { Código dos } \\
\text { radares }\end{array}$ & $\begin{array}{c}\text { Vel. órgão de } \\
\text { controle }\end{array}$ & $\begin{array}{c}\text { Velocidade } \\
\text { atual calibrada } \\
\text { no Software } \\
\text { Aimsun }\end{array}$ & $\begin{array}{c}\text { Velocidade após } \\
\text { a redução no } \\
\text { fluxo de tráfego } \\
\text { de 20\% }\end{array}$ & $\begin{array}{c}\text { Velocidade após } \\
\text { a redução no } \\
\text { fluxo de tráfego } \\
\text { de 50\% }\end{array}$ & $\begin{array}{c}\text { \% máxima } \\
\text { de aumento } \\
\text { na } \\
\text { velocidade }\end{array}$ \\
\hline DF184050 & 60 & 56 & 63 & 64 & $13 \%$ \\
\hline GO177010 & 60 & 38 & 42 & 45 & $16 \%$ \\
\hline GO172020 & 40 & 38 & 41 & 45 & $16 \%$ \\
\hline GO172050 & 40 & 39 & 41 & 45 & $13 \%$ \\
\hline GO177030 & 60 & 59 & 62 & 65 & $9 \%$ \\
\hline GO177040 & 60 & 58 & 62 & 65 & $11 \%$ \\
\hline
\end{tabular}

Quadro 4.7 - Velocidade média em $(\mathrm{km} / \mathrm{h})$ simulada para os diferentes trechos após a redução na frota atual - Sentido Luziânia / Brasília

\begin{tabular}{|c|c|c|c|c|c|}
\hline $\begin{array}{c}\text { Código dos } \\
\text { radares }\end{array}$ & $\begin{array}{c}\text { Vel. órgão de } \\
\text { controle }\end{array}$ & $\begin{array}{c}\text { Velocidade } \\
\text { atual calibrada } \\
\text { no Software } \\
\text { Aimsun }\end{array}$ & $\begin{array}{c}\text { Velocidade após } \\
\text { a redução no } \\
\text { fluxo de tráfego } \\
\text { de 20\% }\end{array}$ & $\begin{array}{c}\text { Velocidade após } \\
\text { a redução no } \\
\text { fluxo de tráfego } \\
\text { de 50\% }\end{array}$ & $\begin{array}{c}\text { \% máxima } \\
\text { de aumento } \\
\text { na } \\
\text { velocidade }\end{array}$ \\
\hline DF184050 & 60 & 56 & 63 & 64 & $13 \%$ \\
\hline GO177010 & 60 & 38 & 42 & 45 & $16 \%$ \\
\hline GO172020 & 40 & 38 & 41 & 45 & $16 \%$ \\
\hline GO172050 & 40 & 39 & 41 & 45 & $13 \%$ \\
\hline GO177030 & 60 & 59 & 62 & 65 & $9 \%$ \\
\hline GO177040 & 60 & 58 & 62 & 65 & $11 \%$ \\
\hline
\end{tabular}

A velocidade média do fluxo de tráfego para a redução da frota em $20 \%$ não causou variações na velocidade de forma significativa. Em contrapartida, para a redução na frota de veículos em 50\%, houve um aumento médio de aproximadamente 10,5\% na velocidade 
média do fluxo para os dois sentidos das vias. Cabe destacar que a limitação desse aumento de velocidade é influenciada pelos dispositivos de controle de velocidade observados na área de estudo.

\subsubsection{Simulação dos cenários futuros}

Mediante uma suposta implantação de um transporte de massa (trem urbano), foram realizadas simulações para dois cenários futuros distintos: um considerando uma redução de $20 \%$ na frota veicular atual, e outro considerado uma redução de 50\% na frota veicular. Associado à redução da frota veicular, também foram consideradas as novas velocidades determinadas em simulações feitas no software Aimsun (Quadro 4.6 e 4.7) para a realização da simulação dos cenários futuros, conforme Figuras 4.7 e 4.8.

Para os respectivos cenários futuros foram feitas apenas as simulações para o $L_{d i a}$, visto que o trem urbano para esta região só rodaria nos horários de pico, não ultrapassando às 20:00h.

Comparando os mapas das Figuras 4.7 e 4.8 (cenário futuro) com o da Figura 4.4 (situação atual) foi constatada algumas mudanças sensíveis, como é o caso da faixa do indicador de 60 a 65 dBA, que sofre uma redução para os dois cenários futuros simulados. Em contrapartida houve um aumento da curva dos valores menores que 55 dB. Essa redução está ligada à combinação dos fatores: redução no número de veículos transitando nas vias e aumento da velocidade média de deslocamento do fluxo de tráfego. 


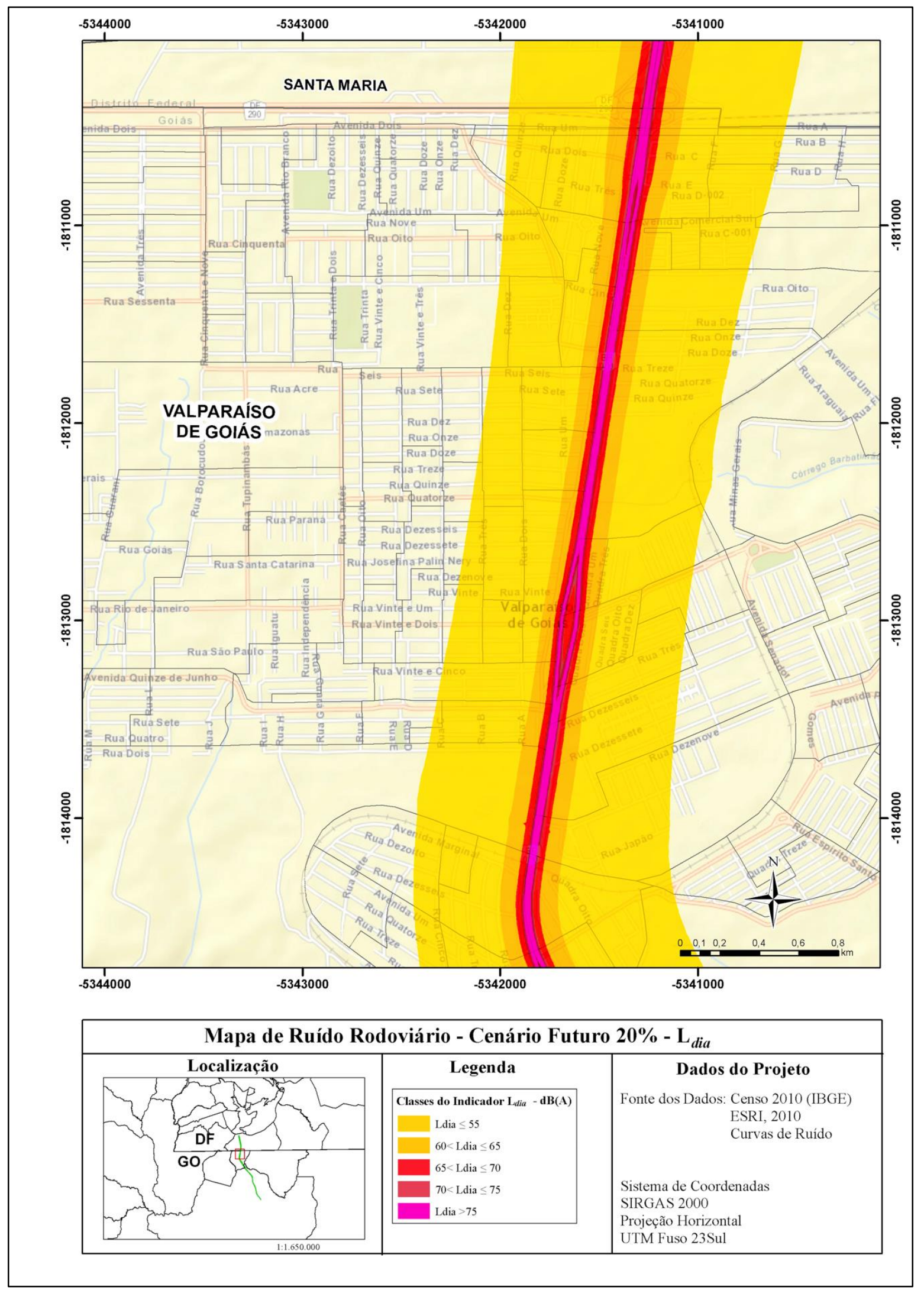

Figura 4.7 - Mapa de ruído - Cenário futuro - redução de $20 \%$ para o parâmetro $\boldsymbol{L}_{\text {dia }}$ 


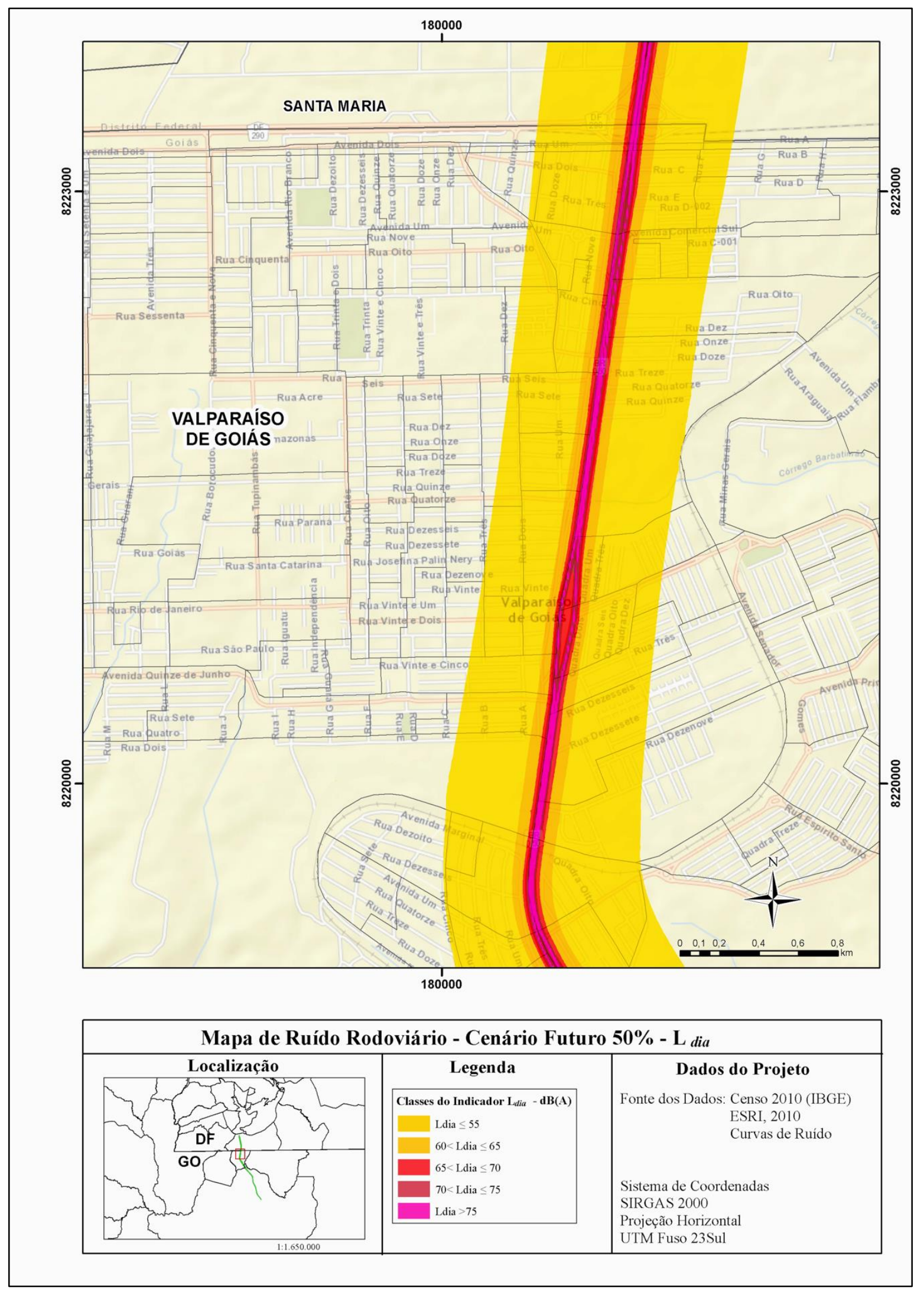

Figura 4.8 - Mapa de ruído - Cenário futuro - redução de 50\% para o parâmetro $\boldsymbol{L}_{\text {dia }}$ 
Por meio do Quadro 4.8 é possível comparar os valores simulados, para os níveis de ruído atual, em relação ao cenário futuro de $20 \%$ e de $50 \%$. Pode-se inferir que para a redução de $20 \%$ alguns pontos tiveram um leve aumento nos níveis de pressão sonora quando comparados com os valores atuais. Esse fato está relacionado com o leve aumento da velocidade média do fluxo de tráfego. Para a redução de $50 \%$, apesar do aumento na velocidade média do fluxo de tráfego, que contribui diretamente com os NPS, houve uma leve redução nas emissões o que se deve à forte redução no número de veículos transitando nas vias. Em alguns pontos essa redução chega a 3,7 $\mathrm{dB}(\mathrm{A})$, notadamente, no ponto que sofre a ação direta do ruído do tráfego.

Quadro 4.8 - Comparativo entre os NPS para os diferentes cenários

\begin{tabular}{|c|c|c|c|c|c|}
\hline \multirow{3}{*}{ Receptor } & \multirow{3}{*}{$\begin{array}{c}L_{d i a} \\
\text { Atual } \\
\mathbf{d B}(\mathbf{A})\end{array}$} & \multicolumn{2}{|c|}{$L_{d i a}$ - Futuro } & \multirow{3}{*}{$\begin{array}{c}\text { Diferença } \\
\text { entre Atual } \\
\text { e a Redução } \\
20 \%\end{array}$} & \multirow{3}{*}{$\begin{array}{c}\text { Diferença } \\
\text { entre Atual } \\
\text { e a Redução } \\
\text { de } 50 \%\end{array}$} \\
\hline & & Redução $20 \%$ & Redução 50\% & & \\
\hline & & $\mathrm{dB}(\mathrm{A})$ & $\mathrm{dB}(\mathrm{A})$ & & \\
\hline M1 & 72,9 & 72,0 & 70,2 & 0,9 & 2,7 \\
\hline M2 & 69,7 & 67,8 & 65,9 & 1,9 & 3,8 \\
\hline M3 & 67,7 & 66,2 & 64,5 & 1,5 & 3,2 \\
\hline M4 & 68,2 & 68,0 & 66,3 & 0,2 & 1,9 \\
\hline M5 & 67,8 & 67,5 & 65,8 & 0,3 & 2,0 \\
\hline M6 & 67,7 & 67,9 & 65,4 & $-0,2$ & 2,3 \\
\hline $\mathrm{T} 1$ & 66,6 & 67,4 & 65,5 & $-0,8$ & 1,1 \\
\hline $\mathrm{T} 2$ & 65,8 & 65,8 & 64,1 & 0,0 & 1,7 \\
\hline $\mathrm{T} 3$ & 66,1 & 66,7 & 65,0 & $-0,6$ & 1,1 \\
\hline $\mathrm{T} 4$ & 65,8 & 65,8 & 64,1 & 0,0 & 1,7 \\
\hline T5 & 67,5 & 65,5 & 63,8 & 2,0 & 3,7 \\
\hline T6 & 66,2 & 64,2 & 62,6 & 2,0 & 3,6 \\
\hline $\mathrm{T} 7$ & 67,4 & 66,0 & 64,3 & 1,4 & 3,1 \\
\hline $\mathrm{N} 1$ & 66,0 & 66,7 & 64,8 & $-0,7$ & 1,2 \\
\hline $\mathrm{N} 2$ & 66,1 & 66,8 & 65,1 & $-0,7$ & 1,0 \\
\hline N3 & 65,6 & 66,2 & 64,5 & $-0,6$ & 1,1 \\
\hline $\mathrm{N} 4$ & 65,7 & 65,8 & 64,2 & $-0,1$ & 1,5 \\
\hline N5 & 67,4 & 65,5 & 63,8 & 1,9 & 3,6 \\
\hline N6 & 66,9 & 64,9 & 63,2 & 2,0 & 3,7 \\
\hline
\end{tabular}

Os valores negativos observados no quadro acima, para a redução de $20 \%$, mostram que nesses casos houve um aumento dos níveis de pressão sonora que não chegam a ultrapassar $1 \mathrm{~dB}$. De forma a visualizar as variações entre os cenários $L_{\text {dia }}$ atual, futuro $20 \%$ e $50 \%$, o Quadro 4.9 faz uma comparativo para os NPS em três cenários simulados. 
Quadro 4.9 - Distribuição dos NPS por pontos para três diferentes cenários acústicos

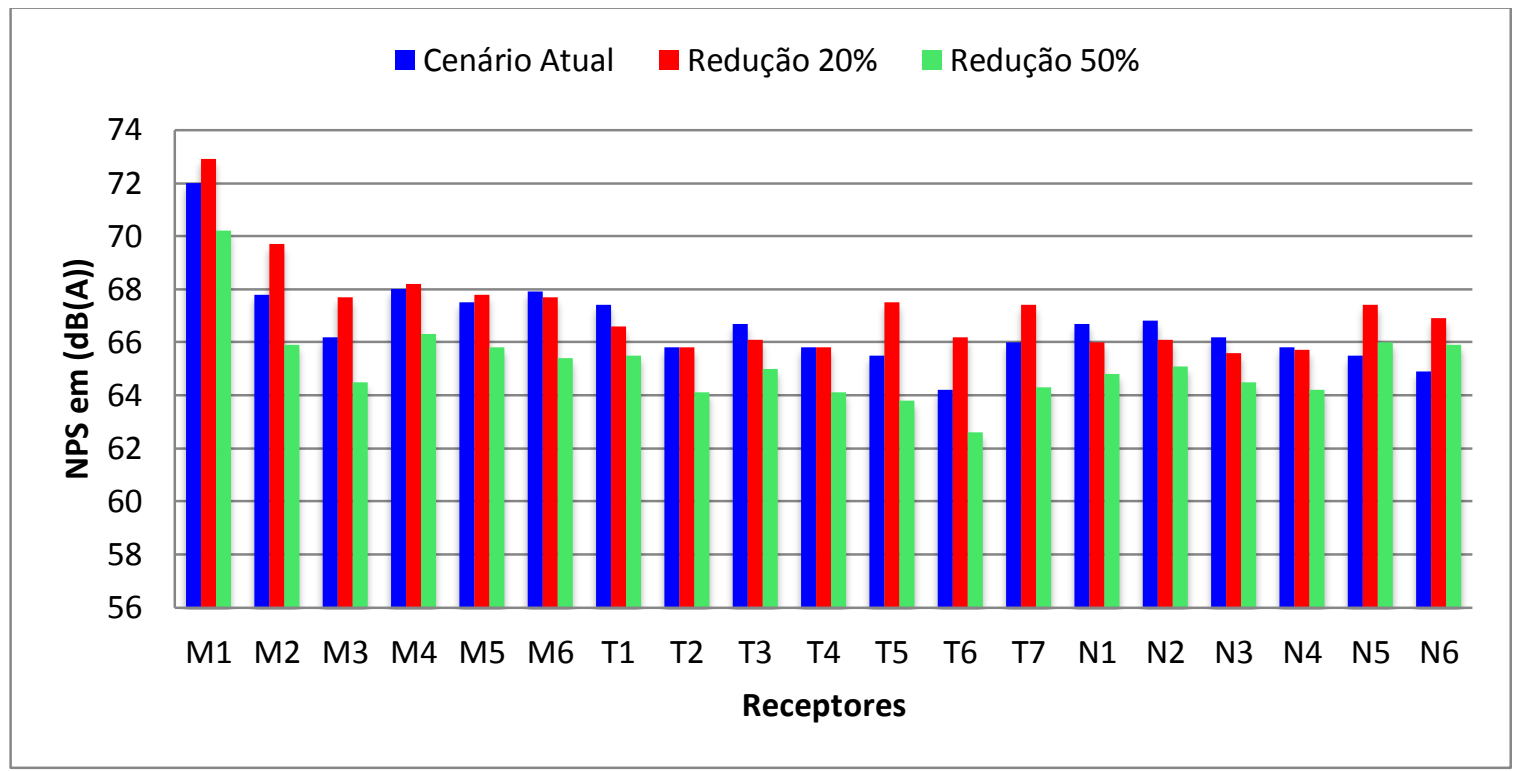

Cabe ainda ressaltar que com a redução da frota em $20 \%$, em relação a atual, observou-se em alguns pontos, um leve aumento nos NPS, fato este que difere dos valores obtidos para a redução na frota veicular em $50 \%$, que chegou a ter uma redução média dos pontos em $2,3 \mathrm{~dB}$.

\section{4 - DESENVOLVIMENTO DE ALTERNATIVAS PARA REDUÇÃO DE RUÍDO}

Por meio das simulações e medidas em in loco, pode-se constatar que os NPS devido ao tráfego veicular na área de estudo encontram-se acima dos estabelecido pelas normas vigentes. Assim, por meio do estudo realizado, foi possível determinar os pontos mais críticos da área de estudo, fazendo essa localidade, que se encontra com níveis de pressão sonora acima do permitido, ser alvo de ações mitigadoras.

Uma das alternativas possíveis, e adotadas nesse estudo, na mitigação do ruído rodoviário é a implantação de barreiras acústicas em áreas habitadas. O intuído é realizar simulações, para os diferentes cenários, de modo a reduzir os valores registados e, desta forma, assegurar o cumprimento dos limites normativos visando à qualidade de vida dos moradores.

Para o cenário atual, $L_{\text {dia }}$ e $L_{n}$, foram realizadas simulações com o software CadnaA para a implantação de barreiras acústicas nas zonas habitadas. As principais características da barreira utilizada nas simulações encontra-se no Quadro 4.10. 
Quadro 4.10 - Principais características da barreira acústica simulada no software CadanaA

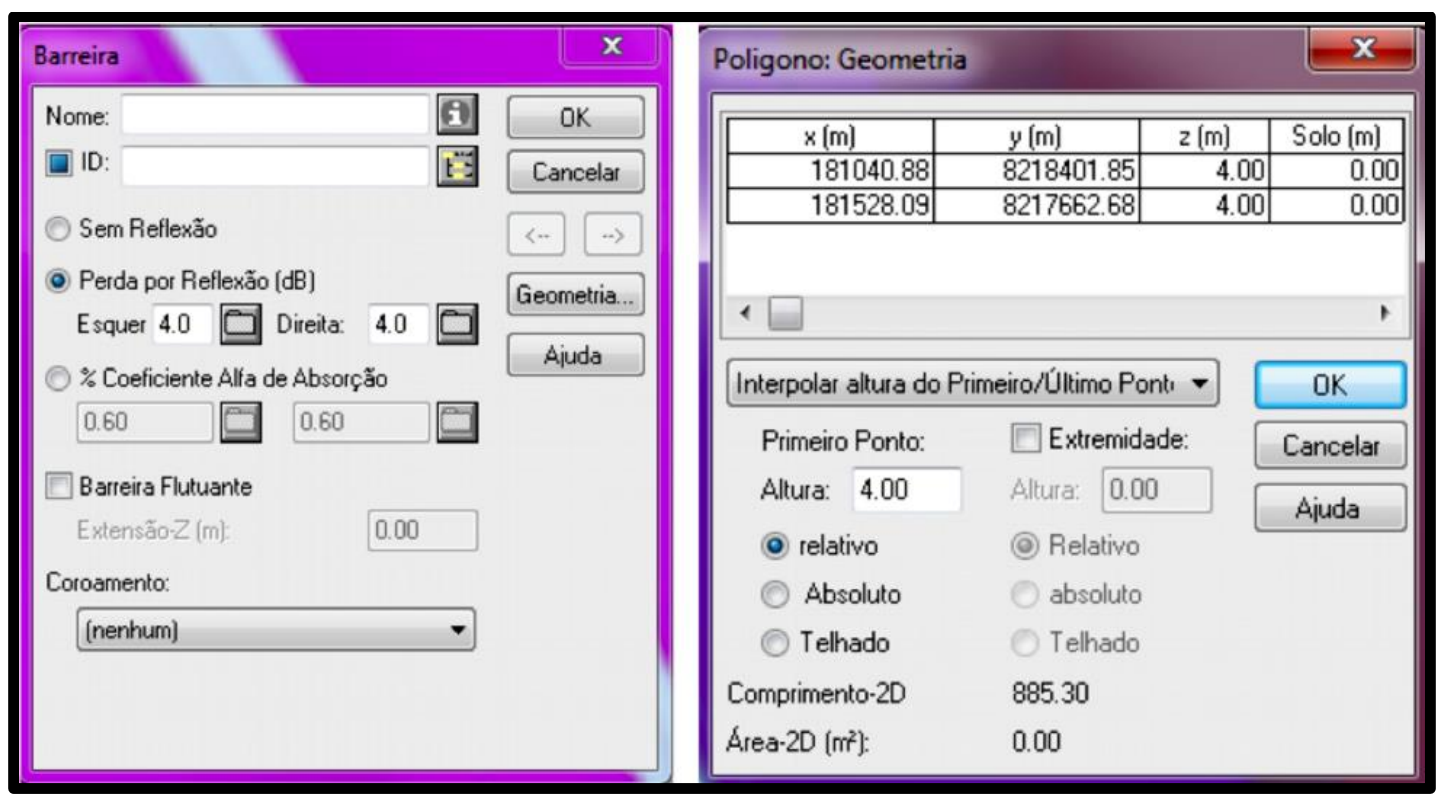

Após entrar com as características da barreira acústica no software foi possível simular o mapa de ruído (Figura 4.9) da região com a implantação de barreira acústica 


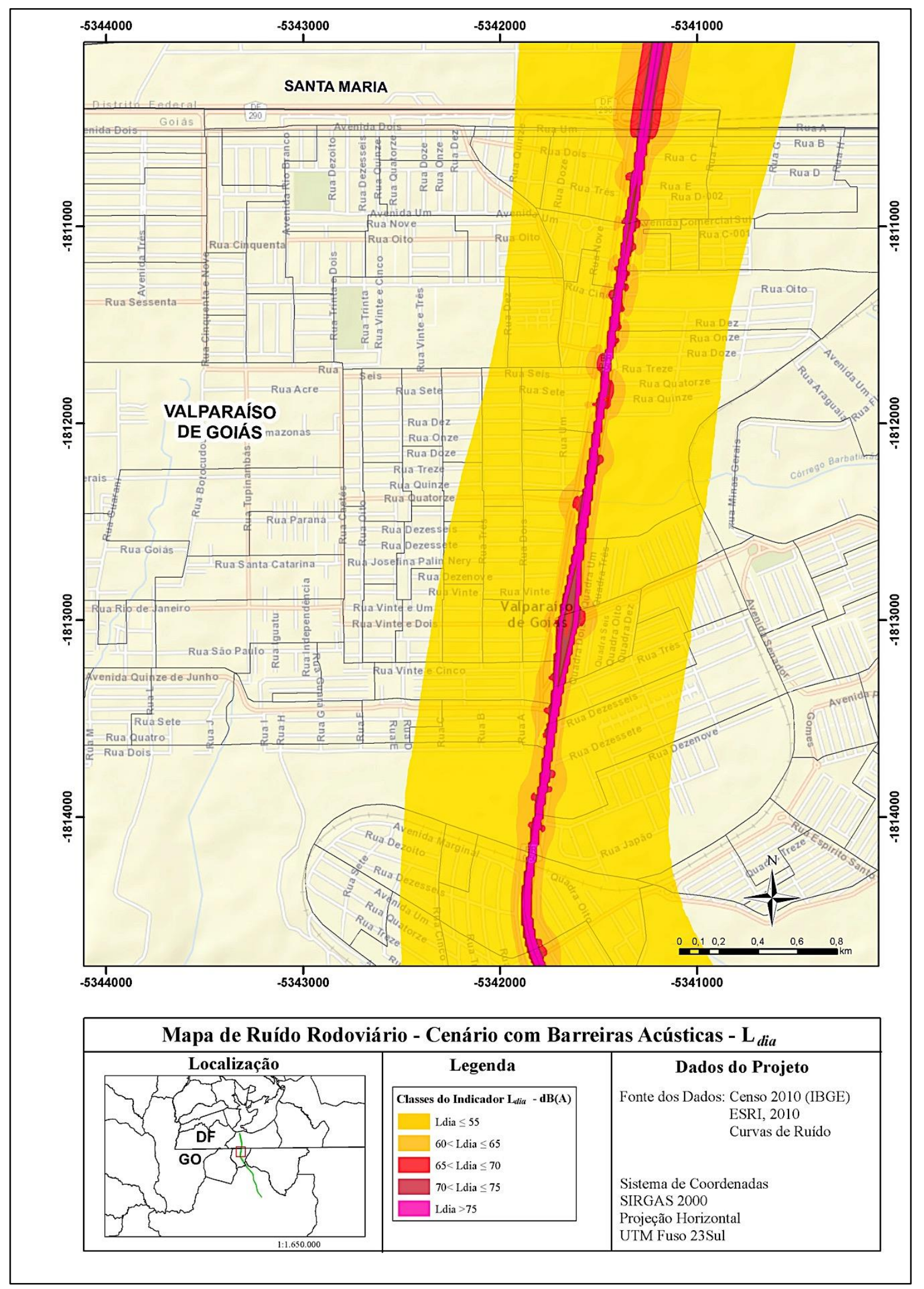

Figura 4.9 - Mapa de ruído - Cenário com Barreira acústica 
Por meio da inserção de barreira acústica, conforme observado no mapa de ruído simulado, é possível visualizar uma redução significativa nos níveis de pressão sonora ao longo da área de estudo. As curvas que chegam às áreas habitadas possuem um forte predomínio na curva de valores abaixo ou igual a 55dB. Isso se deve ao fato de o ruído sofrer uma forte atenuação/reflexão ao interagir com a barreira acústica.

No Quadro 4.11, há a comparação entre os valores dos parâmetros $L_{d i a}$ e $L_{n}$ antes e após a implantação de barreiras acústicas. Para todos os pontos, houve redução significativa nos níveis de pressão sonora, chegando até $12 \mathrm{~dB}$ no receptor M1, e, na média geral dos pontos analisados, 7 dB. Observa-se ainda que os novos valores simulados, após a implantação da barreira acústica nas condições de pico de tráfego $L_{\text {dia }}$ e $L_{n}$, estão dentro dos estabelecidos pelas normas vigentes. Dessa forma, pode-se considerar que o receptor está devidamente protegido do ruído da rodovia.

Quadro 4.11 - Valores para os NPS referentes aos parâmetros $\boldsymbol{L}_{\text {dia }} e \boldsymbol{L}_{\boldsymbol{n}}$ para a implantação de barreira acústica.

\begin{tabular}{|c|c|c|c|c|c|c|}
\hline \multirow{4}{*}{ Receptor } & \multicolumn{3}{|c|}{$L_{d i a}$} & \multicolumn{3}{|c|}{$L_{n}$} \\
\hline & $L_{d i a}$ & $L_{d i a, B a r}$ & $\begin{array}{l}\text { Diferença entre } \\
\text { os parâmetros }\end{array}$ & $L_{n}$ & $L_{n, B a r}$ & $\begin{array}{c}\text { Diferença entre os } \\
\text { parâmetros }\end{array}$ \\
\hline & $\begin{array}{c}\text { Sem } \\
\text { Barreira } \\
\text { acústica }\end{array}$ & $\begin{array}{c}\text { Com } \\
\text { Barreira } \\
\text { acústica }\end{array}$ & $\left(\boldsymbol{L}_{\text {dia }}\right)-\left(\boldsymbol{L}_{\text {dia }, \boldsymbol{B} B \boldsymbol{r}}\right)$ & $\begin{array}{c}\text { Sem } \\
\text { Barreira } \\
\text { acústica }\end{array}$ & $\begin{array}{c}\text { Com } \\
\text { Barreira } \\
\text { acústica }\end{array}$ & $\left(L_{n}\right)-\left(L_{n, B a r}\right)$ \\
\hline & $(d B(A))$ & $(d B(A))$ & $(d B(A))$ & $(d B(A))$ & $(d B(A))$ & $(d B(A))$ \\
\hline M1 & 72,9 & 61,1 & 11,8 & 68,6 & 56,1 & 12,5 \\
\hline M2 & 69,7 & 60,7 & 9,0 & 64,4 & 54,9 & 9,5 \\
\hline M3 & 67,7 & 60,4 & 7,3 & 60,8 & 53,6 & 7,2 \\
\hline M4 & 68,2 & 61,1 & 7,1 & 59,1 & 52,6 & 6,5 \\
\hline M5 & 67,8 & 62,2 & 5,6 & 58,6 & 53,5 & 5,1 \\
\hline M6 & 67,7 & 60,5 & 7,2 & 59,1 & 52,3 & 6,8 \\
\hline T1 & 66,6 & 60,0 & 6,6 & 59,4 & $\begin{array}{l}51,8 \\
\end{array}$ & 7,6 \\
\hline $\mathrm{T} 2$ & 65,8 & $\begin{array}{l}59,3 \\
\end{array}$ & 6,5 & 58,4 & 51,5 & 6,9 \\
\hline T3 & 66,1 & $\begin{array}{l}59,3 \\
\end{array}$ & 6,8 & 58,7 & 51,3 & 7,4 \\
\hline $\mathrm{T} 4$ & 65,8 & $\begin{array}{l}59,3 \\
\end{array}$ & 6,5 & 58,4 & 51,5 & 6,9 \\
\hline $\mathrm{T} 5$ & 67,5 & 60,6 & 6,9 & 61,7 & 54,2 & 7,5 \\
\hline T6 & 66,2 & 60,3 & 5,9 & 60,5 & 54,3 & 6,2 \\
\hline $\mathrm{T} 7$ & 67,4 & 61,0 & 6,4 & 62,3 & 55,8 & 6,5 \\
\hline N1 & 66,0 & 59,9 & 6,1 & 58,7 & 51,7 & 7,0 \\
\hline N2 & 66,1 & 59,6 & 6,5 & 58,8 & 51,5 & 7,3 \\
\hline N3 & 65,6 & 59,1 & 6,5 & 58,2 & 51,0 & 7,2 \\
\hline N4 & 65,7 & 59,5 & 6,2 & 58,3 & 51,7 & 6,6 \\
\hline N5 & 67,4 & 60,7 & 6,7 & 61,7 & 54,3 & 7,4 \\
\hline N6 & 66,9 & 60,2 & 6,7 & 61,1 & 54,3 & 6,8 \\
\hline
\end{tabular}


Os mapas gerados para a implantação de barreiras acústicas na região de estudo são simulações hipotéticas com o objetivo de demonstrar que existem soluções para o problema do ruído do trafego nas "rodovias com características urbanas" e que um software como o CadanA, desenvolvido com base na norma alemã RLS-90, é uma poderosa ferramenta aplicável à execução de projetos de controle do ruído, uma vez que possibilita a visualização gráfica da eficácia das alternativas adotadas nesses projetos.

O uso de barreira acústica é apenas um dos métodos utilizados na mitigação dos níveis de pressão sonora, que nesse estudo teve com caráter apenas de simulação, e caso essa seja a melhor a alternativa adotada para a região será necessário estudo mais aprofundados para a sua implantação.

\section{5 - POPULAÇÃO EXPOSTA}

Com o propósito de identificar o incomodo causado na população da área de estudo, foi feita a quantificação da população por faixas de exposição sonora, o que permite identificar o percentual de pessoas expostas em cada classe de ruído. Para estimar o número de pessoas incomodadas e altamente incomodadas, foi utilizado o indicador $L_{d e n}$.

A partir dos resultados obtidos para a área de estudo, que se referem à exposição da população a diferentes classes de níveis de ruído devido ao tráfego rodoviário, efetuou-se um estudo comparativo da população exposta a níveis do ruído limite. As Figuras (4.10; $4.11 ; 4.12$ e 4.13$)$ apresentam os diferentes cenários e as diferentes classes dos níveis de ruído e demonstram a grande concentração de habitações junto à rodovia para o parâmetro $L_{d e n}$ referente aos diferentes cenários. As cores utilizadas para estes mapas de ruído são as mesmas adotadas pela Agência Portuguesa do Ambiente (APA). 


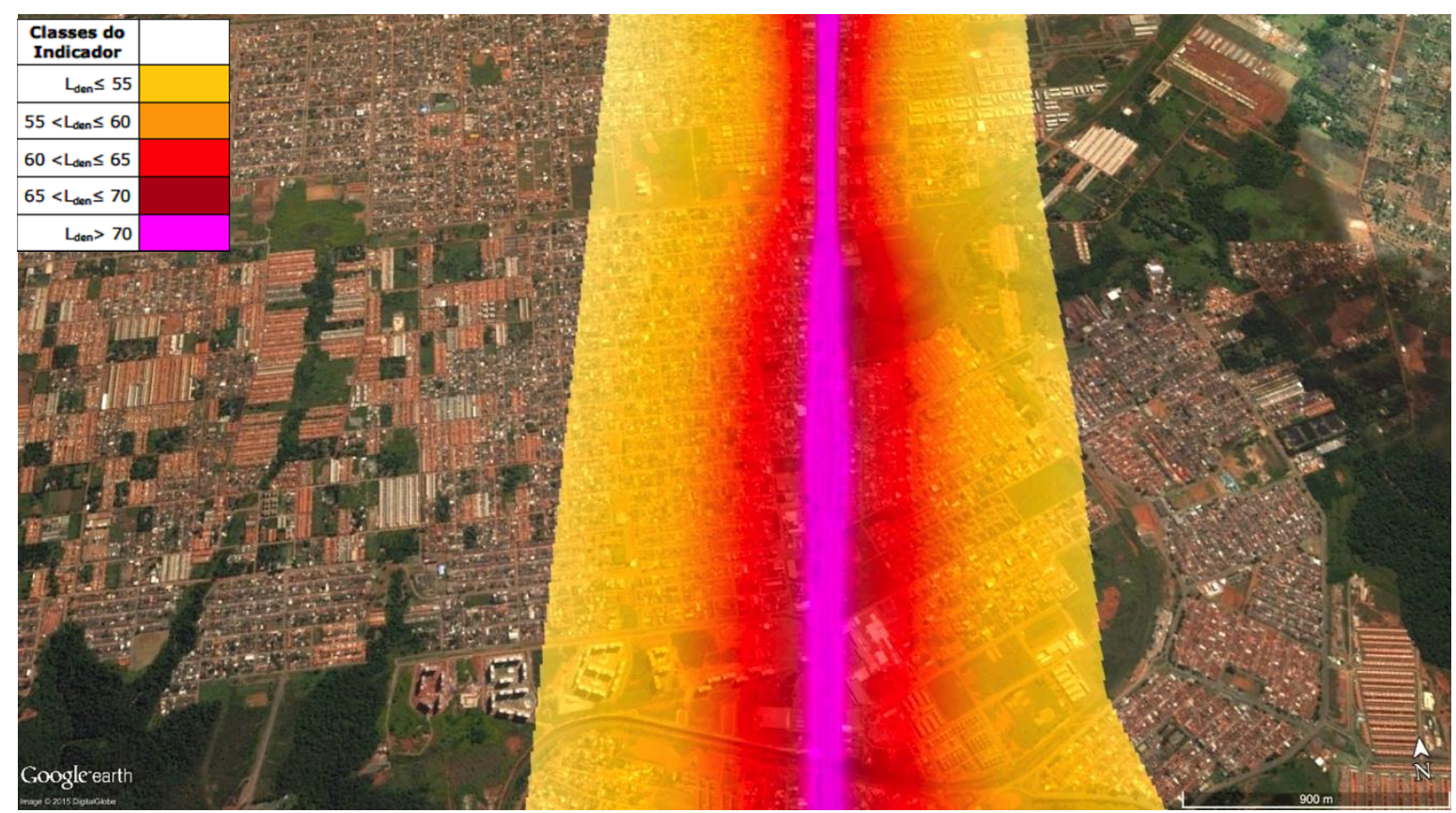

Figura 4.10 - Representação dos NPS por classes para o cenários atual

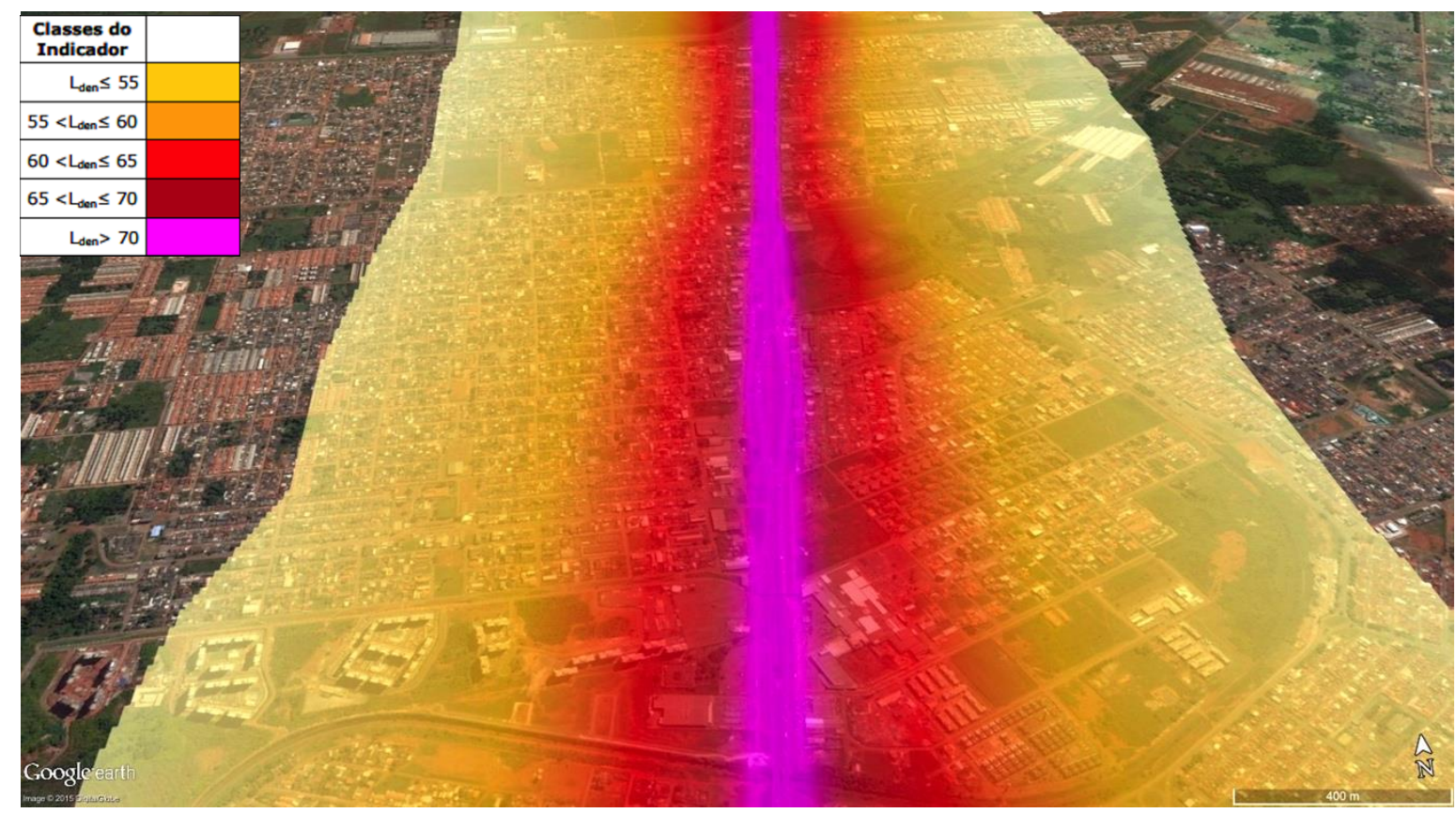

Figura 4.11 - Representação dos NPS por classes para o cenários com redução na frota veicular em $20 \%$ 


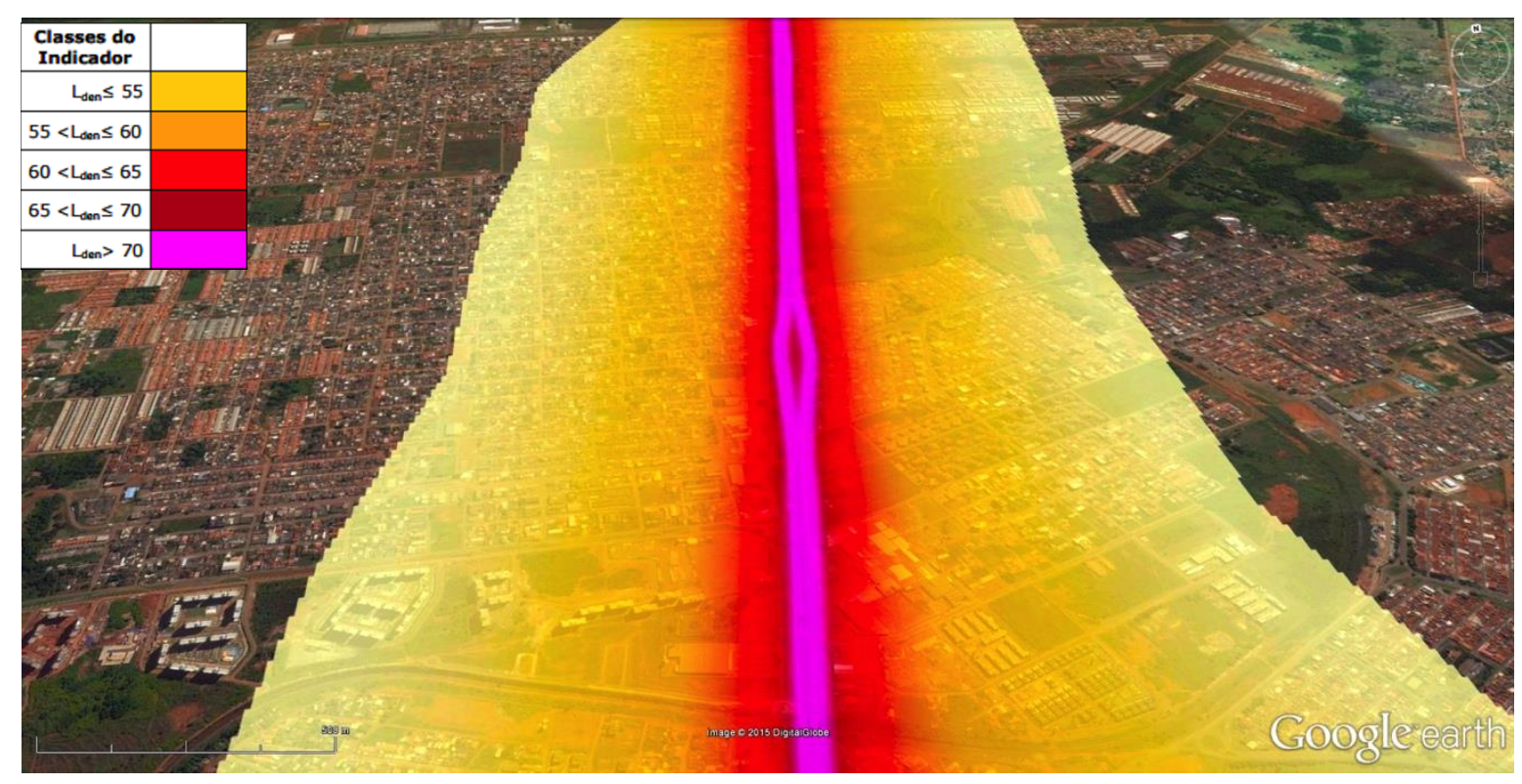

Figura 4.12 - Representação dos NPS por classes para o cenários com redução na frota veicular em $50 \%$

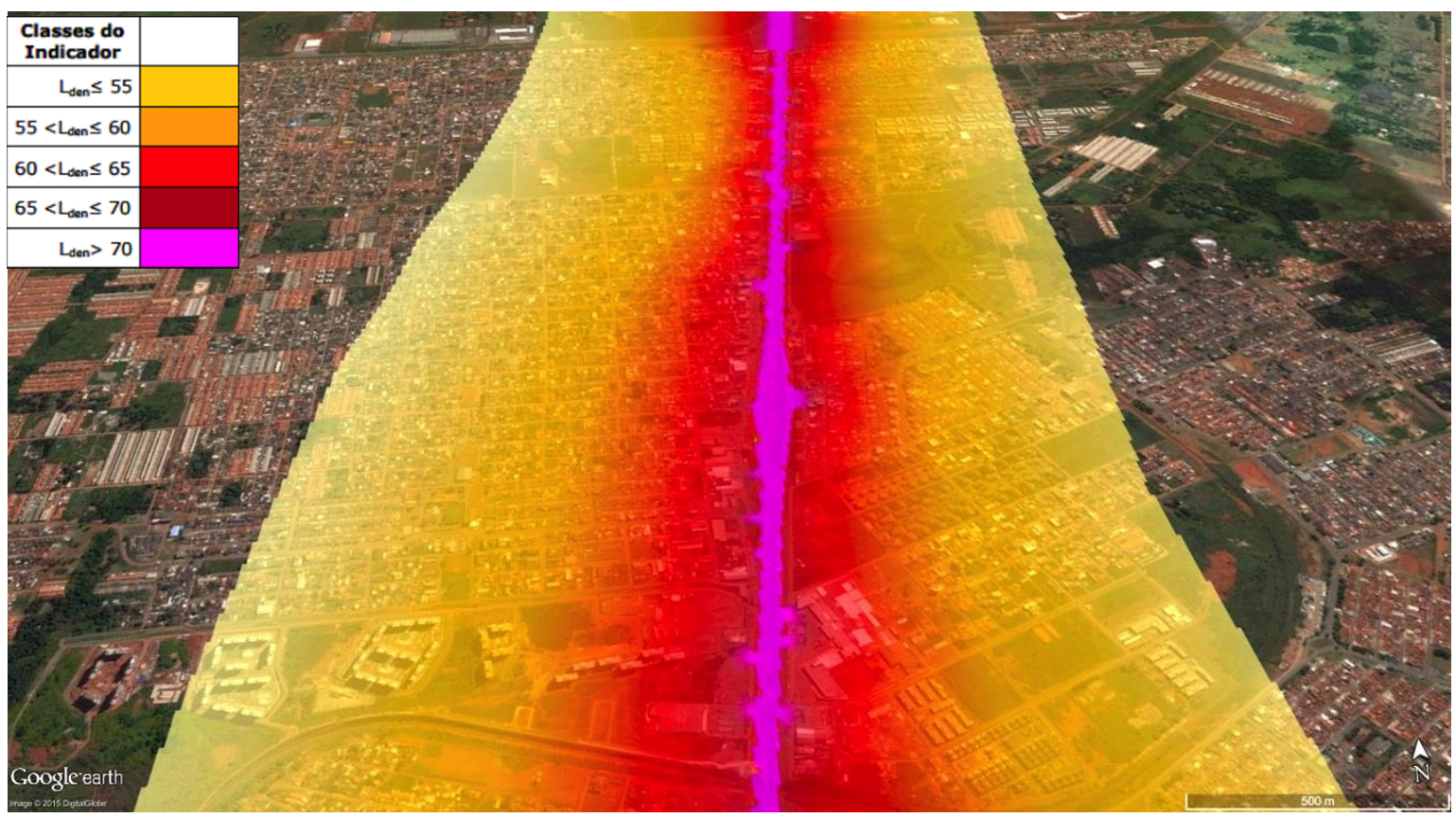

Figura 4.13 - Representação dos NPS por classes para o cenários simulado da implantação de barreira acústica.

A Figura anterior apresenta os mapas de ruído nos diferentes cenários simulados para a área de estudo, em termos do parâmetro $L_{\text {den }}$.

Uma vez que foram feitos os levantamentos da população da área de estudo para todas as curvas, pôde-se determinar a população exposta para cada curva de ruído gerado pelo tráfego rodoviário, levando em consideração os diferentes cenários. As relações obtidas 
acerca do incômodo, consequente do ruído de tráfego rodoviário, para a métrica $L_{d e n}$ são apresentadas no Quadro 4.12.

Quadro 4.12 - População exposta por faixa de indicador

\begin{tabular}{|c|c|c|c|c|}
\hline \multirow{2}{*}{$\boldsymbol{L}_{\text {den }}[\mathbf{d B A}]$} & $\begin{array}{c}\text { Situação atual } \\
\boldsymbol{L}_{\text {den }}\end{array}$ & $\begin{array}{c}\text { Redução na frota } \\
\text { veicular em 20\% }\end{array}$ & $\begin{array}{c}\text { Redução na frota } \\
\text { veicular em 50\% }\end{array}$ & $\begin{array}{c}\text { Implantação de } \\
\text { Barreira acústica }\end{array}$ \\
\cline { 2 - 5 } & $\begin{array}{c}\text { PoP. } \\
\mathbf{E X P}\end{array}$ & $\begin{array}{c}\text { PoP. } \\
\text { ExP }\end{array}$ & $\begin{array}{c}\text { PoP. } \\
\text { ExP }\end{array}$ & $\begin{array}{c}\text { PoP. } \\
\text { ExP }\end{array}$ \\
\hline $\mathbf{L}_{\text {den }}<=\mathbf{5 5}$ & 12860 & 13770 & 14135 & 12670 \\
\hline $\mathbf{5 5}<\mathbf{L}_{\text {den }}<=\mathbf{6 0}$ & 5605 & 5060 & 5840 & 3985 \\
\hline $\mathbf{6 0}<\mathbf{L}_{\text {den }}<=\mathbf{6 5}$ & 2600 & 2320 & 2270 & 40 \\
\hline $\mathbf{6 5}<\mathbf{L}_{\text {den }}<=\mathbf{7 0}$ & 1540 & 1520 & 1440 & 0 \\
\hline $\mathbf{L}_{\mathbf{d e n}}>\mathbf{7 0}$ & 240 & 253 & 156 & 0 \\
\hline
\end{tabular}

Com respeito ao quadro anterior, gerado para os diferentes cenários, pode-se afirmar, que para a faixa de ruído que compreende o intervalo para valores iguais ou menores que $55 \mathrm{~dB}$ o número de pessoas expostas aos diferentes cenários é praticamente igual. Já, na faixa do intervalo de valores maiores que $55 \mathrm{~dB}$ até os valores iguais $65 \mathrm{~dB}$, todos os cenários tiveram uma queda significativa no número de pessoas expostas. Destaca-se o cenário com a implantação de barreira acústica, com uma população exposta, dentro do intervalo de 4025 pessoas.

A diretiva Europeia (2002) estabelece como limites para áreas mistas onde predominam residências um valor máximo para o $L_{\text {den }}$ menor que $65 \mathrm{~dB}$. Assim, adotando esses limites como referência, observa-se que o cenário atual possui quantitativo 1780 pessoas dentro da faixa de valores superiores aos referenciados pela Comunidade Europeia. Nessa mesma linha, os cenários simulados para uma redução de $20 \%$ e de $50 \%$ da frota veicular tiveram valores para a população exposta semelhantes aos do cenário atual. Destaca-se o cenário com implantação de barreira acústica que não possui população exposta para a faixa de valores do intervalo de valores iguais ou superiores a $65 \mathrm{~dB}$.

De forma a analisar o valor do percentual da população incomodada (\% I) e altamente incomodada (\%AI), para cada curva de ruído, foi utilizada as equações apresentadas no Quadro 2.3. O Quadro 4.13 apresenta o número de pessoas incomodadas e altamente incomodadas por faixa de ruído para diferentes cenários.

\footnotetext{
${ }^{6}$ Abreviação do termo População Exposta.
} 
Quadro 4.13 - População incomodada e altamente incomoda para diferentes cenários

\begin{tabular}{|c|c|c|c|c|c|c|c|c|}
\hline \multirow{2}{*}{$\mathbf{L}_{\mathrm{den}}[\mathbf{d B A}]$} & \multicolumn{2}{|c|}{$\begin{array}{c}\text { Situação } \\
\text { atual } \\
\mathbf{L}_{\text {den }}\end{array}$} & \multicolumn{2}{|c|}{$\begin{array}{l}\text { Redução na frota } \\
\text { veicular em } 20 \%\end{array}$} & \multicolumn{2}{|c|}{$\begin{array}{l}\text { Redução na frota } \\
\text { veicular em } 50 \%\end{array}$} & \multicolumn{2}{|c|}{$\begin{array}{l}\text { Implantação de } \\
\text { Barreira acústica }\end{array}$} \\
\hline & I & IA & I & IA & I & IA & I & IA \\
\hline$L_{d e n} \leq 55$ & 2253 & 822 & 2253 & 822 & 2476 & 904 & 2220 & 810 \\
\hline $55<L_{d e n} \leq 60$ & 1438 & 578 & 1438 & 578 & 1498 & 155 & 1022 & 411 \\
\hline $60<L_{d e n} \leq 65$ & 922 & 421 & 922 & 421 & 805 & 367 & 14 & 6 \\
\hline $65<L_{\text {den }} \leq 70$ & 725 & 381 & 725 & 381 & 678 & 168 & 0 & 0 \\
\hline$L_{\text {den }}>70$ & 146 & 88 & 146 & 92 & 95 & 73 & 0 & 0 \\
\hline
\end{tabular}

Com respeito ao Quadro anterior, verifica-se uma quantidade significativa de pessoas dentro da região de estudo no que se refere aos parâmetros incomodado e altamente incomodado, levando em consideração o número de habitantes da região onde foi realizado o estudo que é de 132.982. (IBGE, 2010)

À medida em que se aumenta as faixas de ruído referentes aos NPS, há uma diminuição no número de pessoas incomodadas e altamente incomodadas, visto que os valores para $L_{\text {den }}$ maior que $70 \mathrm{~dB}$ estão concentrados nas faixas de rolamento. O número estimado de pessoas para a faixa de valores acima de $70 \mathrm{~dB}$ se deve, principalmente, a comércios e a alguns prédios próximos das margens da rodovia. Pessoas dentro dessa faixa estão, portanto, mais propensas a efeitos negativos à saúde em decorrência dos níveis de ruído.

Além disso, ressalta-se que as fachadas dos comércios, para os valores do cenário atual, comparados à métrica $L_{d e n}$, são as que estão mais expostas aos maiores níveis de pressão sonora, com valores iguais ou maiores que $65 \mathrm{~dB}$. Esses resultados se devem à grande aproximação da fonte de ruído e têm como consequência a maior exposição das pessoas que ali trabalham ou residem aos níveis de pressão sonora.

Ao analisar os cenários em conjunto, observa-se que não houve diferenças significativas entre cenários com redução de frota veicular em 20 e 50\% para os valores da população da área de estudo incomodada e altamente incomodada, porém, quando comparado ao cenário com implantação de barreira acústica, não há pessoas incomodadas e nem altamente incomodadas para o intervalo de $65 \mathrm{~dB}$ a valores maiores que $70 \mathrm{~dB}$.

Com respeito a população exposta, no que tange aos cenários referentes ao $L_{n}$, foram feitos cálculos que envolvessem o cenário atual e após implantação da barreira acústica. As curvas de ruído $L_{n}$ simuladas estão expostas na Figura (4.14 e 4.15) para os dois cenários: 
$L_{n}$ atual e $L_{n, B a r r e i r a}$, após a implantação de uma barreira acústica.

Não foram realizadas simulações para o parâmetro $L_{n}$ referente aos cenários de 20 e $50 \%$, visto que o trem urbano adotado neste trabalho não funcionaria no intervalo das 23:00 às 07:00 da manhã, que compreende o período noturno e, portanto, não teria influência na fluidez da rodovia.

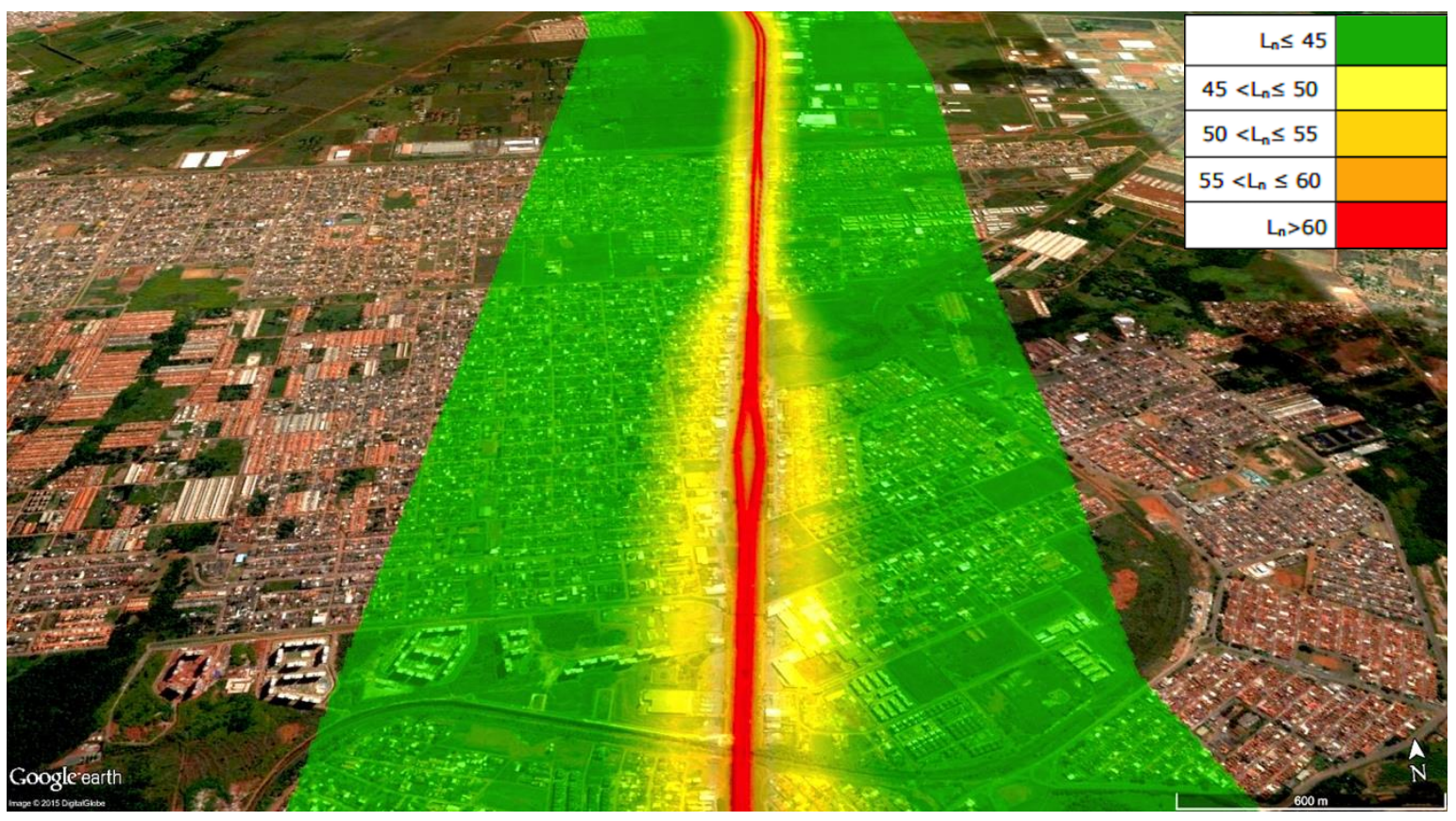

Figura 4. 14 - Representação dos NPS por classes para o cenário $\left(\boldsymbol{L}_{\boldsymbol{n}}\right)$ atual

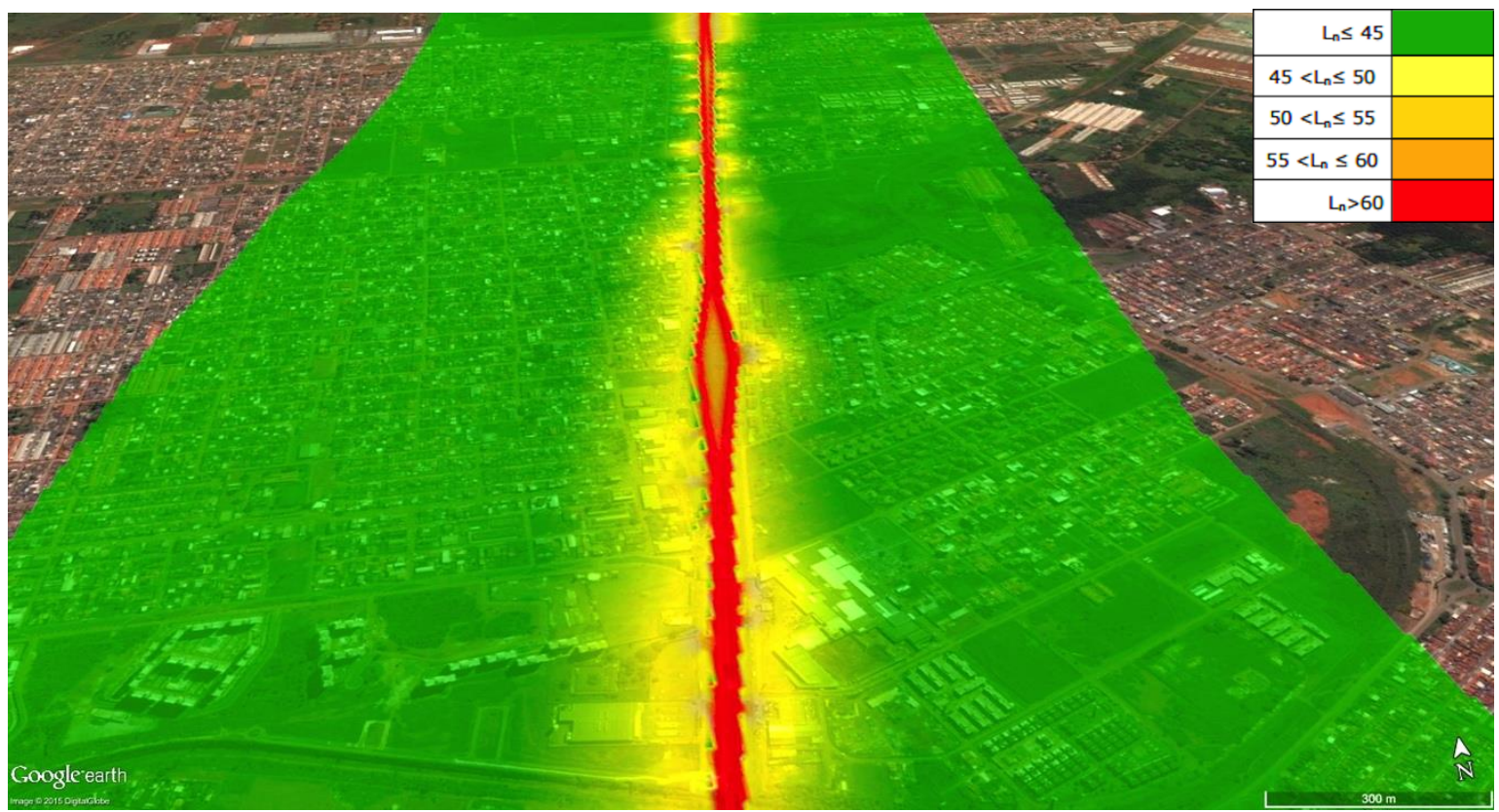

Figura 4.15 - Representação dos NPS por classes para o cenário $\left(\boldsymbol{L}_{\boldsymbol{n}}\right)$ atual após a implantação de uma barreira acústica nas proximidades da rodovia. 
A figura anterior apresenta os mapas de ruído para o cenário atual e com a implantação de barreira acústica ao logo de áreas habitadas na região de estudo, nos termos do parâmetro $L_{n}$. Nota-se que houve uma redução nos níveis de pressão sonora aos quais a população está exposta. Os valores para essa redução, bem como o número de pessoas com distúrbios no sono podem ser visualizados no Quadro 4.14.

Quadro 4.14 - Número de pessoas expostas e número estimado de pessoas com distúrbios no sono.

\begin{tabular}{c|c|c|c|c|c|c}
\hline \multirow{2}{*}{$L_{n}[\mathrm{dBA}]$} & \multicolumn{3}{|c|}{} & \multicolumn{3}{c}{$\begin{array}{c}\text { Implantação de barreira } \\
\text { acústica ao longo da via de } \\
\text { estudo }\end{array}$} \\
\cline { 2 - 8 } & $\begin{array}{c}\text { PoP. } \\
\text { Exp. }\end{array}$ & PDS & PSAP & $\begin{array}{c}\text { PoP. } \\
\text { Exp. }\end{array}$ & PDS & PSAP \\
\hline$L_{n} \leq 45$ & 2780 & 488 & 219 & 60 & 11 & 5 \\
\hline $45<L_{n} \leq 50$ & 1855 & 425 & 207 & 0 & 0 & 0 \\
\hline $50<L_{n} \leq 55$ & 260 & 76 & 39 & 0 & 0 & 0 \\
\hline $55<L_{n} \leq 60$ & 53 & 0 & 0 & 0 & 0 & 0 \\
\hline $60<L_{n} \leq 65$ & 0 & 0 & 0 & 0 & 0 & 0 \\
\hline$L_{n}>65$ & 0 & 0 & 0 & 0 & 0 & 0 \\
\hline
\end{tabular}

O Quadro anterior apresenta o número estimado de pessoas com distúrbios no sono (PDS) e o número estimado de pessoas com o sono altamente perturbado (PSAP) por causa dos níveis de pressão sonora do tráfego veicular.

No que diz respeito ao indicador $L_{n}$, a legislação Europeia limita em $55 \mathrm{~dB}$ os valores máximos para áreas mistas. Em contrapartida, a norma NBR 10151 limita a 50 dB para áreas mistas, predominante residenciais. Dessa forma, com respeito aos cenários simulados no Quadro 4.14 é possível visualizar que as classes de ruído para o cenário atual chegam a ter valores para o $L_{n}$ de até $60 \mathrm{~dB}$ atingindo regiões às margens da rodovia. Logo, pode-se estimar que para uma faixa de intervalo de valores maiores que $45 \mathrm{~dB}$ até valores iguais a 55 dB há aproximadamente 501 pessoas com distúrbio no sono e aproximadamente 246 pessoas com o sono altamente perturbado, para o parâmetro $L_{n}$.

No que concerne ao incômodo no sono para o cenário simulado de uma barreira acústica, ao longo das áreas habitadas da rodovia, observa-se, por meio do Quadro 4.14, que praticamente não houve incômodos sentidos pela população por causa do ruído. 


\section{CONCLUSÕES E SUGESTÕES PARA TRABALHOS FUTUROS}

Com base nos resultados apresentados, pode-se concluir que os níveis de pressão sonora estão diretamente ligados à velocidade do fluxo de tráfego. Por meio desta constatação, é possível trabalhar com medidas mitigadoras dos elevados níveis de ruídos como o gerenciamento do tráfego focado no controle e na redução da velocidade média em rodovias com características urbanas.

O modelo utilizado para realizar as simulações foi calibrado para a região de estudo e os resultados permitiram avaliar questões de fluidez em rodovias com características urbanas. Sobre isso, é preciso considerar que, com a redução de $20 \%$ na frota veicular, houve um pequeno aumento nos níveis de pressão sonora para alguns pontos. Entretanto, para uma possível implantação de um transporte de massa, não haverá alterações significativas no clima acústico da região decorrentes da redução na frota veicular atual em 20 e 50\%.

Os resultados confirmam parcialmente a hipótese deste trabalho, que possuía a premissa de que, com a implantação de um transporte de massa, os níveis de pressão sonora tenderiam a aumentar em termos de uma maior fluidez na via, ou seja, com o aumento da velocidade do fluxo de tráfego, os níveis de pressão sonora tenderiam a ser maiores.

Por meio das simulações e da geração de mapas para o cenário futuro, pode-se constatar que, em cenários de 20 e $50 \%$ de redução na frota veicular, houve uma pequena redução nos indicadores de ruído, ou seja, ocorreu redução na faixa de ruído para os intervalos de 60 a $65 \mathrm{~dB}$ e, consequentemente, aumento na faixa de $50 \mathrm{~dB}$. Para as outras faixas, não foram verificadas mudanças significativas.

Pôde-se ainda, por meio deste estudo, estimar o número de pessoas incomodadas e altamente incomodadas por faixa de ruído para os parâmetros $L_{d e n}$. Ele demonstrou que hoje tem-se uma estimativa de aproximadamente 1.793 pessoas dentro da faixa de incomodadas. Para a faixa de pessoas altamente incomodadas não foi percebido casos que ultrapassassem os limites vigentes, com base a na diretiva da Comunidade Europeia (2002). Ao reduzir esses valores em 20 e 50\% para cenários futuros, não houve alteração significativa no número de pessoas incomodadas e altamente incomodadas em comparação ao cenário atual. 
Entretanto, a região de estudo se mostra com valores acima dos estabelecidos pelas normas vigentes, o que ocorre também para outras importantes rodovias com características urbanas. Por essa razão, sugere-se, neste trabalho, um modo de mitigação, que corresponde à implantação de barreiras acústicas.

A respeito das simulações realizadas, com a implantação de barreira acústica ao longo da área de estudo, elas se mostram como uma alterativa eficaz na atenuação do ruído advindo do tráfego veicular, deixando os valores aos quais os receptores estão expostos a níveis aceitáveis, dentro das normas vigentes, e, ainda, trazendo maior conforto à população e evitando, assim, danos à saúde e, sobretudo, melhorando a qualidade de vida das pessoas que vivem em regiões com essas características.

\section{1 - TRABALHOS FUTUROS}

Para uma abordagem mais especifica, sugere-se dar continuidade a este trabalho por meio da análise de edificações e faixadas de comércios e residências presentes na região. Propõe-se, também, a realização de pesquisa em outras regiões com intuito de generalizar o estudo para diferentes situações.

Um complemento interessante seria calcular o mapa de conformidade, que irá mostrar as regiões em que os NPS estão acima da Lei de uma forma visual.

Estudos que analisem a relação entre o ruído e as condições de fluidez na via, e que demonstrem os níveis de pressão sonora para diferentes condições de fluidez em rodovias com características urbanas devem ser continuados. Após a verificação da influência da velocidade nos NPS, deve-se desenvolver estudo a fim de contemplar as premissas de gerenciamento da mobilidade, e também realizar análises em diversas configurações de pavimento, com objetivo de verificar como aumentar a velocidade do fluxo de tráfego sem necessariamente aumentar os níveis de pressão sonora.

Entre outras pesquisas adicionais que precisam ser feitas, sugere-se a simulação de diferentes configurações/implantação de uma divisão modal que apresente condições operacionais do fluxo de tráfego para se ter parâmetros significativos na tomada de decisão e no controle dos níveis de ruído. 
Por fim, faz-se necessário estudos que avaliem a percepção do ruído sentido por moradores, por meio de modelos dose-resposta em áreas lindeiras, como é o caso de rodovias com características urbanas. 


\section{REFERÊNCIAS}

ABNT. NBR (2000) - 10.151: Acústica - Avaliação de ruído em áreas habitadas, visando o conforto da comunidade - procedimento. Associação Brasileira de Normas Técnicas, Rio de Janeiro.

Affonso, N. S.; Brito, J. M.; Granado, C. (2009) Mobilidade urbana e inclusão social. In: fórum nacional de reforma urbana - FNRU. Movimento nacional pelo direito ao transporte público de qualidade para todos - MDT. Brasília, DF.

Agência Portuguesa do Ambiente (2011) Diretrizes para elaboração de mapas de ruído. Versão 3. Amadora, Portugal.

Albuquerque, F. S.; Núñez, W. P. (2011) Development of Rough- ness Prediction Models for Low-Volume Road Networks in Northeast Brazil. Transportation Research Record, v. 2205, p. 198-205. DOI: $10.3141 / 2205-25$.

Ali S. A. (2004) Investigation of the dose-response relationship for road traffic noise in Assiut, Egypt. Appl. Acoustics; 65(11): 1113-1120.

Ali, S. A. e Tamura, A. (2003) Road traffic noise levels. Restrictions and annoyance in greater Cario, Egypt. Applied Acoustics 64(8): 815-823.

Álvares, P. A. S. e Souza, F. P. (1992) A poluição sonora em belo horizonte. Acústica e vibrações, florianópolis, n. 10, p. 23-42, fev. 1992.

Ansay, S. S (2013) Estudo da Poluição Sonora Através do Mapa de Ruído na Implantação do Novo Campus Universitário da Universidade Tecnológica Federal Do Paraná - UTFPR. Dissertação de Mestrado UFPR. Curitiba.

Avsar,Y. e Gonullu, M. T. (2005) Determination of safe distance between roadway and school buildings to get acceptable school outdoor noise level by using noise barriers. Building and Environment, Oxford, v. 40 , p. $1255-1260$.

Babisch, W (2003). Stress hormones in the research on cardiovascular effects of noise. Noise Health, v. 5, p. $1-11$.

Barretto, D. M. e Freitas, I. M. D. P. (2008) Importância de mapas de ruído na análise do planejamento dos transportes, Anais do XXII Encontro da Sociedade Brasileira de Acústica, Belo Horizonte, 26-29.

Barretto, D. M. (2007) Impacto sonoro da implantação do metrô de Salvador em edificações adjacentes, considerando os reflexos na saúde. 2007. 65 f. Dissertação (Mestrado em Engenharia Ambiental Urbana) - Escola Politécnica - Universidade Federal da Bahia UFBA, Salvador.

Basner, M.; Babisch, W.; Davis, A.; Brink, M.; Clark, C.; Janssen, S.; Stansfeld, S. (2014) Auditory and non-auditory effects of noise on health Volume 383, No. 9925, p1325-1332, 12 April 2014

Belojevic, g.; Jacovlevic, B; Alesksc, O. (1997) Subjective reaction for traffic noise with regard to some personality traits. Environmental international, yugoslavia, v. 23, n. 2, p. 221-226.

Bendtsen, H. (2009). Highway noise abatement Planning tools and Danish examples Road Directorate. Copenhague: $60 \mathrm{p}$.

Bento Coelho, J. L. (2007). "Community Noise Ordinances”, em Handbook of Noise and Vibration Control, Ed. Malcolm J. Crocker, John Wiley \& Sons, New York. 
Bento Coelho, J. L. e Alarcão, D. (2004) Cartografia de Ruído em Grandes Cidades, Acústica 2004, Guimarães, Portugal.

Beranek, 1. L. (1993) Acoustical measurements. 3 ed. Massachusetts: acoustical society of America and American institute of physics, $855 \mathrm{p}$.

Berglund B.; Lindvall, T.; Schwela DH. eds. 1999. Guidelines for Community Noise. London: World Health Organization

Bies, D. A. e Hansen, C. H. (2002) Engineering noise control: theory and practice. 2 ed. New york: sponpress - taylor \& francis group, 736 p., 2002.

Bistafa, S.R (2007) Acústica aplicada ao controle de ruído Ed. Edgard Blucher, São Paulo.

Bortoli, P. S. (2002). Análise da Poluição Sonora Urbana em Zoneamentos Distintos da Cidade de Curitiba . Curitiba, Paraná: Dissertação de Mestrado, Programa de Pós-Graduação em Tecnologia, CEFET-PR.

Bragança, L., Freitas, E.F., Pinheiro, D.d.S. (2006). Eficácia de barreiras acústicas, Tecniacústica. $37^{\circ}$ Congresso Nacional de Acústica, Gandia, Valência, Espanha.

Brüel e Kjaer (2001) Environmental noise. Sound \& Vibration Measurement A/S, Nærum, Denmark.

Calixto, A. (2002) O ruido gerado pelo tráfego de veículos em "rodovias-grandes avenidas" situadas dentro do perímetro urbano de Curitiba, analisado sob parâmetros acústicos objetivos e seu impacto ambiental. 122p. Dissertação de Mestrado. Universidade Federal do Paraná. - Setor de Tecnologia.

Callai, S. C. (2011) Estudo do ruído causado pelo tráfego de veículos em rodovias com diferentes tipos de revestimentos de pavimentos. Dissertação de Mestrado, 93 p. São Paulo: Faculdade de Engenharia Civil, Universidade Federal de São Paulo.

Can, A., Leclercq, L. and Lelong, J. (2008) Dynamic estimation of urban traffic noise: influence of traffic and noise source representations. Applied Acoustics, Volume 69, Issue 10, p.858-867.

Carey, j. H. (1996) Environmental noise monitoring; what to measure? In: simpósio brasileiro de metrologia em acústica e vibrações, 1.; encontro da sociedade brasileira de acústica, 17., 1996, petrópolis. Anais... Petrópolis: sobrac, 1996. P. 207-210.

Carmo, L. I. C. (1999) Efeitos do ruído ambiental no organismo humano e suas manifestações auditivas. Monografia de conclusão do curso de Especialização em Audiologia Clínica. CEFAC - Centro de Especialização em Fonoaudiologia Clínica - Audiologia. Goiânia - GO.

CODEPLAN, (2003) Companhia de Desenvolvimento do Planalto Central, Disponível em: www.codeplan.df.gov.br. Access em: 17/09/2014.

COMISSION OF THE EUROPEAN COMMUNITIES (1996). Future Noise Policy - European Commission - Green Paper. Commission of the European Communities. Brussels.

CONAMA - Conselho Nacional do Meio Ambiente. (1990) Resolução No 001/1990 - "Dispõe sobre critérios e padrões de emissão de ruídos, das atividades industriais" - Data da legislação: 08/03/1990 Publicação DOU, pág. 6408. Brasília - DF.

Costa, C. A. Previsão dos Ruídos Ambientais no Setor Noroeste - DF. 2011.95f. Mestrado em Planejamento e Gestão Ambiental, Universidade Católica. Brasília-DF.

De Coensel, B.; De Muer, T.; Yperman, I.; Botteldoren, D.(2005) The influence of traffic flow dynamics on urban soundscape. Applied Acoustics, 66: p. 175-194.

Diniz, F. B. e Zannin P. H. T. (2002) Environmental noise pollution in the city of Curitiba, Brazil, 2002. Applied Acoustics 2002; 63: 351-358. 
Dintrans, A; Préndez, M. (2013) A method of assessing measures to reduce road traffic: a case study in Santiago, Chile. Applied Acoustics, v.74, n. 12, p. 1486-1491, dez. 2013. http://dx.doi.org/10.1016/j.apacoust.2013.06.012.

Directive 2002/49/CE (2002) Directive 2002/49/CE of the european parliament and of the council of 25 june 2002 relating to the assessment and management of environment noise. In: Official journal of the european communities. Disponível em: http://eur-lex.europa.eu/legalcontent/EN/TXT/?uri=CELEX:32002L0049. Acesso em: 04 de dezembro de 2014.

DISTRITO FEDERAL (2008) Lei Distrital $N^{o}$ 4.092. DODF de 01.02.2008 - republicação DODF de 12.03.2008. Dispõe sobre o controle da poluição sonora e os limites máximos de intensidade da emissão de sons e ruídos resultantes de atividades urbanas e rurais no Distrito Federal. Brasília: Câmara Distrital.

Ferreira, M. S. (2008) Planilha de recomendações para projetos que visem o conforto acústico em edificações marginais as vias de tráfego. 2008. Projeto de pesquisa (Mestrado em Arquitetura e Urbanismo) Faculdade de Arquitetura - Universidade Federal da Bahia UFBA, Salvador.

FHWA (1996). Lee, C S.Y. e Fleming, Gregg G. Measurement of highway related noise. U.S. Department of Transportation U.S. Department of Transportation. Washington, D.C.

FHWA (2003). Surrogate Safety Measures from Traffic Simulation Models. U.S. Department of transportation Federal Highway Administration. Final Report No. FHWA-RD-03-050. Eds. D. Gettman, L. Head (Tuscon, AZ: Siemens Gardner Transportation Systems/FHWA). Transportation Research Record: Journal of the Transportation Research Board. Vol. 1840.

FHWA (2008). Surrogate Safety Assessment Model and Validation. Final Report No. FHWA- HRT-08-051. Eds. Gettman, L. Pu, T. Sayed, S. Shelby, (Tuscon, AZ: Siemens Energy \& Automation, Inc./FHWA). Georgetown Pike. McLean, VA.

Fonseca, R., Inácio, O., Freitas, E.F., Bragança, L. (2008). Determinação do desempenho acústico de dispositivos de redução de ruído do tráfego rodoviário, Acústica 2008, Coimbra, Portugal.

Freitas, E. F e Trabulo, L. (2007) Desempenho de Barreiras Acústicas - dois métodos de avaliação. Universidade do Minho, Departamento de Engenharia Civil. Guimarães, Portugal.

Freitas, E. F. (2008) Desempenho de Barreiras Acústicas - dois métodos de avaliação. Universidade do Minho, Departamento de Engenharia Civil Azurém. Guimarães - Portugal.

Garavelli, S. L; Moraes, A. C. M; Nascimento, J. R. R; Nascimento, P. H. D. P; Maroja, A. M. (2010) Mapa de ruído como ferramenta de gestão da poluição sonora: estudo de caso de Águas Claras - DF. In: $4^{\circ}$ Congresso Luso - Brasileiro para o Planeamento Urbano, Regional, Integrado, Sustentável, Faro, 2010. Anais. Faro: 2010.2 Disponível em: http://pluris2010.civil.uminho.pt/Actas/PDF/Paper377.pdf. Acesso em: 30 de outubro de 2014.

Garavelli, S. L.; Maroja, A. M.; Costa, C. A.; Carvalho Jr., E. B.; Melo, W. C.; Silva, E. F. F. (2013): Mapa de Ruído de Brasília. Relatório Técnico. IBRAN/UNESCO, Brasil.

Gerges, S. N. Y. (2000) Ruído - Fundamentos e Controles. 2 ed. Florianópolis: Universidade Federal de Santa Catarina.

Gonçalves, J (2006) Contribuição à análise quantitativa das potencialidades do trem de passageiros em integrar a estrutura urbana. Tese de Doutorado. PET-COPPE/UFRJ. 
Governo do Distrito Federal - (GDF) - Plano Diretor de Transporte Público, 2010. Disponível em: http://www.semob.df.gov.br/programas-projetos/pdtu.html. Acesso em: 21 de novembro de 2014.

Guedes, Í. C. M. (2005). Influência da forma urbana em ambiente sonoro: um estudo no bairro Jardins em Aracaju (SE). Dissertação (Mestrado) - Universidade Estadual de Campinas- Unicamp, Faculdade de Engenharia Civil, Arquitetura e Urbanismo. Campinas, São Paulo.

Hanson, D. I.; Donavon, P. .; James, R. (2005) tire/pavement noise characteristics for hma pavements. Journal of the association of asphalt paving technologistics, v.74, p.1-38.

HARMONOISE (2004) - HAR22TR-031027-MP02- Coefficients and data version 2, M+P-report prepared for Harmonoise.

HARMONOISE 2005. Disponível em: http://www.imagine-project.org/. Acesso em: 13 de maio 2014.

Harris, C. (1979) Handbook of Noise Control, McGraw-Hill. New York.

Harris, C. M. (1998) Handbook of Acoustical Measurements and Noise Control. 3 ed. New York: McGrawHill.

Házyová, L., et al. (2010) Inserção de barreiras acústicas na paisagem portuguesa. $4^{a}$ Conferência Nacional de Avaliação de Impactes, Portugal.

Hidalgo, D. e Gutiérrez, L. (2012). BRT and BHLS around the world: Explosive growth, large positive impacts and many issues outstanding. In: Research in Transportation Economics. Disponível em: www.elsevier.com. Acesso em: 12 de fevereiro de 2015.

IA (2004). Instituto do ambiente. O ruído e a cidade, traduzido e adaptado de: Le Bruit et al. Ville (1978) Ministère de l'Équipement et de l'Aménagement du Territoire Paris.

IBGE (2010), http://www.ibge.gov.br/estadosat/, acesso em 01/03/2015.

IMAGINE (2004) Review of the suitability of traffic models for noise modelling - WP2 : demand and traffic flow modelling. 2004b: Project funded by the CE under the sixth framework programmme. $132 \mathrm{p}$.

INTERNATIONAL ORGANIZATION FOR STANDARDIZATION. ISO 1996/1: Acoustics: Description and measurements of environmental noise. Part 1: Basic quantities and procedures, 1996/1. Suiça, 1982. 5 p.

INTERNATIONAL ORGANIZATION FOR STANDARDIZATION. ISO 1996/2: Acoustics: Description and measurements of environmental noise. Part 2: Acquisition of data pertinent to land use, 1996/2. Suiça, 1987. 7p.

Jesus, A. D. S; Maroja, A. M.; Garavelli, S. L. (2013) Alterações no clima acústico provocadas pela implantação da linha verde no Distrito Federal. In: XXVII ANPET Congresso de Pesquisa e Ensino em Transportes, 2013, Belém - PA. Anais do XXVII ANPET Congresso de Pesquisa e Ensino em Transportes.

Kang, J. (2007) Towards Science and Practice of Soundscape: COST ActionTD 0804 - Sondscape of European Cities and Landscapes. Forum Acusticum 2011. Aalborg, Dinamarca:

Kephalopoulos, S. Paviotti, M. Anfosso-Lédée, F. - Common Noise Assessment Methods in Europe (CNOSSOS-EU). EU Publications Office, 2012

Kim, M C.; Seong, J. C.; Holt, J. B.; Park, T. H.; Ko, J. H.; Croft, J. B. (2012) Road Traffic Noise Annoyance, Sleep Disturbance, and Public Health Implications. Am J Prev Med 2012; 43(4):353-360. 
KINSLER, L. E.; FREY, A.R.; COPPENS A.B.; SANDERS J.V. Fundamentals of Acoustic, 3 ed., USA, 1982.

Kuby, M.; Barranda, A.; Upehurch, C. (2004) Factors influencing light-rail station boardings in the United States. Transportation Research Part A. 38 (3) p. 223-247.

Leclercq, L. e Lelong J. (2001) Dynamic evaluation of urban traffic noise. in Adriano Alippi, Proceedings of the 17th International congress on Acoustics. Roma.

Mamede, D. A. e C. J. P. Alves (2009) Estudo sobre a acessibilidade de aeroportos no Brasil. Anais do $15^{\circ}$ Encontro de Iniciação Científica e Pós-Graduação do ITA - XV ENCITA / 2009. Instituto Tecnológico de Aeronáutica, São José dos Campos, SP, Brasil, Outubro, 19 a 22.

Mendonça, C, (2012) Transporte rodoviário: Por que o Brasil depende tanto desse sistema? Rio de Janeiro. Disponível em: http://educacao.uol.com.br/geografia/transporte-rodoviario-por-que-o-brasil-dependetanto-desse-sistema.jhtm.Acesso em 28 de maio de 2012.

Miedema H.M.E, (2001) Noise and Health: How does noise affect us? Proceedings of Inter-Noise 2001, Haia: Holanda.

Miedema, (2003) Noise sensitivity and reactions to noise and other environmental conditions. Journal of the Acoustical Society of America, v. 3, (113), p. 1.492-1.504, March, 2003.

Miedema, H. M. E e Oudshoorn, C. G (2001) Annoyance from transportation noise: relationships with exposure metrics DNL and DENL and their confidence intervals. Environmental Health Perspectives. v. 109, n. 4 , p. $409-416$.

Miedema, H.M.E e Vos, H. (1998). Exposure-response relationships for transportation noise. Journal of the Acoustical Society of America. v. 104, n. 6, p. $3432-3445$.

Miedema, H.M.E, Passchier-Vermeer W. e Vos, H. (2003). Elements for a position paper on night-time transportation noise and sleep disturbance. TNO Inro, Delft, 2002-59.

Miedema, H.M.E., \& Vos, H. (1998). Exposure-response relationships for transportation noise. Journal of the Acoustical Society of America, 104 (6), 3432-3445.

Miedema, H.M.E., e Oudshoorn, C.G.M. (2001) Annoyance from Transportation Noise: Relationships with Exposure Metrics DNL and DENL and Their Confidence Intervals Environmental, Health Perspectives, v. 109 (4), April, 2001.

Morais, L. R. (2008), Estudo das Barreiras Acústicas no Controle de Ruído Aeroportuário. Tese de Doutorado. Universidade Federal do Rio de Janeiro. COPPE - UFRJ. Rio de Janeiro.

Mota, D. R; Takano, M. S. M.; Taco, P. W. G. (2014) Método de localização de estações ferroviárias urbanas com a técnica do diagrama de Voronoi: uma aplicação ao eixo sul de Brasília-Brasil. Anais do XVIII Congreso Panamericano de Ingeniería de Tránsito, Transporte y Logística (PANAM 2014).

Murgel, E. (1999) Acústica rodoviária - fundamentos e medidas de controle. Revista Infraestrutura, São Paulo, n. 2.

Murgel, E. (2007) Fundamentos de acústica ambiental. 1. ed. Editora Senac. São Paulo.

Murphy, E. e King, E. A. (2011) Scenario Analysis and Noise Action Planning: modelling the impact of mitigation measures on population exposure. Applied Acoustics, v.72, p. 487-494.

Neto, M. de. F. (2002) Estudo de Barreiras Acústicas ao Ar Livre, sob a Perspectiva de Eficiência e Qualidade Sonora. Tese de Mestrado. Universidade Estadual de Campinas.

Parlamento Europeu (2002). Directiva 2002/49/CE. [S.l.]: [s.n.]. Relativa à avaliação e gestão do ruído 
ambiente - Declaração da Comissão no Comité de Conciliação da directiva relativa à avaliação e gestão do ruído ambiente. Disponível em: http://eur-lex.europa.eu/legalcontent/PT/TXT/?uri=CELEX:32002L0049. Acesso em: 13 de fevereiro de 2015.

PDTU. (2011). Plano Diretor de Transporte Urbano e Mobilidade do Distrito Federal e Entorno. Secretaria de Estado de Transportes, Altran-TCBR, Brasília.

Project Cnossos-EU (2012) disponível em: https://ec.europa.eu/jrc/sites/default/files/cnossoseu\%2520jrc\%2520reference\%2520report_final_on\%2520line\%2520version_10\%2520august\%25202 012.pdf. Acesso em: 10 de abril 2014

Project SILVIA (2006) Disponível em:

ftp://ftp.mecanica.ufu.br/LIVRE/Ricardo/Ac\%FAstica/normas\%20e\%20artigos/Artigos/In\%20situ/SILVIATRL-007-06-WP2-010405.PDF. Acesso em: 18 de junho 2014.

Quartieri, J.; Mastorakis, N. E.; Iannone, G.; Guarnaccia, C.; d'Ambrosio, S.; Troisi, A.; Lenza; Tll. (2009) A Review of Traffic Noise Predictive Models. In: Proceedings of the 5th WSEAS Int. Conf. on "Applied and Theoretical Mechanics" (MECHANICS'09), Puerto De La Cruz, Canary Islands, Spain, December 14-16.

Raia, G. B.; Medeiros, P. B.; Nishimori, F. T. I.; Raia Junior, A. A. (2010) Dilema na Sustentabilidade Urbana: a Disposição da População em Migrar do Transporte Individual para o Coletivo. Fórum Ambiental da Alta Paulista. São Paulo.

Ramalingeswara R. P. e Seshagiri R. M. G. (1992) Community reaction to road traffic noise. Applied acoustics, indian, v. 37, p. 51 - 60.

Ramis, A. J.; Garcia, D.; Hernandez, F. (2003) Noise effects of reducing traffic flow through a Spanish city. Applied Acoustics 64(3): 343-364.

Rasmussen, R. O.; Bernhard, R. J.; Sandberg, U.; Mun, E. P. (2007) The Little Book of Quieter Pavements. Federal Highway Administration Office of Pavement Technology, HIPT-11200 New Jersey Avenue, SE Washington, DC 20590. July.

Recomendação da Comissão 2003/613/CE (Orientações sobre os métodos de cálculo provisórios).

Recomendações para a Selecção de Métodos de Cálculo a Utilizar na Previsão de Níveis Sonoros (2011) Instituto do Ambiente, Setembro.

Robinson, d. W. (1971) Towards a unified system of noise assessment. Journal of sound and vibration, uk, versão r14, p. 179-298.

Rodrigues e Araújo. (2012). Comparação entre Ferramentas Específicas dos Softwares de Microssimulação AIMSUN e SYNCHRO/SIMTRAFFIC na Construção de Pequenas Redes. X Rio de Transportes, Agosto 2012, Rio de Janeiro.

Rodrigues, F. (2006) Análise de Ruido em Terminais de Transporte Coletivo Urbano: Desenvolvimento de Modelos de Previsão, Dissertação de Mestrado, 136 p. Uberlândia: Faculdade de Engenharia Civil, Universidade Federal de Uberlândia.

Rodrigues, F. (2010) Metodologia para Investigação de Relação entre Ruído de Tráfego e Condições Operacionais do Fluxo em Centros Urbanos. UFRJ/COPPE, Rio de Janeiro.

Rossing, T. D. (2007) Springer handbook of acoustics. New York, N.Y. ;: Springer.

Sandberg, U. e Ejsmont, J. (2002) Tyre/Road Noise Reference Book. INFORMEX Ejsmont Sandberg 
Handelsbolag, Kisa, Swe- den.

Sandberg, U. (2003) Vehicle Categories for Description of Noise Sources. Draft for Final Technical Report. Document identity: HAR11TR-030108-VTI04 (vehicle categories).

Schultz, T. J. (1978) Synthesis of social surveys on noise annoyance. In: Journal of Acoustical Society of America, v. 64, pp. 377-405.

Secretaria de Estado de Transportes do Distrito Federal (2010). Plano Diretor de Transporte Urbano do Distrito Federal e Entorno. Disponível em: http://www.st.df.gov.br/programas-projetos/pdtu.html. Acesso em 03 de Novembro de 2014.

SILVA, A. M. C. Mapa de ruído do bairro "Vila Universitária” Bauru, Brasil - Situação de pico. 2010. Dissertação de Mestrado - Universidade do Minho, Braga, 2010.

Silva, J. R. A. (2009). Caracterização do Ruído Emitido por Veículos Rodoviários num Troço da EN109 em Vagos. Universidade de Aveiro. Departamento de Engenharia Civil. Portugal.

Simonetti, h (2010) Estudo de impactos ambientais gerados pelas rodovias: sistematização do processo de elaboração de eia/rima, dissertação de mestrado, porto alegre: faculdade de engenharia civil, universidade federal do rio grande do sul.

Singal, S. P. (2005) Noise pollution and control strategy. Alpha Science International. Oxford.

Souza, J. L. S. de (2003) RS-122 em Bom Princípio: duplicação ou contorno? Um estudo sobre os impactos sócio-econômicos ambientais da instalação de contorno rodoviário urbano ou duplicação da rodovia existente. Dissertação de Mestrado. Universidade Federal do Rio Grande do Sul. Instituto de Geociências. Programa de Pós-Graduação em Geografia. Porto Alegre - RS.

Souza, R. B. E. (2010) O som nosso de cada dia: uma análise do comportamento da acústica urbana a partir de modificações na forma urbana. 2010. 141f. Dissertação (Mestrado em Desenvolvimento Urbano) Programa de Pós-Graduação em Desenvolvimento Urbano, Universidade Federal de Pernambuco Recife.

Sudeco (2012) autoriza início dos estudos do trem Brasília-Luziânia. Disponível em: http://www.brasil.gov.br/infraestrutura/2014/01/sudeco-autoriza-inicio-dos-estudos-do-trem-brasilialuziania.Portal Brasil. Acesso em: 21 de abril de 2014.

Tarrio, F. R. (1992) Ruido: medidas correctoras: experiencias. In: simposio nacional sobre carreteras y medio ambiente, 2., 1992, las palmas de gran canaria, madrid. Anais... Madrid: asociacion tecnica de carreteras, 1993. P. 97- 109.

IA (2002) Técnicas de Prevenção e Controlo de Ruído”, Instituto do Ambiente, Outubro.

Van Kempen, E.E.M.M., H. Kruize, H.C. Boshuizen, C.B. Ameling, B.A.M. Staatsen, A.E.M. de Hollander (2002). The association between noise exposure and blood pressure and ischemic heart diseases: a meta-analysis. Environmental Health Perspectives.

Villela, m. de m. (2004) Contribuição metodológica para estudos de localização de estação intermodal em transporte público coletivo. Dissertação de Mestrado Universidade Federal do Rio de Janeiro COPPE.

Voltolini, L (2011). Trechos urbanos de rodovias. Disponível em: http://infraestruturaurbana.pini.com.br/solucoes-tecnicas/8/trechos-urbanos-de-rodovias-avanco-damancha-urbana-em-239368-1.aspx. Acesso em: 12 de dezembro de 2014. 
Watts G. (2005). Harmonoise prediction model for road traffic noise. TRL Report PPR 034, Department for Transport Roads Policy Division, England; p. 81.

WG-AEN, Working Group Assessment of Exposure to Noise. Good practice guide for strategic noise mapping and production of associated data on noise exposure, version 2, 2006. Disponível em: http://ec.europa.eu/environment/noise/pdf/wg_aen.pdf. Acesso em: 19 de janeiro de 2015.

WG3. Working Group 3 (eds.). Computational and Measurement. Progress Report. 2001.

WHO (2003) World Health Organization. Protection of the Human Environment. Assessing the environmental burden of disease at national and local levels: introduction and methods. Geneva.

WHO (2011) World Health Organization. Burden of disease from environmental noise: Quantification of healthy life years lost in Europe. W.H.O. Regional Office for Europe: Dinamarca.

Wismans, L. J. J., E.C. Van Berkum (2000) Network impact of dynamic traffic management measures. Bookchapter (ed. M.F.A.M. van Maarseveen) The African touch of transportation engineering \& Management, Part 2: Road traffic information and control, pp. 111-120, (ISBN 90-365-1474-6), Civil Engineering, University of Twente, Enschede, The Netherlands.

Zannin, P. H. T. ; Ferreira, A. M. C.; Ferreira, J. A. C. (2007) Avaliação de poluição sonora na cidade de Fortaleza. 


\section{Apêndice 1}

Tráfego médio horário distribuído em leves e pesados.

\begin{tabular}{|c|c|c|c|c|c|c|c|c|}
\hline \multirow{2}{*}{$\begin{array}{c}\text { Nome } \\
\text { Radares }\end{array}$} & \multicolumn{2}{|c|}{ Diurno } & \multicolumn{2}{|c|}{ Entardecer } & \multicolumn{2}{|c|}{ Noite } & \multirow{2}{*}{$\begin{array}{l}\text { Veloc. } \\
\text { Via }\end{array}$} & \multirow{2}{*}{ Sentido } \\
\hline & $\begin{array}{l}\text { Global } \\
\text { Diurno }\end{array}$ & $\begin{array}{c}\% \\
\text { Pesados }\end{array}$ & $\begin{array}{c}\text { Global } \\
\text { Entardecer }\end{array}$ & $\begin{array}{c}\% \\
\text { Pesados }\end{array}$ & $\begin{array}{c}\text { Global } \\
\text { Noite }\end{array}$ & $\begin{array}{c}\% \\
\text { Pesados }\end{array}$ & & \\
\hline \multicolumn{9}{|c|}{ Sentido Brasília - Luziânia } \\
\hline Rad $1-$ DF & 1706 & 7,5 & 2365 & 4,1 & 473 & 6,7 & 60 & $\mathrm{DF} / \mathrm{GO}$ \\
\hline Rad 3-DF & 2101 & 6,3 & 2470 & 4,2 & 461 & 7,1 & 60 & $\mathrm{DF} / \mathrm{GO}$ \\
\hline Radar 1 - GO & 2377 & 6,7 & 2281 & 5,1 & 499 & 8,3 & 40 & $\mathrm{DF} / \mathrm{GO}$ \\
\hline Radar 3-GO & 2318 & 6,5 & 2253 & 4,9 & 723 & 7,6 & 60 & $\mathrm{GO} / \mathrm{DF}$ \\
\hline Radar 7-GO & 2177 & 5,4 & 2223 & 4,1 & 417 & 7,6 & 60 & $\mathrm{DF} / \mathrm{GO}$ \\
\hline Radar 10 - GO & 2026 & 6,8 & 2125 & 5,2 & 377 & 9,2 & 60 & $\mathrm{GO} / \mathrm{DF}$ \\
\hline Radar 12 - GO & 1167 & 5,0 & 618 & 2,1 & 442 & 2,5 & 40 & $\mathrm{GO} / \mathrm{DF}$ \\
\hline Radar 13 - GO & 1577 & 8,5 & 1354 & 7,3 & 290 & 10,6 & 40 & $\mathrm{GO} / \mathrm{DF}$ \\
\hline Radar 15 - GO & 1402 & 9,6 & 1283 & 8,1 & 261 & 14,7 & 60 & $\mathrm{DF} / \mathrm{GO}$ \\
\hline \multicolumn{9}{|c|}{ Sentido Luziânia - Brasília } \\
\hline Rad 2-DF & 1146 & 1,7 & 592 & 1,8 & 465 & 3,1 & 60 & $\mathrm{GO} / \mathrm{DF}$ \\
\hline Radar 2-GO & 1240 & 1,5 & 648 & 1,7 & 445 & 1,7 & 40 & $\mathrm{DF} / \mathrm{GO}$ \\
\hline Radar 4-GO & 2300 & 6,0 & 1344 & 5,6 & 925 & 8,0 & 40 & $\mathrm{GO} / \mathrm{DF}$ \\
\hline Radar 8- GO & 2241 & 6,7 & 1421 & 5,7 & 840 & 9,3 & 60 & $\mathrm{GO} / \mathrm{DF}$ \\
\hline Radar 9- GO & 1288 & 4,2 & 659 & 1,8 & 451 & 2,4 & 40 & $\mathrm{GO} / \mathrm{DF}$ \\
\hline Radar 11 - GO & 1241 & 8,1 & 1217 & 6,6 & 561 & 4,7 & 60 & $\mathrm{GO} / \mathrm{DF}$ \\
\hline Radar 14 - GO & 1503 & 9,4 & 937 & 8,3 & 583 & 12,7 & 60 & $\mathrm{GO} / \mathrm{DF}$ \\
\hline Radar 16 - GO & 1034 & 11,4 & 565 & 11.7 & 298 & 19,3 & 60 & $\mathrm{DF} / \mathrm{GO}$ \\
\hline Radar 17 - GO & 1028 & 9,7 & 768 & 10,4 & 204 & 14,4 & 60 & GO/DF \\
\hline
\end{tabular}


Apêndice 2

TABELA DE MEDIDAS (07h às 09h)

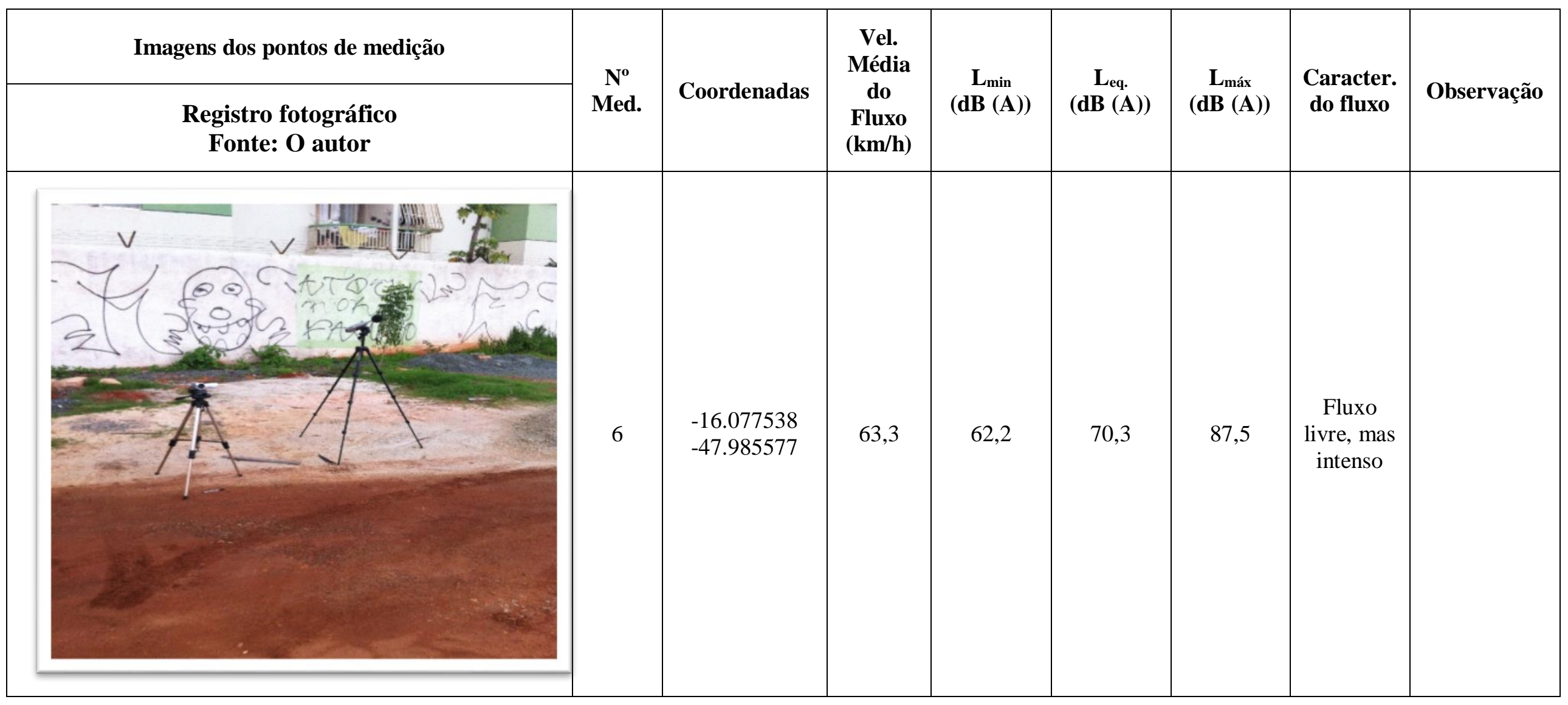




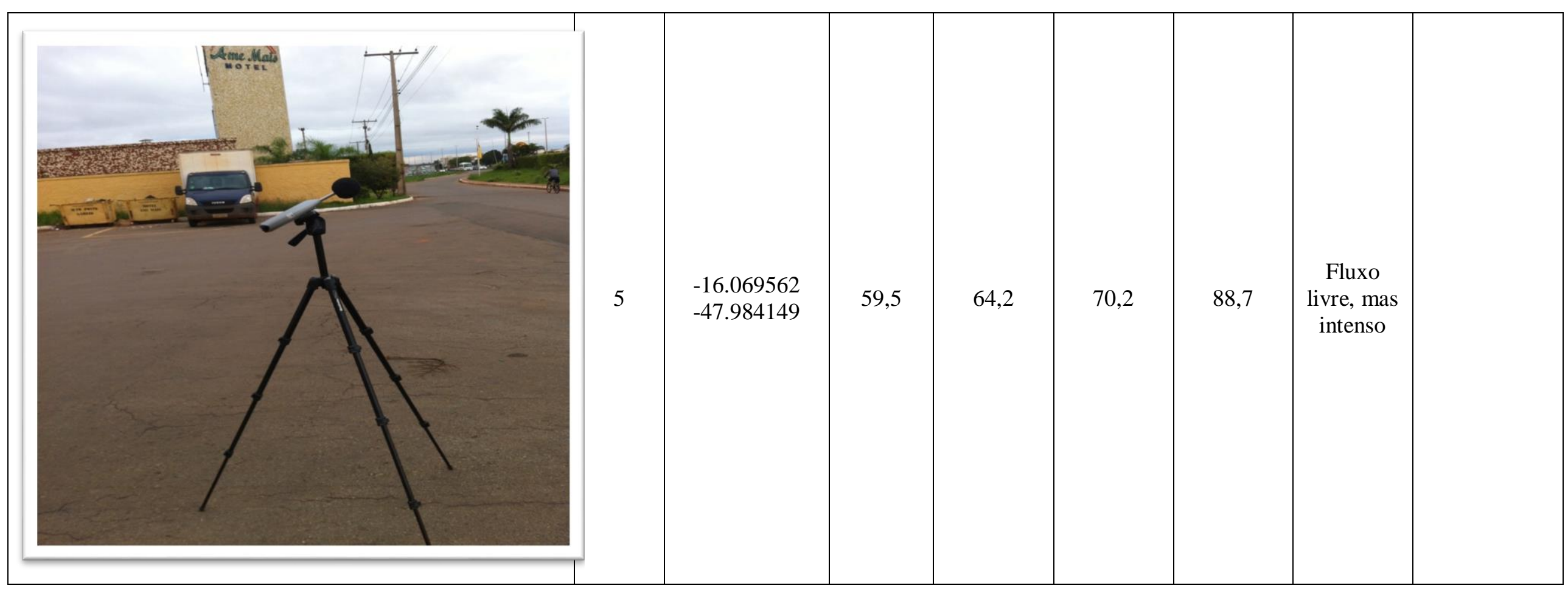




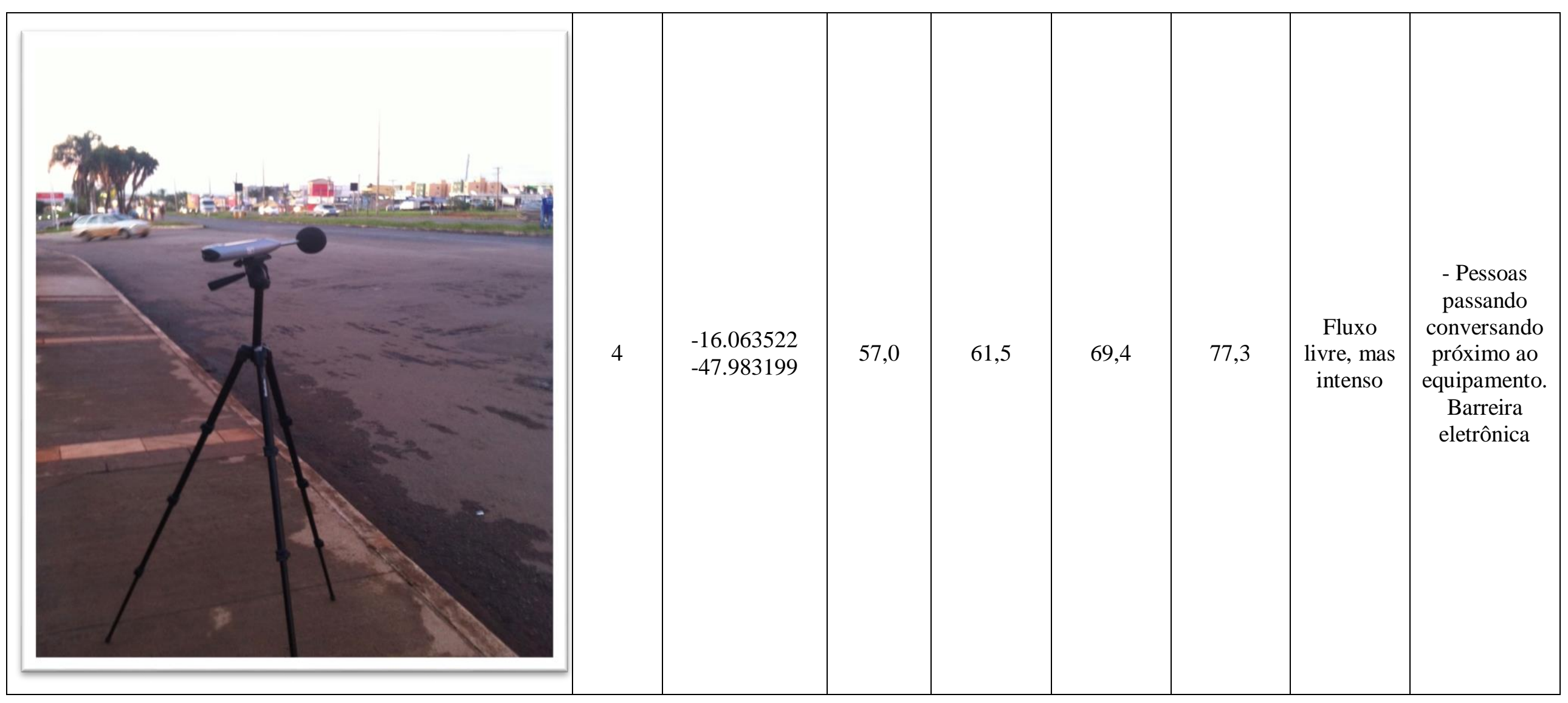




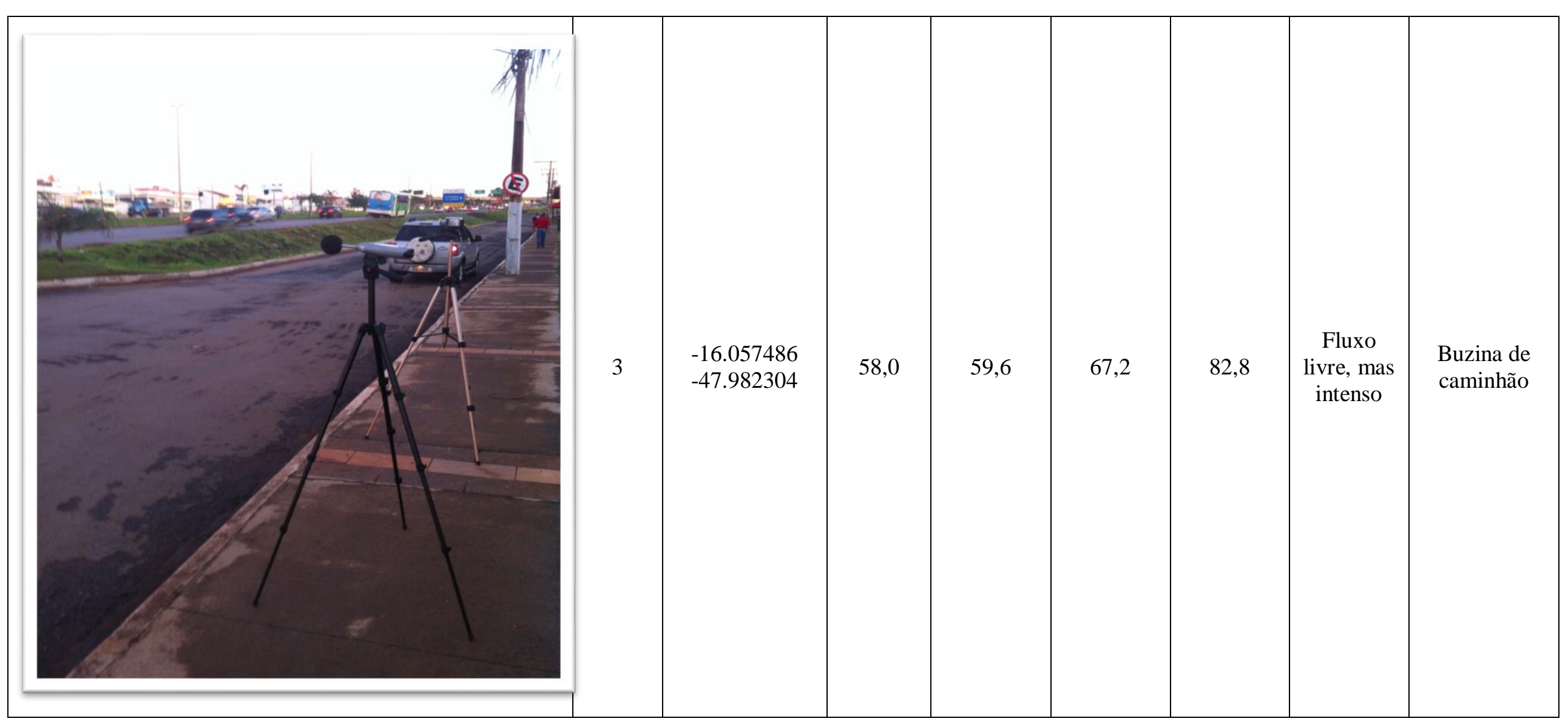




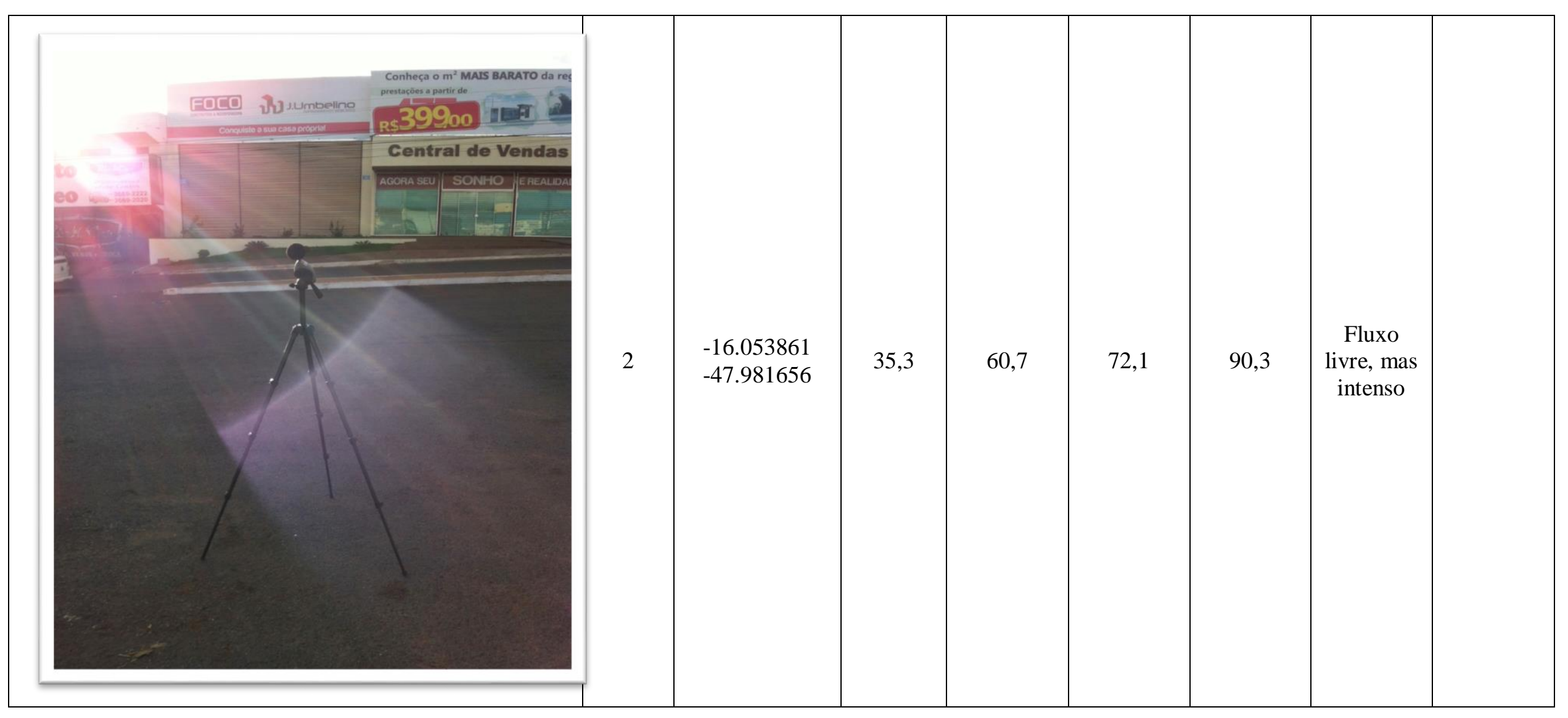




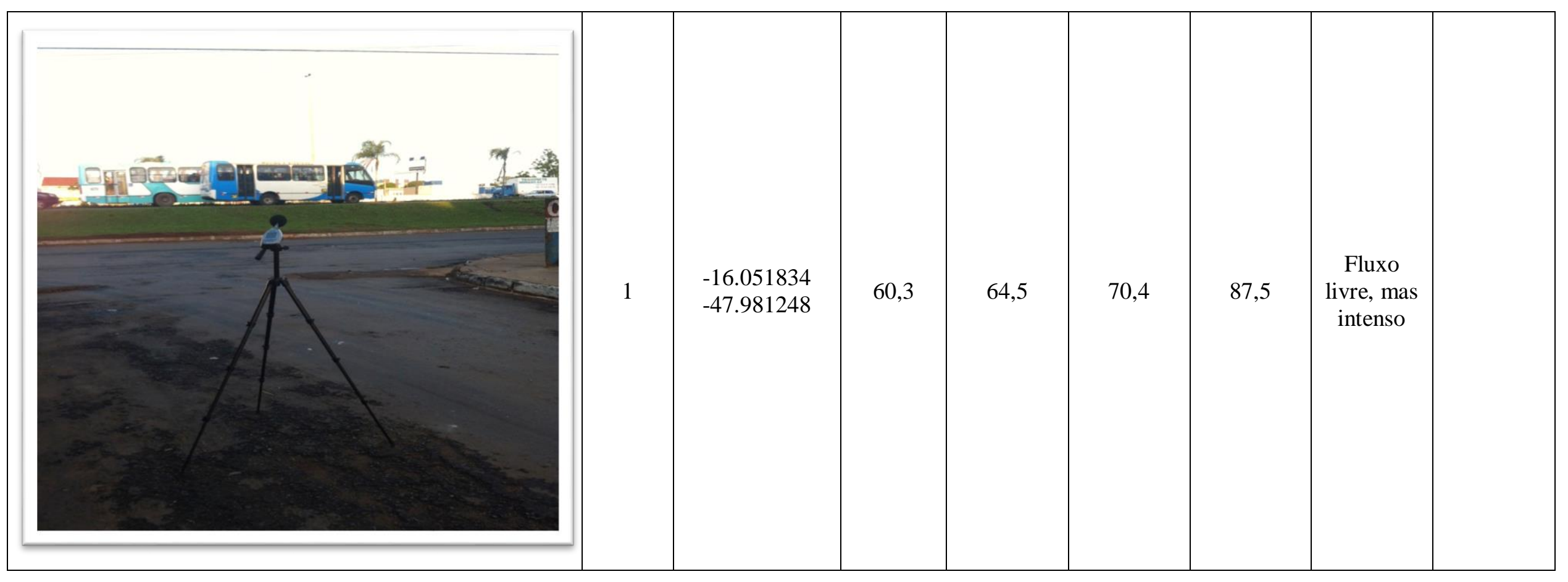


TABELA DE MEDIDAS (14h às 16h)

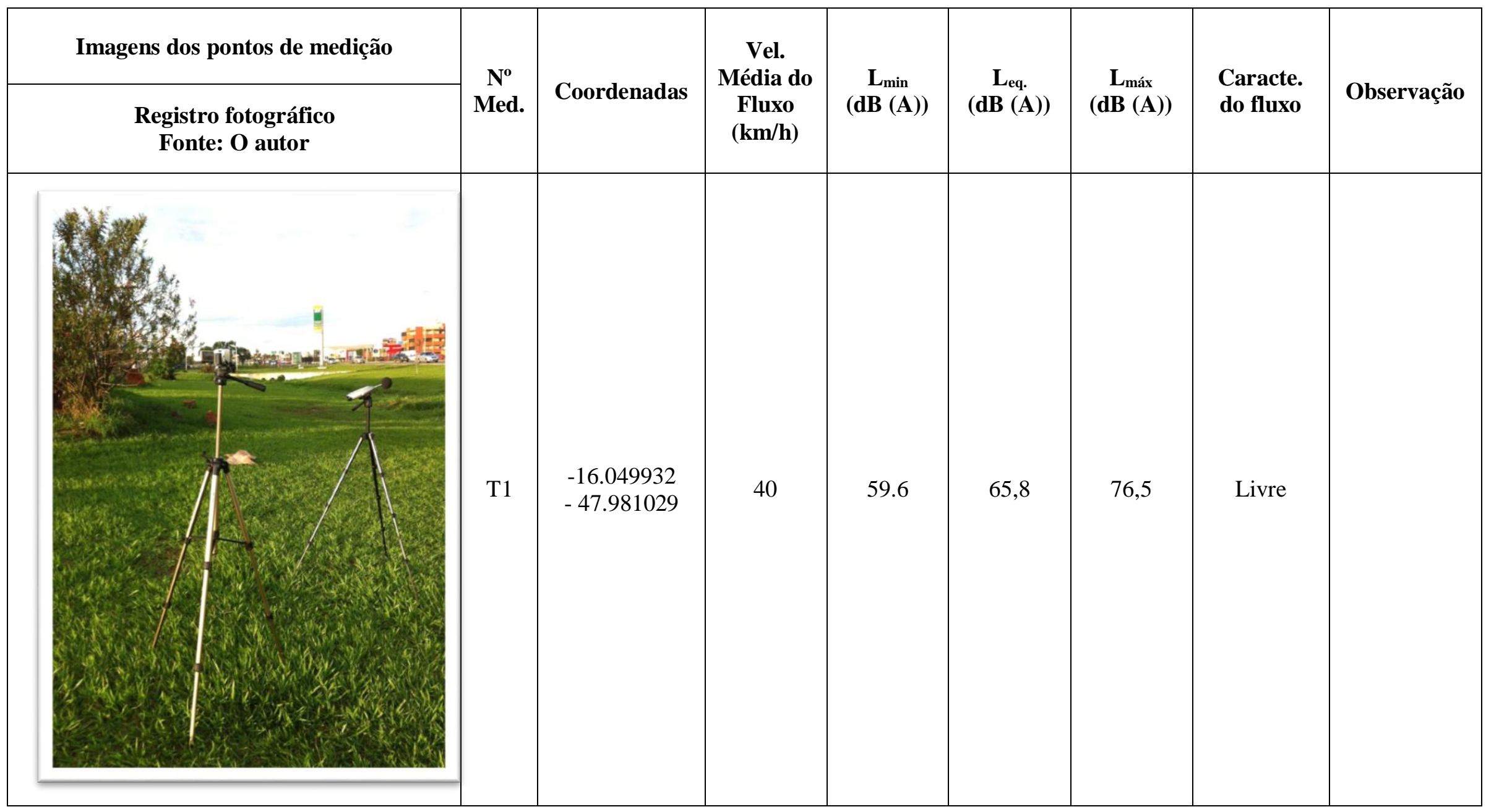




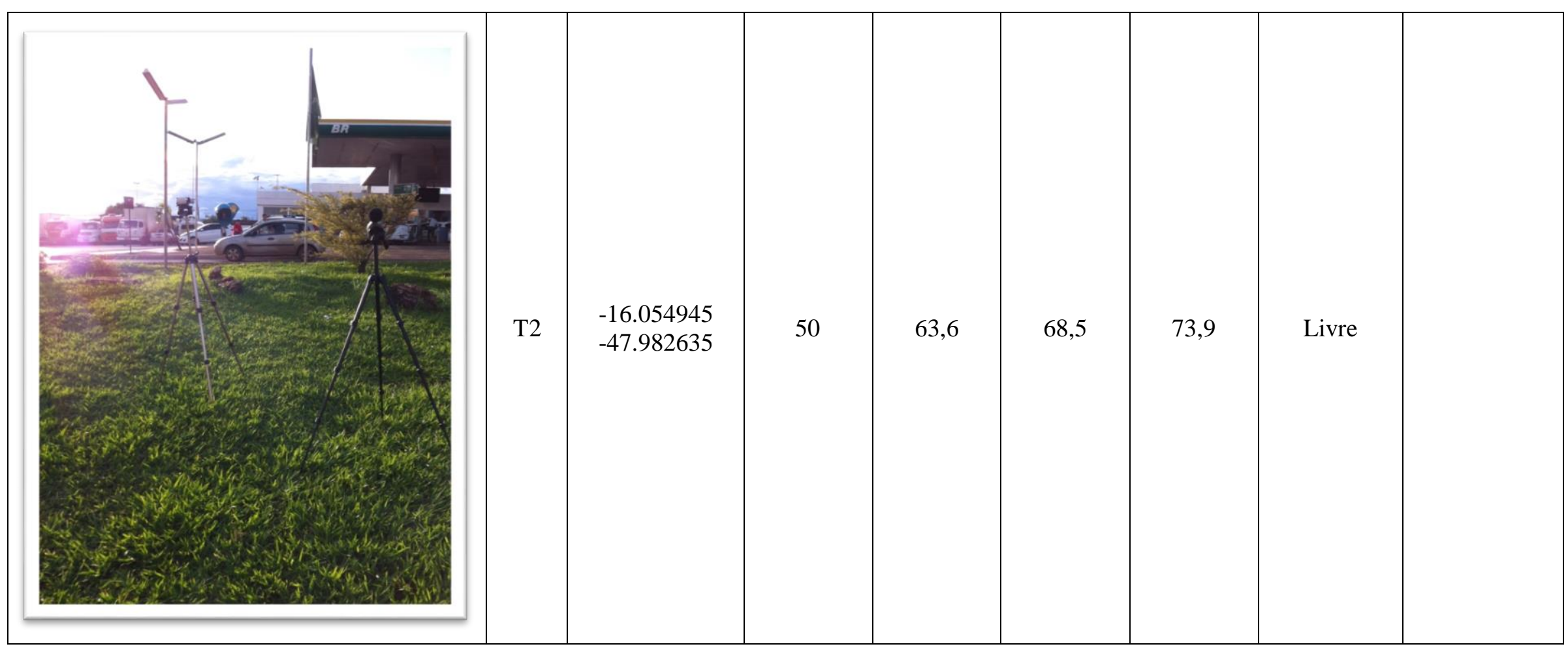




\begin{tabular}{|l|l|l|l|l|l|l|}
\hline & & & & & & \\
\hline \\
\hline
\end{tabular}




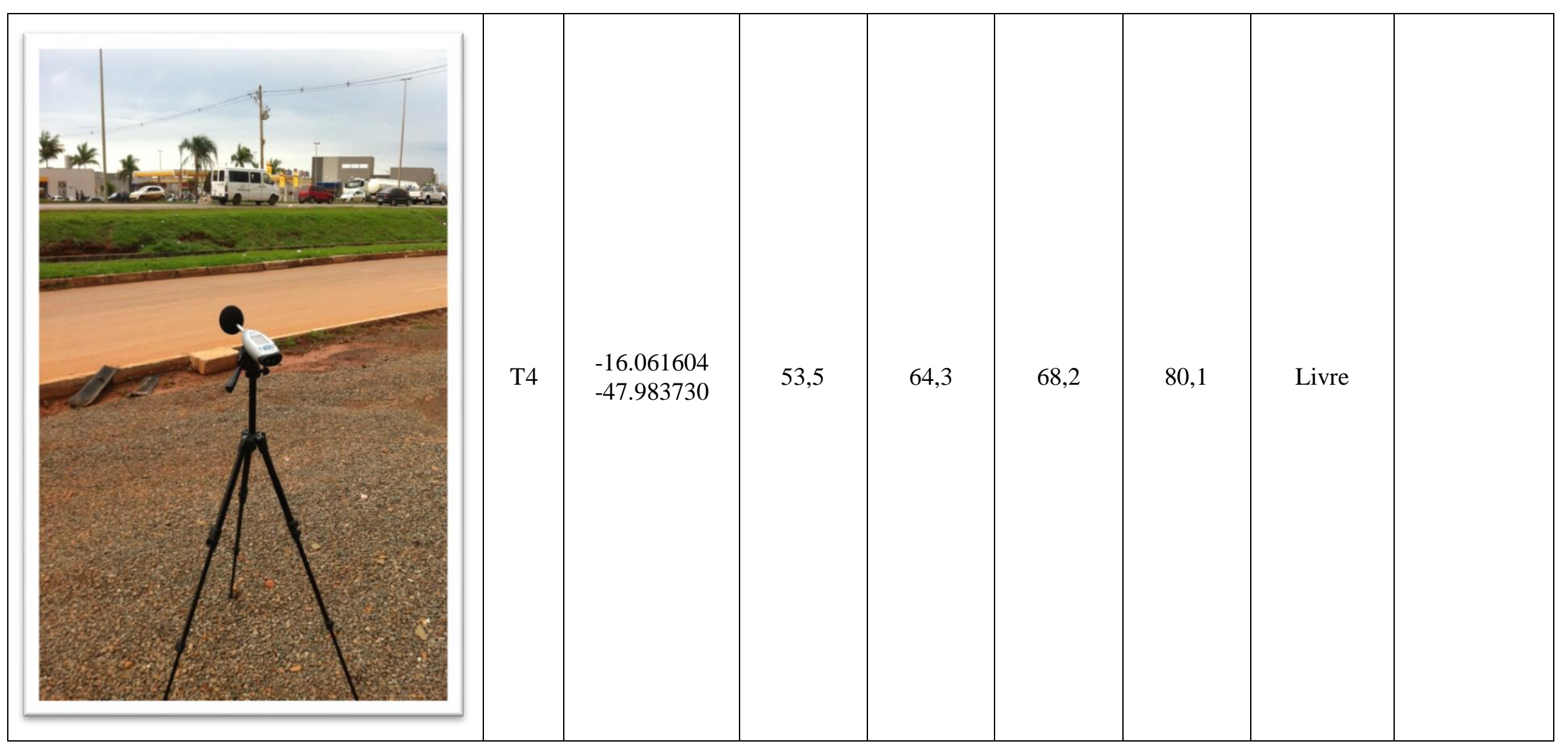




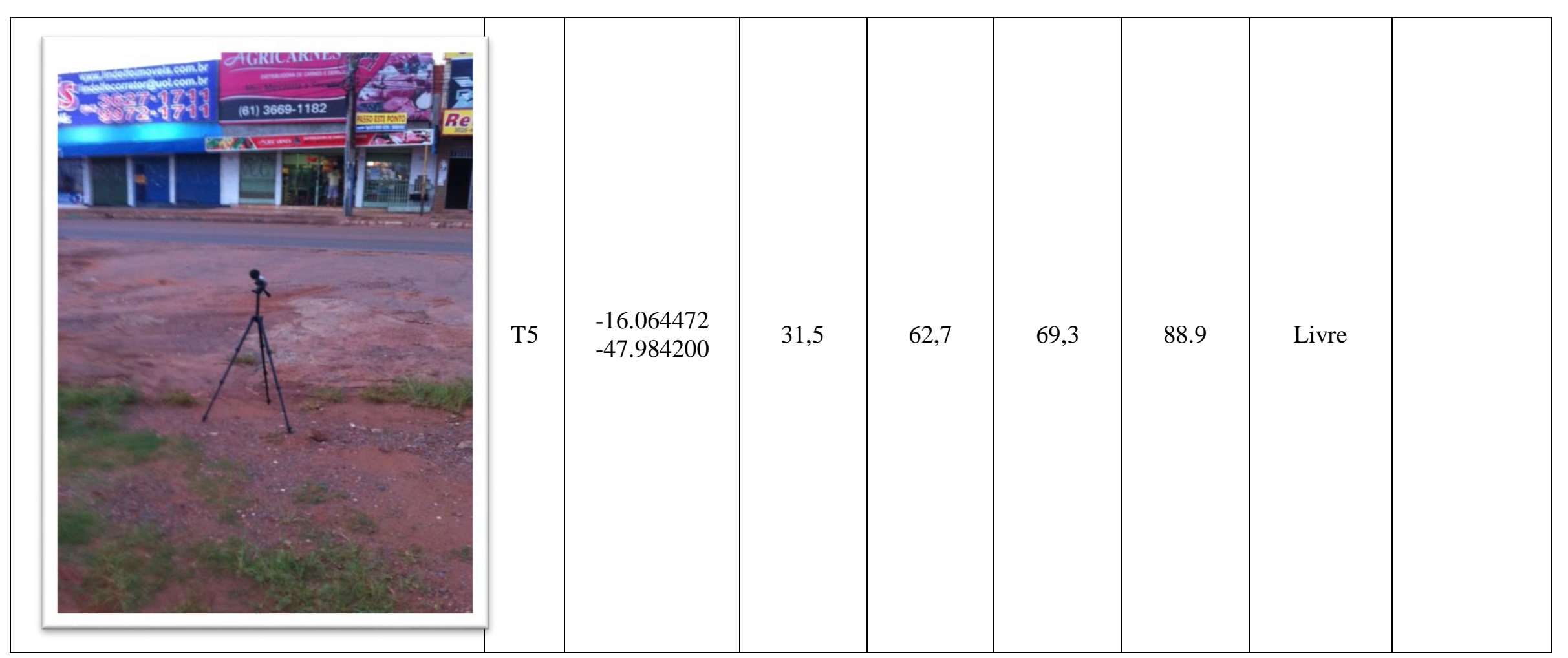




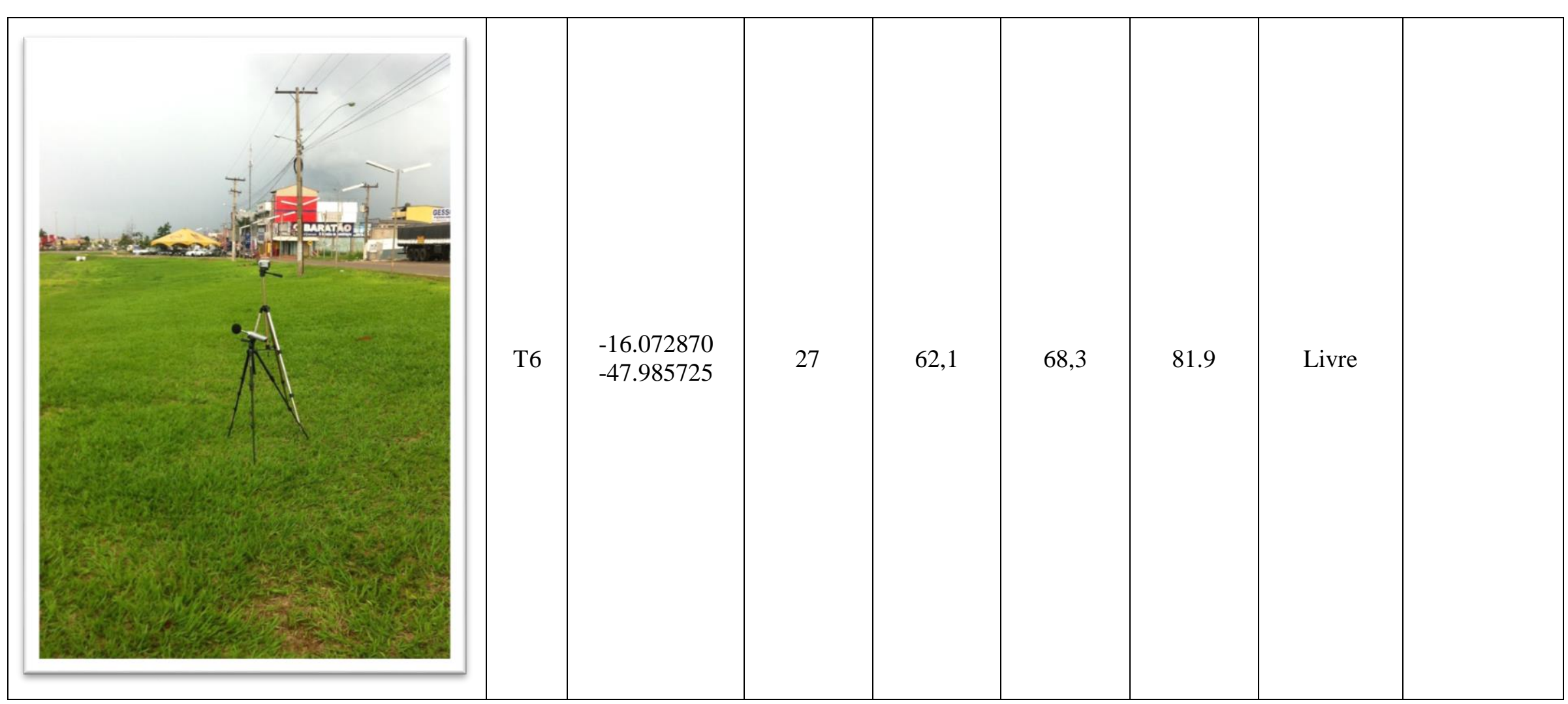




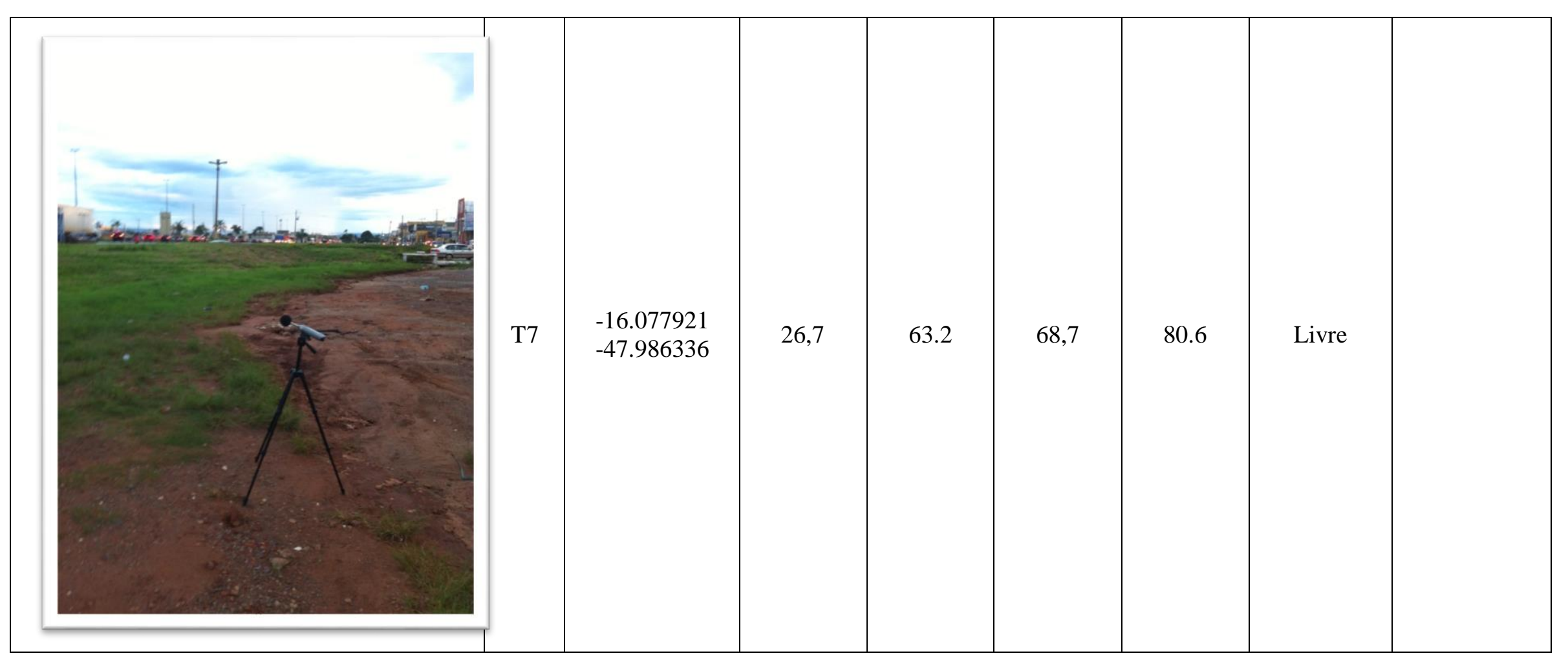


TABELA DE MEDIDAS (17h às 19h)

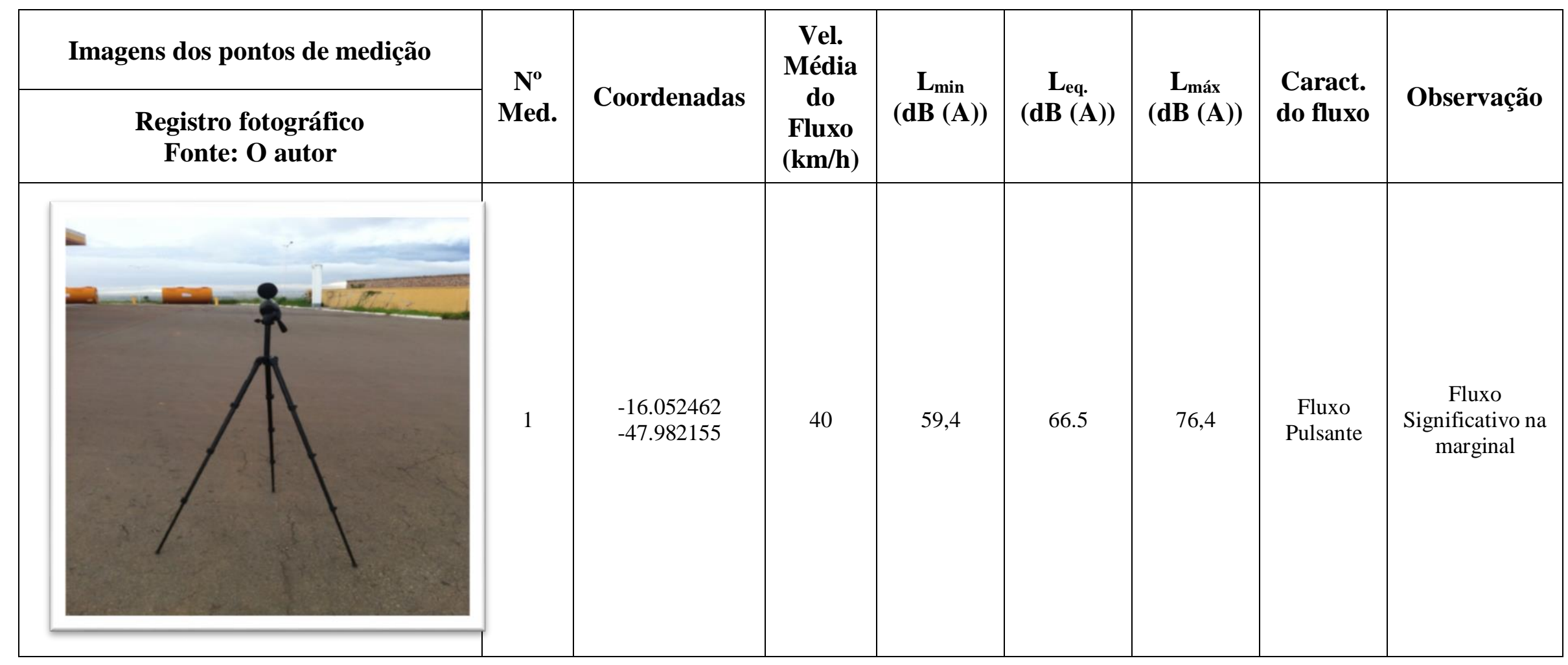




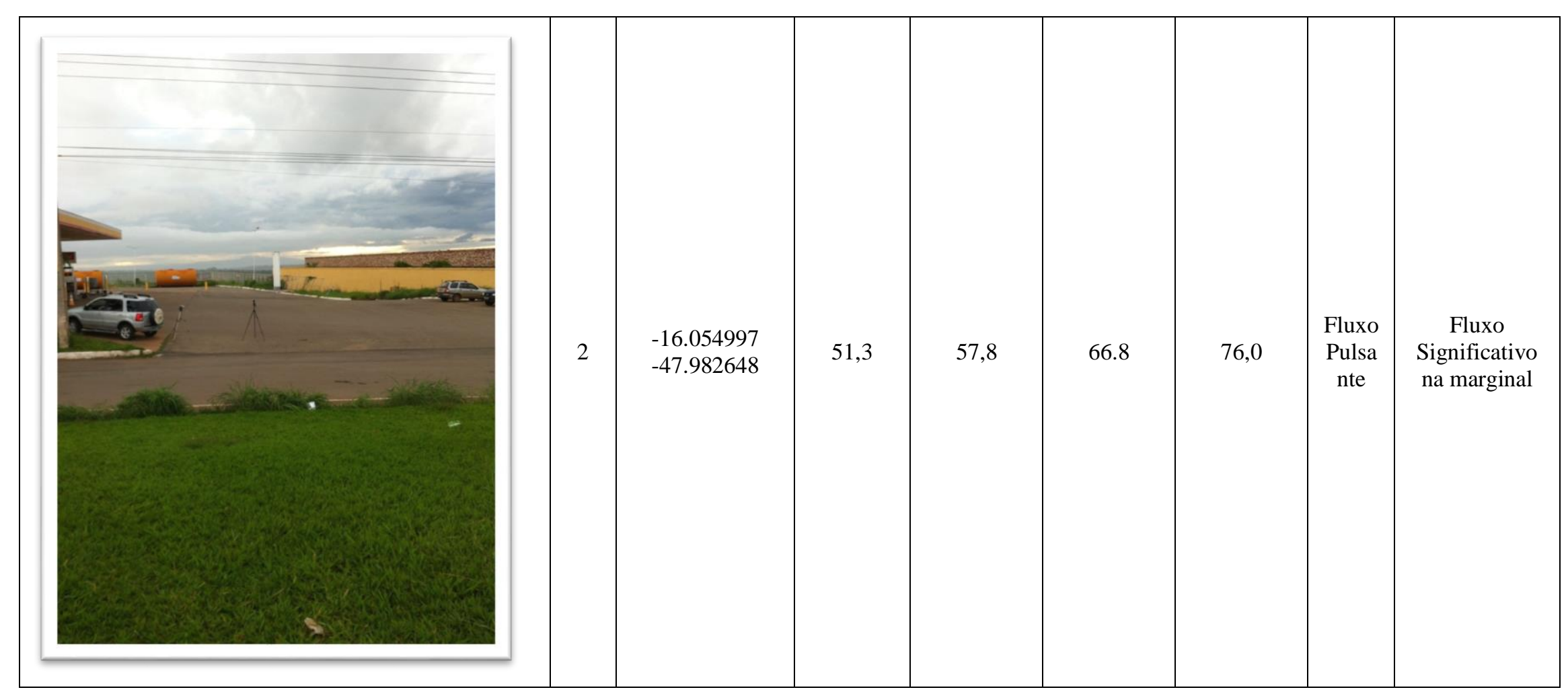




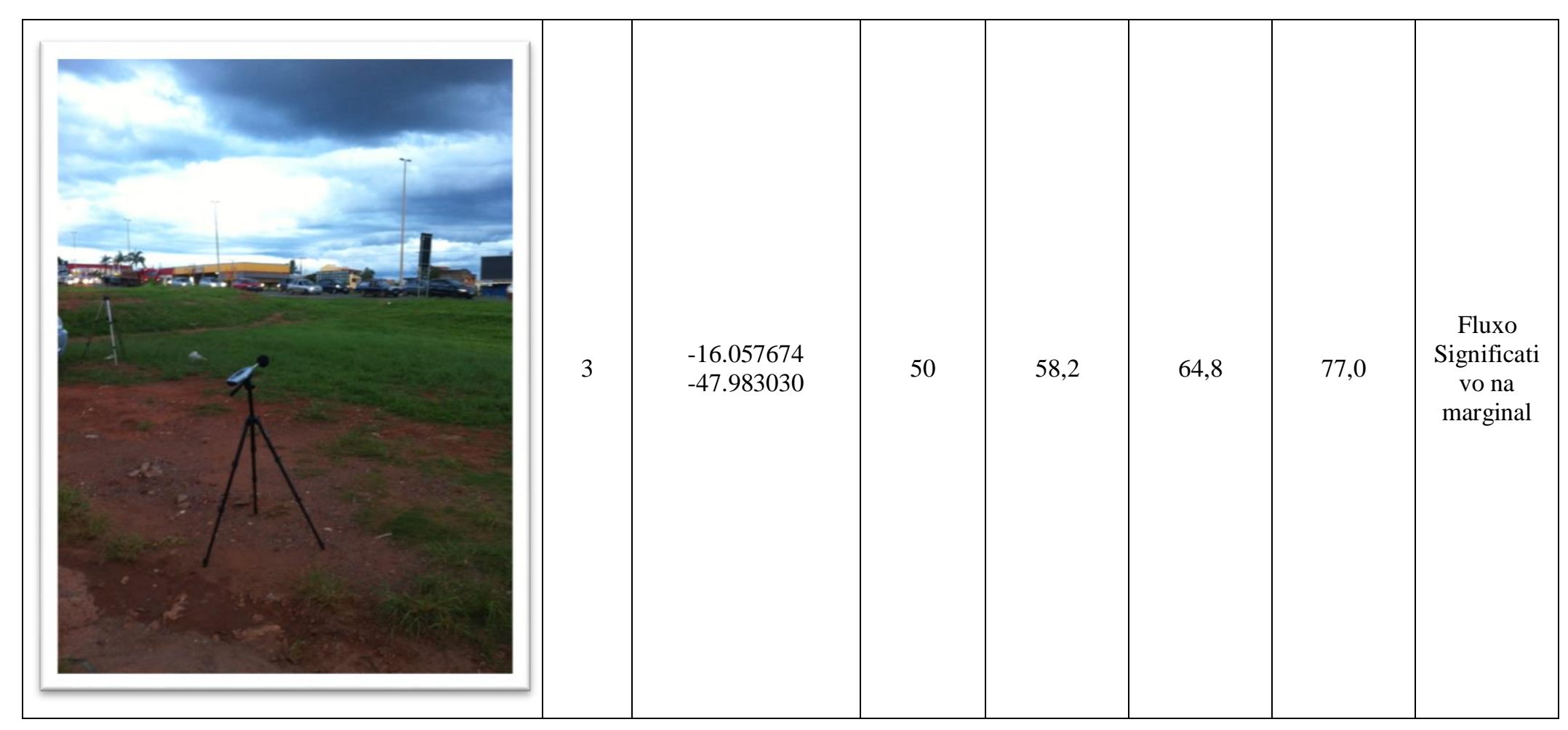




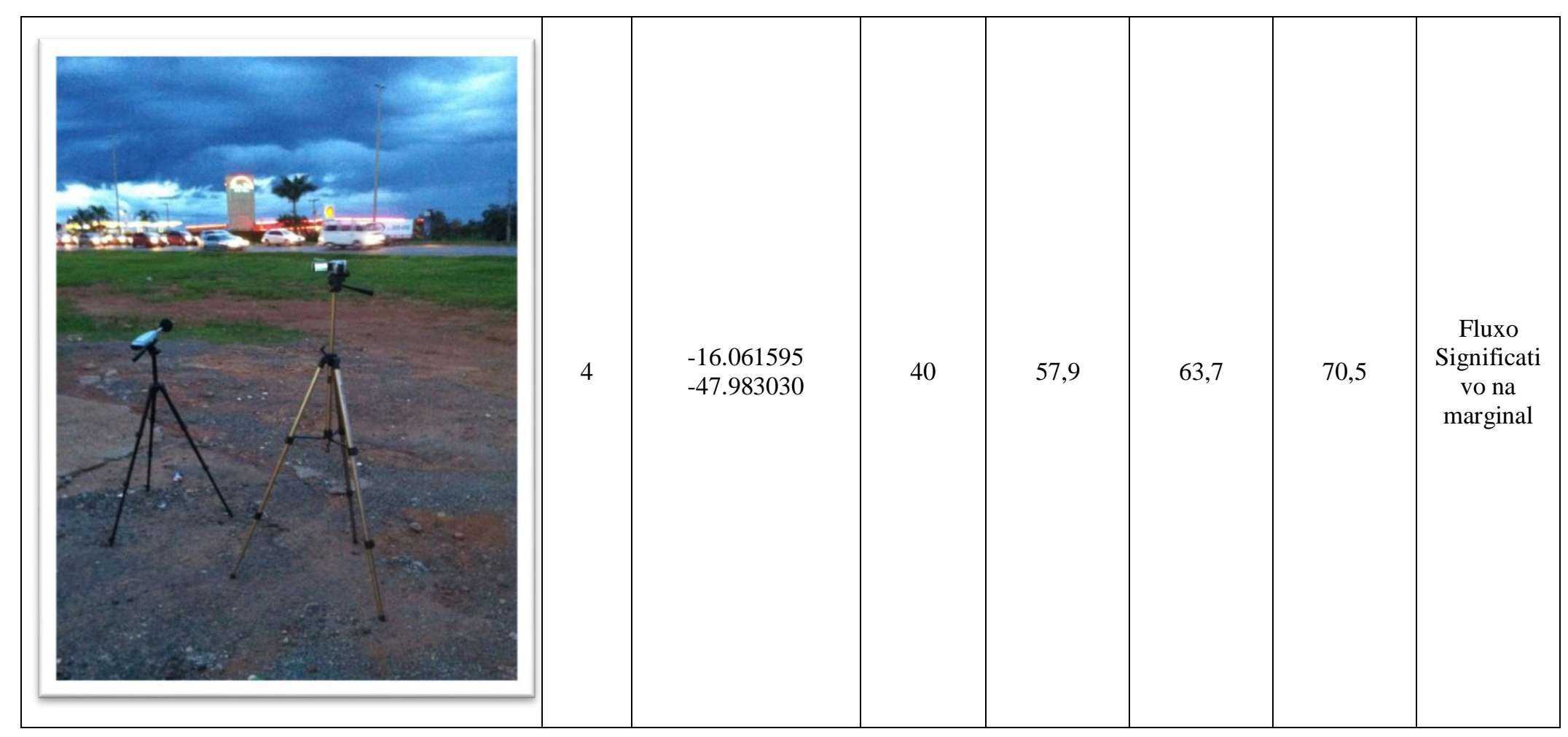




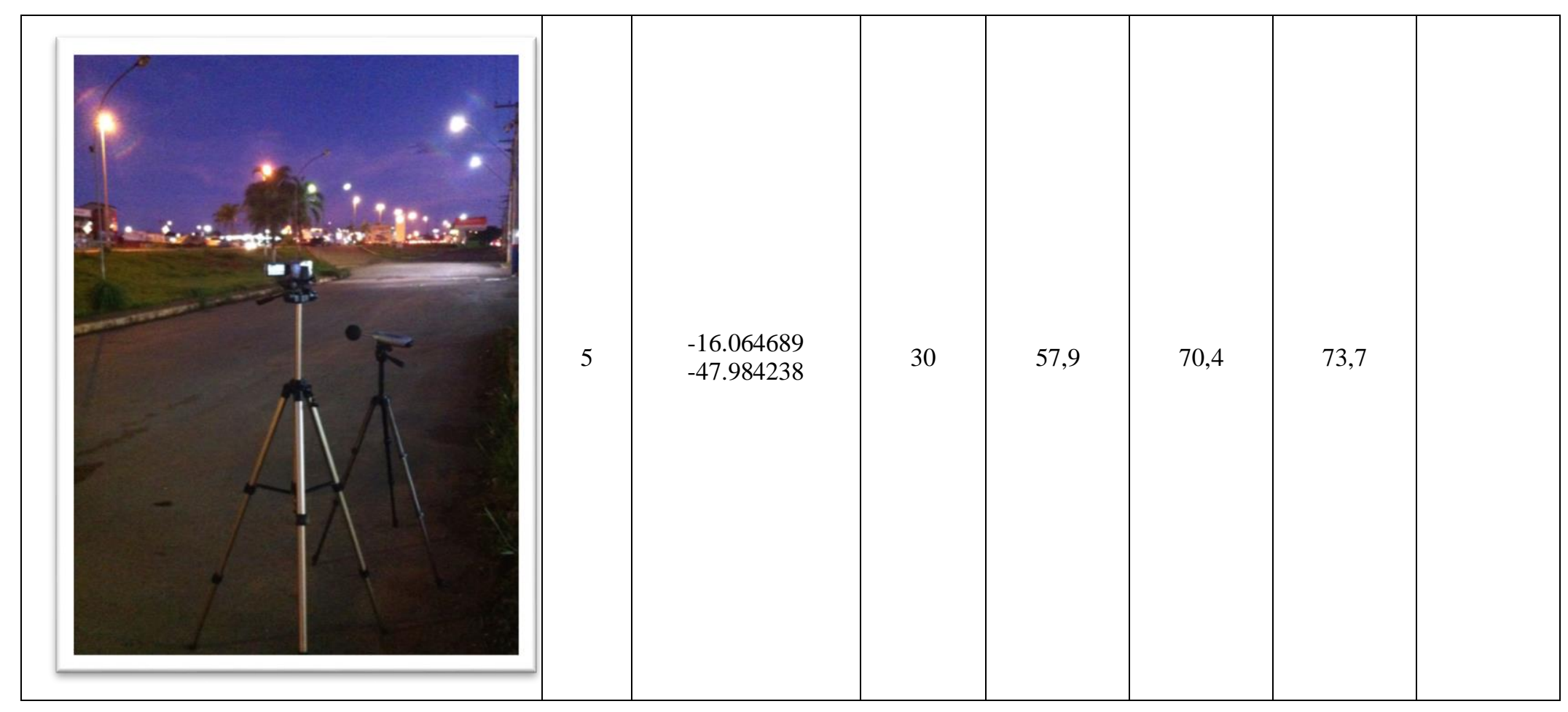




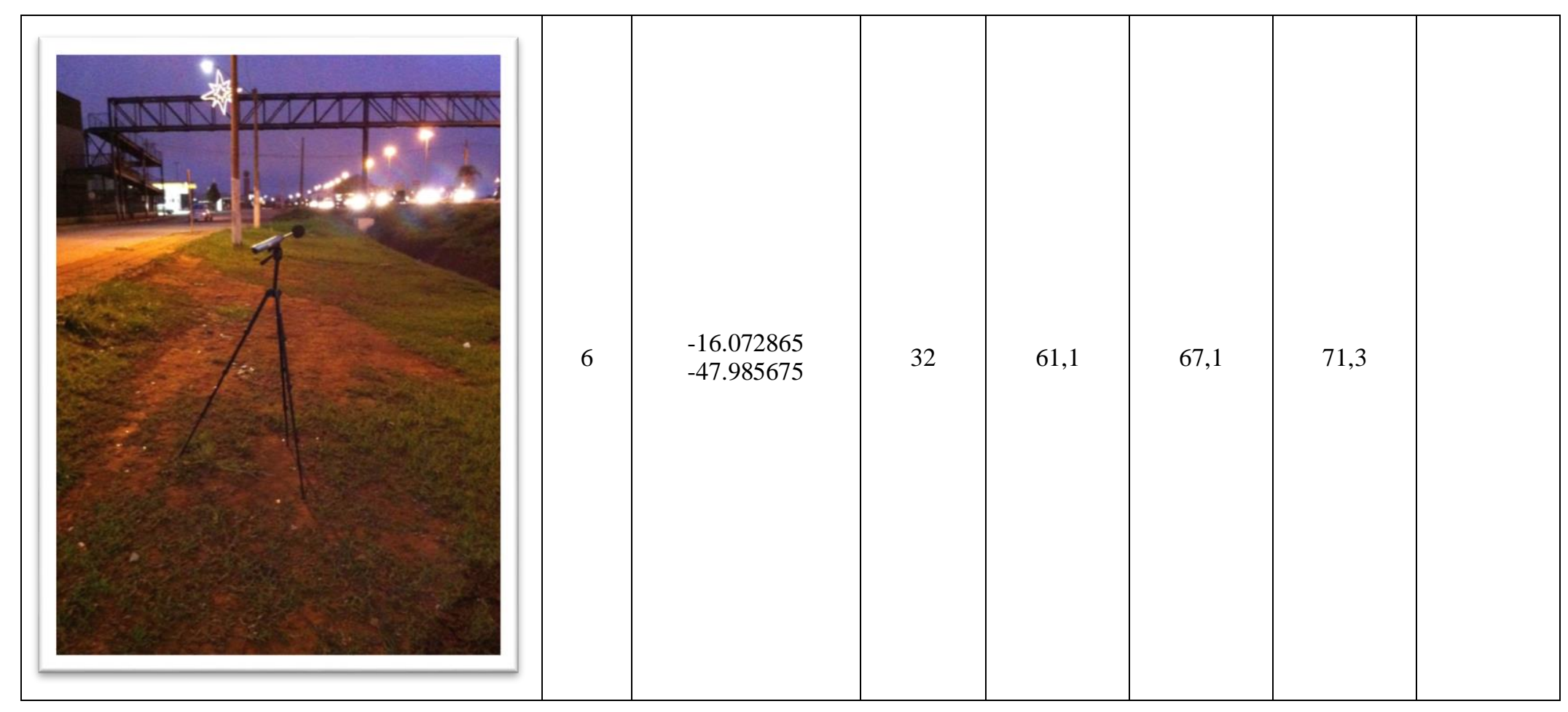




\section{Apêndice 3}

\section{DNIT=- Coordenaçăo Geral de Operaç̄ôs Rodoviár Coordenaçāo de Operã̄es \\ Programa Nacional de Controle Eletrônico de Velocidade - PNCV \\ Equipamentos e Faixas em Operação}

\begin{tabular}{|c|c|c|c|c|c|c|c|c|c|c|c|c|}
\hline \multirow{2}{*}{ Tipo de Equipamento } & \multirow{2}{*}{ UF } & \multirow{2}{*}{ BR } & \multirow{2}{*}{ KM } & \multirow{2}{*}{ Municipio } & \multicolumn{3}{|c|}{ Localização Geográfica (UTM) } & \multirow{2}{*}{$\begin{array}{c}\text { Código do } \\
\text { Equipamento }\end{array}$} & \multirow{2}{*}{$\begin{array}{c}\text { Sentido } \\
\text { Fiscalizado }\end{array}$} & \multirow{2}{*}{ Faixa } & \multicolumn{2}{|c|}{ Velocidade Fiscalizada $\mathrm{Km} / \mathrm{h}$} \\
\hline & & & & & Zona & $\mathrm{N} / \mathrm{s}$ & $E$ & & & & Veículos Leves & Veículos Pesados \\
\hline BARREIRA ELETRÔNICA & 60 & 040 & 0,300 & VALPARAISO DE GOIAS & $23 \mathrm{~K}$ & 8222928 & 180907 & GOB00176010 & CRESCENTE & 1 & 40 & 40 \\
\hline BARREIRA ELETROONICA & 60 & 040 & 0,300 & VALPARAISO DE GOIAS & $23 \mathrm{~K}$ & 8222928 & 180907 & & CRESCENTE & 2 & 40 & 40 \\
\hline BARREIRA ELETRÔNICA & 60 & 040 & 0,400 & VALPARAISO DE GOIAS & $23 \mathrm{~K}$ & 8222731 & 180916 & GOB00177010 & DECRESCENTE & 1 & 40 & 40 \\
\hline BARREIRA ELETRÔNICA & 60 & 040 & 0,400 & VALPARAISO DE GOIAS & $23 \mathrm{~K}$ & 8222731 & 180916 & & DECRESCENTE & 2 & 40 & 40 \\
\hline RADAR FIXO & 60 & 040 & 1,300 & VALPARAISO DE GOIAS & $23 \mathrm{~K}$ & 8221809 & 180762 & GOR00172010 & CRESCENTE & 1 & 60 & 60 \\
\hline RADAR FIXO & 60 & 040 & 1,300 & VALPARAISO DE GOIAS & $23 \mathrm{~K}$ & 8221809 & 180762 & & CRESCENTE & 2 & 60 & 60 \\
\hline RADAR FIXO & 60 & 040 & 1,500 & VALPARAISO DE GOIAS & $23 \mathrm{~K}$ & 8221836 & 180775 & GOR00172020 & DECRESCENTE & 1 & 60 & 60 \\
\hline RADAR FIXO & 60 & 040 & 1,500 & VALPARAISO DE GOIAS & $23 \mathrm{~K}$ & 8221836 & 180775 & & DECRESCENTE & 2 & 60 & 60 \\
\hline RADAR FIXO & Go & 040 & 3,000 & VALPARAISO DE GOIAS & $23 \mathrm{~K}$ & 8219842 & 180497 & GOR00172030 & DECRESCENTE & 1 & 60 & 60 \\
\hline RADAR FIXO & 60 & 040 & 3,000 & VALPARAISO DE GOIAS & $23 \mathrm{~K}$ & 8219842 & 180497 & & DECRESCENTE & 2 & 60 & 60 \\
\hline RADAR FIXO & 60 & 040 & 3,050 & VALPARAISO DE GOIAS & $23 \mathrm{~K}$ & 8220158 & 180533 & GOR00176020 & CRESCENTE & 1 & 60 & 60 \\
\hline RADAR FIXO & 60 & 040 & 3,050 & VALPARAISO DE GOIAS & $23 \mathrm{~K}$ & 8220158 & 180533 & & CRESCENTE & 2 & 60 & 60 \\
\hline RADAR FIXO & 60 & 040 & 4,150 & VALPARAISO DE GOIAS & $23 \mathrm{~K}$ & 8219043 & 180563 & GOR00172040 & CRESCENTE & 1 & 60 & 60 \\
\hline RADAR FIXO & 60 & 040 & 4,150 & VALPARAISO DE GOIAS & $23 \mathrm{~K}$ & 8219043 & 180563 & & CRESCENTE & 2 & 60 & 60 \\
\hline BARREIRA ELETROONICA & 60 & 040 & 4,500 & VALPARAISO DE GOIAS & $23 \mathrm{k}$ & 8218942 & 180682 & GOB00177020 & DECRESCENTE & 1 & 40 & 40 \\
\hline BARREIRA ELETRÔNICA & 60 & 040 & 4,500 & VALPARAISO DE GOIAS & $23 \mathrm{~K}$ & 8218942 & 180682 & & DECRESCENTE & 2 & 40 & 40 \\
\hline RADAR FIXO & 60 & 040 & 5,884 & VALPARAISO DE GOIAS & $23 \mathrm{~K}$ & 8217747 & 181428 & GOR00172050 & DECRESCENTE & 1 & 60 & 60 \\
\hline RADAR FIXO & 60 & 040 & 5,884 & VALPARAISO DE GOIAS & $23 \mathrm{~K}$ & 8217747 & 181428 & & DECRESCENTE & 2 & 60 & 60 \\
\hline RADAR FIXO & 60 & 040 & 5,884 & VALPARAISO DE GOIAS & $23 \mathrm{~K}$ & 8217719 & 181425 & GOR00172060 & CRESCENTE & 1 & 60 & 60 \\
\hline RADAR FIXO & 60 & 040 & 5,884 & VALPARAISO DE GOIAS & $23 \mathrm{~K}$ & 8217719 & 181425 & & CRESCENTE & 2 & 60 & 60 \\
\hline BARREIRA ELETROONICA & 60 & 040 & 7,000 & VALPARAISO DE GOIAS & $23 \mathrm{k}$ & 8216829 & 181972 & GOB00176030 & CRESCENTE & 1 & 40 & 40 \\
\hline BARREIRA ELETRÔNICA & 60 & 040 & 7,000 & VALPARAISO DE GOIAS & $23 k$ & 8216829 & 181972 & & CRESCENTE & 2 & 40 & 40 \\
\hline BARREIRA ELETRÔNICA & 60 & 040 & 7,000 & VALPARAISO DE GOIAS & $23 \mathrm{~K}$ & 8216873 & 182000 & GOB00177030 & DECRESCENTE & 1 & 40 & 40 \\
\hline BARREIRA ELETRÔNICA & 60 & 040 & 7,000 & VALPARAISO DE GOIAS & $23 \mathrm{~K}$ & 8216873 & 182000 & & DECRESCENTE & 2 & 40 & 40 \\
\hline BARREIRA ELETRÔNICA & 60 & 040 & 9,350 & CIDADE OCIDENTAL & $23 \mathrm{~K}$ & 8214664 & 183352 & GOB00176040 & CRESCENTE & 1 & 40 & 40 \\
\hline BARREIRA ELETRÔNICA & 60 & 040 & 9,350 & CIDADE OCIDENTAL & $23 \mathrm{~K}$ & 8214664 & 183352 & & CRESCENTE & 2 & 40 & 40 \\
\hline BARREIRA ELETROONICA & 60 & 040 & 9,850 & CIDADE OCIDENTAL & $23 \mathrm{~K}$ & 8214546 & 183476 & GOB00177040 & DECRESCENTE & 1 & 40 & 40 \\
\hline BARREIRA ELETRÔNICA & 60 & 040 & 9,850 & CIDADE OCIDENTAL & $23 \mathrm{~K}$ & 8214546 & 183476 & & DECRESCENTE & 2 & 40 & 40 \\
\hline RADAR FIXO & 60 & 040 & 10,300 & LUZIANIA & $23 \mathrm{~K}$ & 8214007 & 183839 & GOR00172070 & CRESCENTE & 1 & 60 & 60 \\
\hline RADAR FIXO & 60 & 040 & 10,300 & LUZIANIA & $23 \mathrm{~K}$ & 8214007 & 183839 & & CRESCENTE & 2 & 60 & 60 \\
\hline RADAR FIXO & 60 & 040 & 14,000 & LUZIANIA & $23 \mathrm{~K}$ & 8211271 & 186349 & GOR00172080 & DECRESCENTE & 1 & 60 & 60 \\
\hline RADAR FIXO & 60 & 040 & 14,000 & LUZIANIA & $23 \mathrm{~K}$ & 8211271 & 186349 & & DECRESCENTE & 2 & 60 & 60 \\
\hline RADAR FIXO & 60 & 040 & 14,000 & LUZIANIA & $23 \mathrm{~K}$ & 8211306 & 186276 & GOR00176050 & CRESCENTE & 1 & 60 & 60 \\
\hline RADAR FIXO & Go & 040 & 14,000 & LUZIANIA & $23 \mathrm{~K}$ & 8211306 & 186276 & & CRESCENTE & 2 & 60 & 60 \\
\hline RADAR FIXO & 60 & 040 & 15,350 & LUZIANIA & $23 \mathrm{~K}$ & 8210072 & 186650 & GOR00176060 & CRESCENTE & 1 & 60 & 60 \\
\hline RADAR FIXO & 60 & 040 & 15,350 & LUZIANIA & $23 \mathrm{~K}$ & 8210072 & 186650 & & CRESCENTE & 2 & 60 & 60 \\
\hline BARREIRA ELETRÔNICA & Go & 040 & 16,000 & LUZIANIA & $23 \mathrm{~K}$ & 8209254 & 186775 & GOB00177050 & DECRESCENTE & 1 & 40 & 40 \\
\hline BARREIRA ELETRÔNICA & 60 & 040 & 16,000 & LUZIANIA & $23 \mathrm{~K}$ & 8209254 & 186775 & & DECRESCENTE & 2 & 40 & 40 \\
\hline BARREIRA ELETRÓNICA & 60 & 040 & 16,100 & LUZIANIA & $23 \mathrm{~K}$ & 8209244 & 186733 & GOB00176070 & CRESCENTE & 1 & 40 & 40 \\
\hline BARREIRA ELETRÔNICA & 60 & 040 & 16,100 & LUZIANIA & $23 \mathrm{~K}$ & 8209244 & 186733 & & CRESCENTE & 2 & 40 & 40 \\
\hline RADAR FIXO & 60 & 040 & 21,810 & LUZIANIA & $23 \mathrm{~K}$ & 8203957 & 188432 & GOR00172090 & DECRESCENTE & 1 & 60 & 60 \\
\hline RADAR FIXO & 60 & 040 & 21,810 & LUZIANIA & $23 \mathrm{~K}$ & 8203957 & 188432 & & DECRESCENTE & 2 & 60 & 60 \\
\hline RADAR FIXO & 60 & 040 & 21,950 & LUZIANIA & $23 \mathrm{~K}$ & 8203727 & 188437 & GOR00176080 & CRESCENTE & 1 & 60 & 60 \\
\hline RADAR FIXO & 60 & 040 & 21,950 & LUZIANIA & $23 \mathrm{~K}$ & 8203727 & 188437 & & CRESCENTE & 2 & 60 & 60 \\
\hline BARREIRA ELETRÔNICA & 60 & 040 & 24,000 & LUZIANIA & $23 \mathrm{~K}$ & 8201846 & 189189 & GOB00176090 & CRESCENTE & 1 & 40 & 40 \\
\hline BARREIRA ELETRÔNICA & 60 & 040 & 24,000 & LUZIANIA & $23 \mathrm{~K}$ & 8201846 & 189189 & & CRESCENTE & 2 & 40 & 40 \\
\hline BARREIRA ELETRÔNICA & 60 & 040 & 24,200 & LUZIANIA & $23 \mathrm{~K}$ & 8201755 & 189310 & GOB00176100 & $\begin{array}{l}\text { DECRESCENTE } \\
\end{array}$ & 1 & 40 & 40 \\
\hline BARREIRA ELETRÔNICA & 60 & 040 & 24,200 & LUZIANIA & $23 \mathrm{~K}$ & 8201755 & 189310 & & DECRESCENTE & 2 & 40 & 40 \\
\hline RADAR FIXO & DF & 040 & 5,700 & BRASILIA & $23 \mathrm{~K}$ & 8225785 & 181198 & DFR00184050 & DECRESCENTE & 1 & 60 & 60 \\
\hline RADAR FIXO & DF & 040 & 5,700 & BRASILIA & $23 \mathrm{~K}$ & 8225785 & 181198 & & DECRESCENTE & 2 & 60 & 60 \\
\hline RADAR FIXO & DF & 040 & 7,000 & BRASILIA & $23 \mathrm{~K}$ & 8224342 & 181104 & DFR00184060 & CRESCENTE & 1 & 60 & 60 \\
\hline RADAR FIXO & DF & 040 & 7,000 & BRASILA & $23 \mathrm{~K}$ & 8224342 & 181104 & & CRESCENTE & 2 & 60 & 60 \\
\hline
\end{tabular}

